\title{
EFFECT OF CHEMICAL MODIFIERS \\ ON BORAX CRYSTAL GROWTH, NUCLEATION AND HABIT
}

by

Avinash Dev Puri

A Thesis Submitted to the Faculty of the DEPARTMENT OF CHEMICAL ENGINEERING

In Partial Fulfillment of the Requirements For the Degree of

MASTER OF SCIENCE

In the Graduate College

THE UNIVERSITY OF ARIZONA 
This thesis has been submitted in partial fulfillment of requirements for an advanced degree at The University of Arizona and is deposited in the University Library to be made available to borrowers under rules of the Library.

Brief quotations from this thesis are allowable without special permission, provided that accurate acknowledgment of source is made. Requests for permission for extended quotation from or reproduction of this manuscript in whole or in part may be granted by the head of the major department or the Dean of the Graduate College when in his judgment the proposed use of the material is in the interests of scholarship. In all other instances, however, permission must be obtained from the author.

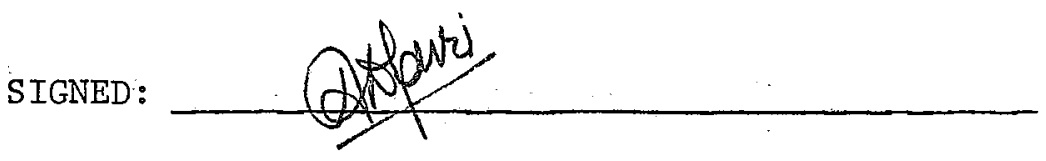

\section{APPROVAL BY THESIS DIRECTOR}

This thesis has been approved on the date shown below:
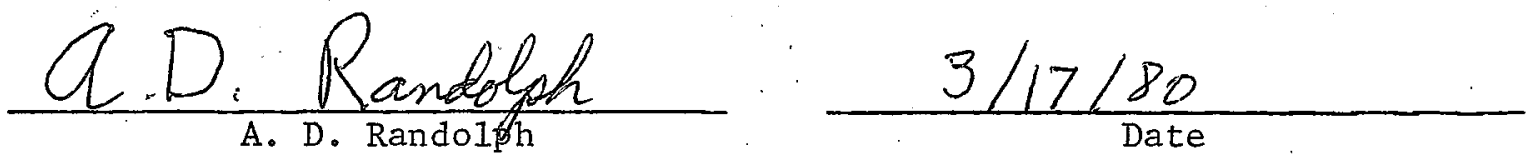

Professor of Chemical Engineering 


\section{ACKNOWLEDGMENTS}

I express my deepest gratitude to Dr. Alan D. Randolph, my advisor, for his interest and timely suggestions during the course of research and the subsequent writing of this thesis. I also thank the other faculty members of the Department of Chemical Engineering at the University of Arizona for their assistance and guidance during my stay at the University. My sincere thanks are to Dr. E.T. White of the University of Queensland for his valuable suggestions.

I am thankful to Mr. Dick Van Reeth of the College of Mines Machine Shop and Mr. Sal Gonzales of the Electronic shop for their help in many things crucial for this study. I am also thankful to Mrs. Sandralyn Faust for her patience in typing this thesis.

I gratefully acknowledge the financial assistance for this study and the financial support afforded me through a Research Assistantship provided by National Science Foundation through Grant ENG 77-23925. 
TABLE OF CONTENTS

Page

LIST OF ILLUSTRATIONS . . . . . . . . . . . . . . . . • vi

LIST OF TABLES. • • • . • . . • . • • • • • • • • • • IX

ABSTRACT . . . . . . . . . . . . . . . . . . . . . x

1. INTRODUCTION. . . . . . . . . . . . . . . . . . . 1

2. LITERATURE REVIEW . . . . . . . . . . . . . . . . 4

Nucleation. . . . . . . . . . . . . . . 4

Crystallization Medium. . . . . . . . . . 4

Homogeneous Nucleation. . . . . . . . . . . 6

Heterogeneous Nucleation. . . . . . . . . . 8

Secondary Nucleation. . . . . . . . . . . . 8

Growth. . . . . . . . . . ......... 12

Habit......................... 14

3. THEORY . . . . . . . . . . . . . . . . . . . 17

Population Balance. . . . . . . . . . . . . . 17

Growth Rate . . . . . . . . . . . . . . . 19

Nucleation Rate..... . . . . . . . . . . 20

4. EXPERTMENTAL EQUIPMENT • . . . . . . . . . . . . . 22

Particle Data Counter . . . . . . . . . . . . . 24

Auxiliary Equipment .................. 26

5. EXPERIMENTAL PROCEDURE •. . . . . . . . . . . . . 28

Calibration . . . . . . . . . . . . . . . 28

Preparation of Solutions. . . . . . . . . . . . 30

Preparation of Seeds.................. 30

Nucleation Experiments. . . . . . . . . . . . 30

6. EXPERIMENTAL DATA AND OBSERVATIONS . . . . . . . •. . . . . 34

Borax-Water System ................ 34

Borax-Water-Impurity System ... . . . . . . . . 37

Organic Additives................ . 37

Inorganic Additives . . . . . . . . . . . 49 
TABLE OF CONTENTS - Continued

Page

7. DATA REDUCTION AND RESULTS . . . . . . . . . . . . . . 63

Method of Data Reduction ................. 63

Growth and Nucleation Kinetics . . . . . . . . . 66

8. DISCUSSION OF RESULTS . . . . . . . . . . . . . . . . . . . 82

Mechanism of Impurity Effects . . . . . . . . . . 86

9. SUMMARY AND CONCLUSION . . . . . . . . . . . . . . . . . 93

APPENDIX A: CALCULATION OF VOLUMETERIC AVERAGE SIZE SHAPE

FACTOR ..................... 95

APPENDIX B: GENERAI OPERATIONAI CONDITIONS AND EXPERTMENTAL

DATA . . . . . . . . . . . . . 96

APPENDIX C: SUMMARY OF DATA OF SUSPENSION DENSITY AND SEED

CRYSTAI SIZE . . . ............. 109

APPENDIX D: POPULATION DENSITY DATA . . . . . . . . . . 114

NOMENCLATURE . . . . . . . . . . . . . . . . . . . . 118

LIST OF REFERENCES . . . . . . . . . . . . . . . . 120 
LIST OF ILLUSTRATIONS

Figure

1. Typical Solubility Diagram ........... 5

2. Schematic Diagram of Crystallization Apparatus . . . . 23

3. Front View of Crystallization Research Apparatus . . . . 25

4. Front View of Particle Data Counter ......... 27

5. Effect of Sudden Increase of Stirring RPM on Nucleation

Rate (Borax-Water System) ......... 35

6. Nucleation Rate Data for Surfactant Sodium Dodecylbenzene Sulfonate Runs ............. . 38

7. Nucleation Rate Data for Sodium Oleate Runs. . . . . . 39

8. Nucleation Rate Data for Surfactant Sodium Lauryl Sulfate Runs ..................... 40

9. Effect of Surfactant Sodium Dodecylbenzene sulfonate on Nucleation Rate . . . . . . . . . . 42

10. Influence of Surfactant Sodium Dodecylbenzene Sulfonate on the Population Density Distribution of Fine Borax Crystals............... 44

11. Influence of Sodium Oleate on the Population Density Distribution of Fine Borax Crystals . . . . . . . 44

12. Transient Population Densities of Fine Borax Crystals for a Typical Run with $5 \mathrm{ppm}$ Sodium Oleate. . . . . . 46

13. Effect of Surfactant Sodium Dodecylbenzene Sulfonate on the Dynamic Population Densities of Fine Borax Crystals . . 47

14. Effect of Surfactant Sodium Lauryl sulfate on the Transient Population Densities of Fine Borax Crystals . . . . 48

15. Borax Crystals (40 times magnification)

(a) $-50+60$ mesh initial seeds

(b) Product Crystals from Run 2 Withdrawn after

140 minutes .............. 51 
LIST OF ILLUSTRATIONS - Continued

Figure

16. Borax Crystals (40 times magnification)

Product Crystals from (a) Run 15

(b) Run 16 withdrawn after 150 minutes. . . . . . . 52

17. Borax Crystals (40 times magnification)

Product Crystals from (a) Run 13

(b) Run 20 withdrawn after 165 and 145 minutes,

respectively................. 53

18. Nucleation Rate Data for Sodium Chloride Runs. . . . . . 54

19. Nucleation Rate Data for Magnesium Chloride Runs . . . . . 56

20. Effect of Sodium Chloride on the Population Density

Distribution of Fine Borax Crystals . . . . . . . 57

21. Effect of Magnesium Chloride on the Population Density

Distribution of Fine Borax Crystals . . . . . . . 58

22. Influence of Sodium Chloride on the Transient Population

Densities of Fine Borax Crystals. . . . . . . . 59

23. Influence of Magnesium Chloride on the Dynamic Population

Densities of Fine Borax Crystals. . . . . . . . 60

24. Borax Crystals (40 times Magnification)

Product Crystals from (a) Run 26 (b) Run 29 withdrawn

after 145 and 140 minutes, respectively . . ... . 62

25. Effect of Surfactant Sodium Dodecylbenzene Sulfonate on

Nucleation and Growth Rate of Sodium Tetraborate

System .......................

26. Effect of Sodium Oleate on Nucleation and Growth Rate of Sodium Tetraborate System . . . . . . . . . 68

27. Effect of Surfactant Sodium Lauryl Sulfate on Nucleation and Growth Rate of Sodium Tetraborate System. . . . 69

28. Effect of Sodium Chloride on Nucleation and Growth Rate of Sodium Tetraborate System. . . . . . . . . . 70

29. Effect of Magnesium Chloride on Nucleation and Growth Rate of Sodium Tetraborate System. . . . . . . . . 71 
LIST OF ILLUSTRATIONS - Continued

Figure

Page

30. Comparison Between Experimental and Calculated Nucleation

Rates (pure borax system).............. 75

31. Comparison Between Experimental and Calculated Nucleation

Rates (pure borax system). . . . . . . . . 76

32. Comparison Between Experimental and Calculated Nucleation

Rates for Organic Additives. . . ........ 80

33. Comparison Between Experimental and Calculated Nucleation

Rates for Organic Additives. . . . . . . . . 81

34. Graph Showing Languir's Adsorption Isotherm for Organic

Additives ....................... 90

35. Langmuir's Adsorption Isotherm for Inorganic Impurities . . 992 


\section{LIST OF TABLES}

Tiable.,

Page

1. Seed Crystal Growth Rate Data for Organic Additives. . . . . . 50

2. Seed Crystal Growth Rate for Inorganic Additives . . . . . . 61 
ABSTRACT

Trace concentrations of certain additives sometimes have profound effects on nucleation rate, growth rate and crystal habit. This work represents an attempt to investigate the effect of such additives on the crystallization of sodium tetraborate decahydrate using a mixedsuspension crystallizer. Sodium tetraborate nucleates by secondary mechanisms at the supersaturations obtained in this study.

An existing crystallization apparatus of previous investigators was used. Commercial seeds were used to initiate secondary nucleation. Supersaturation was obtained by cooling. During an experimental run seed crystals were totally retained in the crystallizer. Fine-crystal populations in the effluent were counted by a Particle-Data Counter in the size range of 7 to 17 microns. The population balance technique was employed to determine nucleation and growth kinetics.

Organic and inorganic impurities were used to illustrate the influence of two completely different types of additives. The organic additives used were sodium dodecylbenzene sulfonate, sodium oleate and sodium lauryl sulfate whereas the inorganic additives were sodium chloride and magnesium chloride. For each impurity three or four experiments were carried out under similar experimental conditions, but at different levels of impurity concentration.

Sodium tetraborate exhibits size-independent growth rate in the size range of 7 to 17 microns. The nucleation rate of sodium tetraborate 
depends on the supersaturation, agitator RPM and slurry density of seed crystals. Borax crystallizes from pure borax solution as multi-crystals. Organic additives inhibited the nucleation rate whereas the inorganic additives increased the nucleation rate. A simultaneous reduction in both linear-crystal growth rate and multi-crystal habit was observed in both the cases. These effects correlated with the modifier concentration, but not with modifier/solids ratio.

The effects of the organic impurities on the crystallization of borax are explained using an adsorption mechanism whereas the effects of inorganic impurities are rationalized with collision probability theory. 
CHAPTER 1

INTRODUCTION

Crystallization from solution is an important industrial process. This process begins with the formation of nuclei in supersaturated solutions, the subsequent growth of these nuclei and finally separation of solid phase from the liquid phase.

It has long been recognized that the production of crystals to meet a specified size distribution is a problem principally of the control of nucleation rate. Nuclei formation can result from homogeneous, heterogeneous or secondary mechanisms. Homogeneous nucleation is the formation of new nuclei as a result of supersaturation alone. Heterogeneous nucleation generally refers to new particle formation resulting from the presence of foreign insoluble material. This foreign material provides sites where nuclei can form because of reduced energy requirements. Secondary nucleation refers to nucleation induced by the presence of suspended crystals of solute. Recent developments related to this phenomenon of nucleation has identified that secondary nucleation is the dominant source of nuclei in industrial crystallizers.

Kinetics of nucleation and growth are important factors in the design and analysis of industrial crystallizers. Nucleation rate is usually a function of supersaturation driving force, temperature, solids concentration and agitation level, while growth rate is primarily determined by supersaturation. Typical correlations of the form 


$$
\text { 이 } \begin{aligned}
\mathrm{B}^{\circ} & =k_{N}(T, R P M) s^{i} M_{T}^{j} \\
\text { and } \quad G & =k s^{a}
\end{aligned}
$$

have been extensively used in literature to fit the data for secondary nucleation and growth rates.

Purity, crystal habit and crystal size distribution are measures of product quality that determine the end uses of any crystallizer materia1. Thus to produce specification product, nucleation rate must be understood and the factors that affect it understood.

The presence of trace amounts of impurities in the crystallizing solution sometimes has a spectacular effect on nucleation rate, growth rate and crystal habit. Such impurities are also called additives or crystal growth modifiers. These additives are often used in crystal1ization practice to suppress nucleation rate of new crystals, to affect growth rate of existing crystals or to improve habit of product crystals. Such additives can be organic or inorganic compounds. Examples are the use of chromium and tin ions to affect elongation of EDT'and ADP crystals and sodium oleate in reducing multi-crystal habit of borax crystals. Multi-crystal habit can be defined as the formation of some new $\left(h^{\gamma} k^{\prime} I^{\prime}\right)$ faces in addition to the already existing. (hkl) faces. In spite of the importance ascribed to the use of additives in crystallization processes, very little is known about the actual mechanism of such modifiers.

The selection of an additive usually involves the trial-and-error testing of specific compounds to observe those which favorably influence chemical properties and are compatible with the chemical process. No general theory has yet been stipulated which could predict the effect a 
particular additive would have on a given crystal system. Thus, finding a specific additive for a crystallizing system continues to be an art. The present work describes the effect of surface active agents and ionic additives on the nucleation rate, growth rate and habit of borax crystals. This work was carried out in a Mixed Suspension, Mixed Product Removal (MSMPR) crystallizer. The borax system was chosen for the present experimental study because it readily crystallizes in multicrystal habit at high supersaturation unless a modifier is present. The specific goals of this study were as follows:

1. Evaluate the quantitative effects of surface active agents and ionic modifiers on the nucleation and growth rate of borax crystals.

2. Determine the concentration effectiveness of such modifiers.

3. Illustrate the intimate relationship between secondary nucleation rate and habit-determining crystal growth mechanisms when both are affected by chemical modifiers. 
CHAPTER 2

\section{LITERATURE REVIEW}

This chapter is divided into three parts: nucleation, growth and crystal habit.

\section{Nucleation}

The spontaneous appearance of a new phase occurs when a system is in a non-equilibrium state and the departure from equilibrium is sufficient for the appearance of such a phase. The minimum amount (size) of the new phase capable of independent existence is called a nucleus. These nuclei can be liquid droplets from vapor, solids from melt, or solids from solution. The present work deals with solids crystallizing from an aqueous solution and the subsequent discussion will emphasize this aspect of nucleation.

Crystallization Medium

Miers represented the various states of a solution as shown in Figure (1). The part of the diagram which lies above the supersolubility curve $\left(B^{\prime}\right)$ represents the labile state of solution. The region below the solubility curve $\left(\mathrm{AA}^{\prime}\right)$ represents the stable zone of unsaturated solution; and the region between $\mathrm{AA}^{\prime}$ and $\mathrm{BB}^{\prime}$ is the metastable zone. In this zone crystals will grow but do not spontaneously form. In contrast to the solubility curve, the supersolubility curve is not a solute/solvent property, but depends on the rates of cooling, agitation level, and 


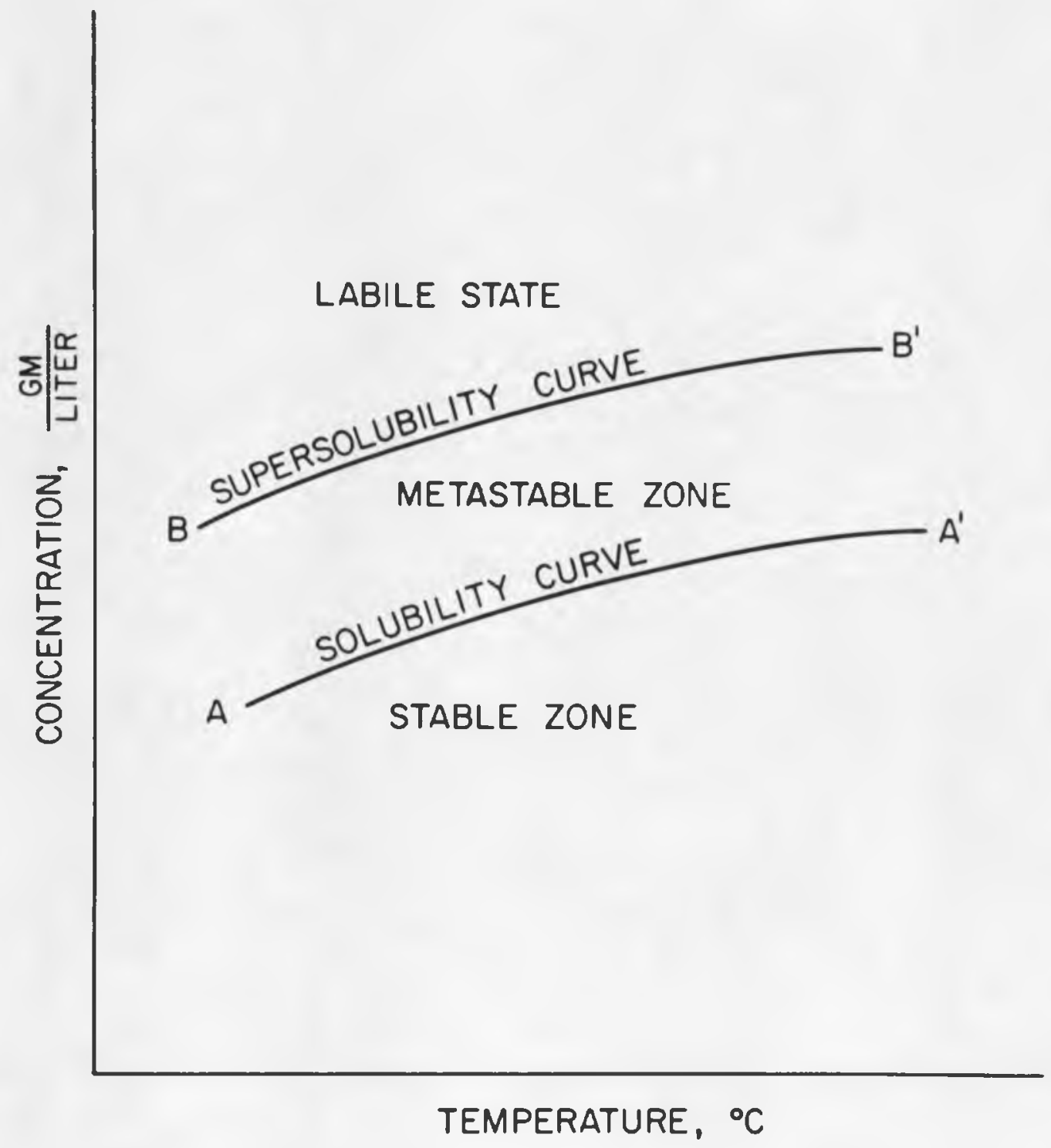

Figure 1. Typical Solubility Diagram 
in general the environment in which the process is being carried out. Nevertheless, the concept of metastability is useful in rationalizing crystallization behavior.

Akhumov (1960) demonstrated that carefully purified supersaturated salt solutions may be stored for years even with high supercooling without causing spontaneous nucleation. However, the presence of tiny foreign particles may act as nucleation centers and induce nucleation at low levels of supersaturation. Nucleation may also occur at low supersaturation, $i . e$. in the metastable state, if the solution contains the crystals of the solute being crystallized, especially if these crystals are mechanically contacted. The above types of nucleation can be distinguished as follows:

1. Homogeneous Nucleation: an ordening process of solute molecules or ions in solution having sufficient energy to form a critical size nucleus. Rate depends critically on supersaturation.

2. Heterogeneous Nucleation: a similar process catalysed by a foreign substrate or interacting molecules in solution which act to lower the free energy barrier.

3. Secondary Nucleation: nucleation induced by the presence of crystalline solute usually requiring mechanical contacts of existing crystals.

Homogeneous Nucleation

Homogeneous nucleation is the result of an agglomeration or ordening process of solute molecules or ions. Molecular aggregates of various sizes exist in a supersaturated environment; but only those that exceed the critical nucleus size are capable of forming a stable nucleus. 
The size of the critical nucleus can be calculated from general thermodynamic relationships (Gibbs, 1918). Thus

$$
\mathrm{L}_{\text {crit }}=\frac{4 \sigma \mathrm{V}_{\mathrm{m}}}{\mathrm{K}_{\mathrm{b}} \mathrm{T} \operatorname{In}(\mathrm{S})}
$$

For spherical clusters the free energy of formation corresponding to the critical nucleus is

$$
\Delta G_{\text {crit. }}=\frac{16}{3} \frac{\pi \sigma^{3} \mathrm{~V}^{2} \mathrm{~m}}{\mathrm{~K}_{\mathrm{b}}^{2} \mathrm{~T}^{2} 1 \mathrm{n}^{2}(\mathrm{~S})}
$$

The equations above represent the size of nuclei and the free energy of nucleation, but they give no information about the rate of formation of the new phase. This problem was considered by Volmer. Volmer pointed out that the probability of formation of nuclei is governed by the value of work which must be done to form a nucleus, i.e. $\Delta G_{\text {crit. }}$

Becker (1938) moved a step further by considering the rate of formation of nuclei to be proportional to the probability of their appearance. Consequent1y.

$$
\mathrm{B}^{\mathrm{O}}=\mathrm{C} \exp \left(-\frac{\Delta \mathrm{G}_{\text {crit }}}{\mathrm{K}_{\mathrm{b}} \mathrm{T}}\right)
$$

Melia (1965) calculated the nucleation rate by combining Equations (2) and (3)

$$
B^{o}=C \exp -\left\{\frac{16 \pi \sigma^{3} \cdot v_{m^{2} N^{3}}}{3(R T)^{3}\left[1 n^{2}(s)\right]}\right\}
$$

Equation (4) illustrates that the three major variables influencing homogeneous nucleation rate are temperature, supersaturation and 
surface tension. Homogeneous nucleation is a critical phenomenon in terms of supersaturation and above the critical supersaturation an enormous increase in nucleation occurs.

Heterogeneous Nucleation

Heterogeneous nucleation occurs due to the catalytic action of foreign substrates or large molecules in solution which coordinate solute molecules. The molecules in the substrate affect the ordering process and lower the energy barrier for nucleation. The influence of the substrate can be characterized by a factor $\phi(0<\phi<1)$, which modifies the free energy of homogeneous nucleation. If there is no affinity between the substrate and the cluster then $\phi=1$. For complete affinity $\phi=0$ and nucleation would occur readily with no energy barrier.

Theoretical considerations show that the nucleation rate for heterogeneous nucleation depends upon the contact angle between the forming phase and the foreign surface and the radius of the foreign particle, but is otherwise similar to homogeneous nucleation.

Secondary Nucleation

Secondary nucleation occurs due to the presence of crystals of the material being crystallized. In most cases of industrial interest, e.g. the production of crystals from continuous crystallizers, secondary nucleation is dominant. Hence, much recent effort has been devoted to determine the mechanisms and kinetics of secondary nucleation.

The history of secondary nucleation is not new. As early as 1906, Miers reported that supersaturated solutions which were stable when left undisturbed often nucleated when a seed crystal was introduced. 
Ting and McCabe (1934) showed that in the presence of solute crystals nucleation occurred in a reproducible manner even in the metastable zone, but no effort was made to explain the limited occurrence of nuclei. Melia and Moffitt (1964) and Cayey and Estrin (1967) postulated from their experiments in well-stirred' batch cooling crystallizers that a fluid mechanical shearing mechanism prevails for generation of nuclei from the crystal surface. However, collisions of the crystals with the impeller or walls is a more likely cause of nucleation.

Mason and Strickland-Constable (1963) gave some qualitative observations on the secondary nucleation of inorganic salts and in a further development of this work the subject was explored in greater depth (Mason and Strickland-Constable, 1966; Strickland-Constable, 1972). These researchers can well be credited with elucidation of the contact mechanism for secondary nucleation.

Working mainly with magnesium sulfate and to a lesser extent potassium chloride and potassium bromide, they identified several mechanisms by which secondary nucleation may occur. They used the terminology of initial breeding, needle breeding, polycrystalline breeding and collision breeding to distinguish between various mechanisms. Strickland-Constable's pioneering work identified the following mechanisms of secondary nucleation:

(a) Initial Breeding: Results when dry seeds are placed in supersaturated solutions and microscopic crystal dust washes off to form nuclei. Initial breeding can be eliminated by ripening the seeds in slightly undersaturated solutions. 
(b) Needle Breeding: Results from the breakage of large dendritic. growths when the crystals are grown in highly supersaturated solutions. Such supersaturations are higher than that which exists in a typical continuous crystalizer.

(c) Polycrystalline Breeding: In highly supersaturated solutions, a crystal occasionally grows as a polycrystalline mass. The breakage of weak polycrystalline structure leads to formation of new nuclei.

(d) Collision Breeding: Nucleation is induced by collision of seed crystals with solid surfaces. This is the mechanism most often encountered in well-designed continous crystallizers.

The first three mechanisms do not represent true secondary nucleation, as the first represents a seeding effect and the others a gross breakage effect.

In a classic study, Clontz and McCabe (1969). measured the number of nuclei resulting from the impact of a glass rod on the face of a $\mathrm{MgSO}_{4} \cdot 7 \mathrm{H}_{2} \mathrm{O}$ crystal. They concluded that the number of nuclei produced per unit crystal area were approximately linear with impact energy and supersaturation.

Johnson, Rousseau and McCabe (1970) extended this work to show that surface roughness and hardness of the crystal face as well as hardness of the contacting surface affect the number of nuclei produced. Al1 the above studies showed that secondary nucleation is due to collision breeding.

Larson, Timm and Wolf (1968) studied secondary nucleation in a MSMPR crystallizer. They concluded that new crystals were generated by secondary nucleation and nucleation rate was linearly dependent upon suspension density. 
Youngquist and Randolph (1972) and Randolph and Cise (1972)

studied secondary nucleation of the ammonium sulfate-water and potassium sulfate-water system. They observed secondary nucleation rate to be dependent upon supersaturation, seed crystal mass and size, stirring rate and crystal habit.

Shor and Larson (1971) investigated the effect of ionic additives and surface active agents on the crystallization kinetics of potassium nitrate in an MSMPR crystallizer. They suggested that there are specific sites on the crystal in suspension at which nucleation occurs. The additives should alter the surface characteristics and so affect nucleation rate if secondary nucleation processes are related to surface characteristics. Inorganic additives were found to decrease nucleation rate while small amounts of surfactants increased the nucleation rate.

Denk and Botsaris (1972) proposed a model for the origin of secondary nuclei. They demonstrated that a liquid layer next to the crystal may differ from the bulk liquid in the structure of solvent molecules. An ordening of solvent molecules near the interface may lead to secondary nucleation if the solubility of the crystallizing species in the ordered solvent structure was less than the solubility in the bulk solution.

Botsaris, Denk and Chua (1972) developed an Impurity-ConcentrationGradient mechanism for secondary nucleation. Essentially, this mode1 states that an impurity concentration gradient might occur in solutions containing dissolved impurities. In the boundary layer between crystal and solution the impurity concentration may be lowered due to incorporation of impurity in the crystal. This reduction may give rise to 
'primary nucleation' in the boundary layer. 'This mechanism was demonstrated with $\mathrm{KCl}$ solutions containing $\mathrm{Pb}^{++}$as impurity.

Though the 1iterature does not depict any general theory of secondary nucleation, most studies indicate that secondary nucleation by a collision mechanism is the predominant source of grain in continuous crystallizers operating with low supersaturation.

\section{Growth}

Once nuclei are formed, they begin to grow. Crystal growth is a process in which molecules or ions are incorporated into the crystal lattice. Comprehensive reviews of crystal growth can be found in the work of Buckley (1951), Verma (1953), Strickland-Constable (1968), and Mullin (1972). A recent critical review of crystal growth theory applied to growth from solutions is the work of Ohara and Reid (1973).

Crystal growth from solutions can be thought to involve two steps, namely:

(1) Volume diffusion: diffusion of molecules or ions from the bulk of solution to the crystal face,

(2) Surface integration: the incorporation of molecules or ions into the crystal lattice.

It is assumed that these steps take place in series and are independent of each other. Depending upon conditions, either may be rate controliing.

Several theories have been proposed regarding the nature of the surface growth mechanism. Earlý growth theories are based on the assumption of formation of a two-dimensional nucleus on the existing 
crystal surface followed by the completion of a growth layer by surface diffusion. The Stranskii-Kossel growth model assumes the growth layer step is fast compared to the rate limiting mononuclear two-dimensional nucleation step. Benneman (1967) proposed a polynuclear two-dimensional nucleation model and suggested that the process of formation of nuclei on the crystal surface was faster than the formation of growth layers. The above theories predict very slow growth rates of low supersaturations, a consequence not supported by data. This problem was overcome by Frank (1949) who showed that crystal dislocations were capable of providing the sources of steps required for continuous growth of a crystal, even at low supersaturations. His ideas formed the basis of the screw dislocation theory, postulated by Burton, Cabrera and Frank (1951). The BCF model suggests the rate of growth of a crystal should be modelled as

$$
G=A \frac{S^{2}}{B} \tanh \left(\frac{B}{S}\right)
$$

where A, B are constants. This equation gives a parabolic relation between growth rate and supersaturation at low supersaturations and a linear relation at high supersaturations. Furthermore, the conditions for growth may vary from crystal to crystal and from crystal face to crystal face depending upon the type and number of dislocations. Evidence that the growth rates of similar crystallographic faces are not always the same for all crystals is given by Mullin and Garside (1969) for (100) faces of potassium alum and by Botsaris et al. (1972) for sodium chloride whiskers. Since the overall growth rate is determined by growth rates of all faces, a variation in growth rate might occur. 
This variation in growth rate leads to the phenomenon of growth dispersion, i.e. a widening of CSD with time in batch processes. Furthermore if the variation in growth rate is not completely random, these fluctuations can lead to increases or decreases in average growth rate with increasing crystal size. Such size-dependent growth rates are often reported in the literature.

Thus the literature of growth theories suggests that either surface integration or volume diffusion or both control the growth rate.

\section{$\underline{\text { Habit }}$}

The manner in which crystals grow determines the habit. Habit is the overall shape of the crystal made up of a whole of (hkl) faces. A change in habit may be considered as a change in the relative development of the already existing ( $h k 1$ ) faces, or the appearance of some new $\left(h^{\top} k^{\urcorner} l^{\gamma}\right)$ faces.

Crystal habit can be modified by variations in operating conditions or by the addition of some impurity. Kirov and Filizova (1970) showed that supersaturation affects both habit and phase transformations. They demonstrated that calcium carbonate crystallizes as calcite at low supersaturations and as aragonite elongated along (001), then along (100) when the supersaturation is increased.

Crystallizer temperature can also influence crystal habit. Kahlweit (1970) showed that ammonium chloride (100) whiskers have a growth rate highly influenced by temperature whereas (111) whiskers grow independent of temperature.

Variations in $\mathrm{pH}$ also influence habit. Mullin et a1. (1970) postulated for ADP crystals that at low supersaturations and normal $\mathrm{pH}$ 
(3.8) tapered crystals are produced, but at slightly higher $\mathrm{pH}$ ( 5 ) linear growth rates of both principal axes are increased.

The presence of certain impurities in the crystallizing solution can modify crystal habit. The influence of an impurity is closely related to its concentration in the solution, $C_{i}$. A number of conflicting mechanisms have been proposed to explain the effect of impurities on crystal habit. It is generally believed that impurities adsorb at certain sites of a growing crystal.

Larson and Mul1in (1973) explained polygonization of the growth layers of ammonium sulfate in the presence of $\mathrm{Cr}^{3+}$ (added as $\mathrm{CrCl}_{3}$ ) by adsorption of $\mathrm{Cr}^{3+}$ at kink sites. Davey and Mullin (1974) postulated formation of single monolayer steps of ammonium dihydrogen phosphate in the presence of $\mathrm{Cr}^{3+}$ ions. They based their interpretation on the hypothesis of progressive coverage of steps by the impurity. Adsorption on surface sites has been suggested to explain the effect of $\mathrm{AlCl}_{3}$ and $\mathrm{FeCl}_{3}$ on ammonium dihydrogen phosphate crystals by Davey and Mullin (1974). The impurity was assumed to diminish the number of adsorption sites available for the solute, resulting in a decrease of flux to steps and kinks.

The above cited literature shows the effect of ionic impurities. However, a large number of organic compounds are also known which modify habit. Their effect is probably due to the presence of polar groups which are easily adsorbed on the surfaces of inorganic substances and thence modify habit. Such compounds are often surface active agents or surfactants. For example, addition of trace quantities of dodecylbenzene sulfate and trimethyldodecylammonium chloride to a crystallizing 
solution of adipic acid favors the formation of needle crystals and micaccous flakes, respectively.

In conelusion, crystal habit can be controlled by supersaturation, crystallizing temperature, $\mathrm{pH}$ of the solution and trace impurities, both organic and inorganic. 


\section{CHAPTER 3}

\section{THEORY}

Chapter 2 discussed the several mechanisms for secondary nucleation which have been postulated by different workers. This chapter will discuss the kinetic correlation of such nucleation data and the predicted effects of such nucleation models on crystal size distribution.

Mass and energy balances can be utilized to predict process production rate and efficiency. However, mass and energy balances do not give sufficient information for the analysis of Crystal Size Distribution (CSD). A population balance of crystals within the crystallizer along with kinetics of formation and growth of particles can be coupled with mass and energy balances to determine the entire CSD as well as the production rate and energy requirements.

\section{Population Balance}

Population balance algorithms have been discussed in detail in a recent book by Randolph and Larson (1971). The most useful form of the population balance, written for a mixed-suspension crystallizer (Randolph, 1964) is as follows:

$$
\frac{\partial \mathrm{n}}{\partial \mathrm{t}}+\frac{\partial(\mathrm{Gn})}{\partial \mathrm{L}}+\frac{\mathrm{d}(\mathrm{InV})}{\mathrm{d} t}=\sum_{i} \frac{\mathrm{n}_{i} \overline{\mathrm{Q}}_{i}}{\mathrm{~V}}+\mathrm{B}(\mathrm{L})-\mathrm{D}(\mathrm{L})
$$

where

$\frac{\partial \mathrm{n}}{\partial t}=$ Rate of change of population density of particles at a particular size with time. 
$\frac{\partial(\mathrm{Gn})}{\partial \mathrm{L}}=$ Net change in population of particles of size $L$, due to crystal growth.

$\mathrm{B}(\mathrm{L})$ = Birth rate of particles due to breakage, attrition, agglomeration and nucleation.

$\mathrm{D}(\mathrm{L}) \quad$ = Disappearance rate of particles at size $\mathrm{L}$, due to breakage into two or more particles.

$\sum_{i} \frac{n_{i} \bar{Q}_{i}}{V}=$ Rate of change in population density due to streams entering or leaving the crystallizer.

The complex relationship of Equation (6) may be simplified by imposing some constraints which apply to a MSMPR crysta11izer. These restrictions are (a) steady state operation, (b) perfect mixing, (c) clear liquid feed, (d) no breakage or attrition of crystals in the stirred medium. Thus the resultant relationship becomes

$$
\frac{\mathrm{d}(\mathrm{Gn})}{\mathrm{dL}}=-\frac{\mathrm{n}}{\tau}
$$

Assuming McCabe's $\Delta \mathrm{L}$ Law, $\mathrm{G} \neq \mathrm{G}(\mathrm{L})$, Equation (7) may be integrated directly to

$$
\mathrm{n}=\mathrm{n}^{\mathrm{o}} \exp \left[-\frac{\mathrm{L}}{\mathrm{G} \tau}\right]
$$

In a typica1 MSMPR analysis, a plot of $10 \mathrm{~g}(\mathrm{n})$ versus $\mathrm{L}$, yields a straight line of slope $(-1 / G \tau)$ and intercept $n^{0}$. The nucleation rate is calculated as

$$
B^{O}=n^{O} G
$$

This assumes that a11 new crystals are formed at zero size and larger sizes are populated by. growth alone. 
For practical purposes a mass or weight distribution is generally used to characterize CSD. The differential weight-size distribution can be obtained by multiplying the population distribution by the cube of the size. Similarly, the number distribution can be used to calculate specific length, specific surface area, specific mass etc. For example, the specific mass of the crystals in the distribution is

$$
M_{T}=\rho k_{V} \int_{0}^{\infty} n(L) L^{3} d L
$$

The above development for the MSMPR crystallizer holds for any nucleation/growth kinetics model so long as growth rate is independent of size. However, the position of the distribution curve on the size axis is determined by kinetic rates of nucleation and growth. The following discussion deals with growth and nucleation kinetics.

\section{Growth Rate}

Size-independent growth rate is usually correlated as a function of supersaturation: Thus

$$
G=\mathrm{ks}^{\mathrm{a}}
$$

The constant $k$ embodies the effects of independent variables such as temperature and hydrodynamic conditions. The value of ' $a$ ' is often unity or lies in the range of one to two. Shor and Larson (1971) and Iiu and Botsaris (1973) concluded from their impurity experiments that impurity effects on growth rate could be correlated by a simple power function. The exponents were constants independent of impurity concentration. A kinetic model of growth with impurities as developed by Liu and Botsaris (1973) is as follows 


$$
G_{i}=k\left[s / C_{i}^{b}\right]^{a}
$$

where $G_{i}$ is the growth rate in the presence of impurity and $C_{i}$ is the impurity concentration.

\section{Nucleation Rate}

A generalized nucleation rate kinetics expression can be represented as

$$
B^{o}=f\left(s, T, X_{1}, X_{2}, Y, Z, I\right)
$$

where s: supersaturation

T: temperature

$\mathrm{X}_{1}$ : some property representing the presence of foreign solid particles (heterogeneous nucleation effect)

$\mathrm{x}_{2}$ : some property representing the presence of crystals of solute (secondary nucleation effect)

Y: some property representing past history of solution (e.g. rate of supersaturation generation)

Z: some property representing the affect of hydrodynamic conditions (e.g. agitation rate)

I: some property representing the effect of chemical environment (e.g. dissolved impurity concentration).

Experimental results from MSMPR crystallizer studies indicate the utility of a simple power function of supersaturation to describe the effect of supersaturation on nucleation rate (Larson, Timm and Wolff, 1968; Randolph and Rajagopa1, 1970). 
Bransom et a1. (1969) and Cayey and Estrin (1967) proposed that the total crystal surface area, $A_{T}$, could be used as a parameter for $x_{2}$ to characterize the effect of solids. Larson, Timm and Wolff (1968), Rando1ph and Rajagopal (1970) and Desai et a1. (1974) used suspension density, $\mathrm{M}_{\mathrm{T}}$, to characterize the effects of crystal solids on secondary nucleation. However, Randolph and Cise (1972) and Randolph and Sikdar (1976) found that the fourth moment of the parent crystal size distribution would best correlate nucleation data. Thus the second (area), third (mass) and fourth moments of the crystal distribution have been used to characterize secondary nucleation effects.

Hydrodynamic conditions $\mathrm{Z}$ may be represented by impeller speed (Youngquist and Rando1ph, 1972; Randolph and Sikdar, 1976) or impeller Reynold's number (Randolph and Cise, 1972).

This nucleation rate may be adequately correlated with a simple power-1aw model as

$$
\mathrm{B}^{\mathrm{o}}=\mathrm{k}_{\mathrm{N}} \mathrm{s}^{\mathrm{i}} \mathrm{X}_{2}^{\mathrm{j}} \mathrm{z}^{\mathrm{k}}
$$

The constant $\mathrm{k}_{\mathrm{N}}$ includes the temperature dependence.

Thus, to fit the data for the present study the suspension density $\mathrm{M}_{\mathrm{T}}$ was used to characterize the effect of crystal solids on secondary nucleation rate. The impeller speed, RPM, was used to represent the affect of hydrodynamic conditions. Supersaturation was replaced by growth rate $G$ with the utilization of Equation (11). The impurity concentration $C_{i}$ was used to represent the affect of impurities. Thus the power-law model of secondary nucleation rate used in this study was

$$
B^{0}=k_{N} G^{i} M_{T}^{j}(R P M)^{k} \exp \left(\ell x C_{i}\right)
$$


CHAPTER 4

\section{EXPERIMENTAL EQUIPMENT}

The experimental set-up used for this study has been described in detail by Cise. Figure (2) shows the various components of the crystallization apparatus. Their functions are described below:
(i) Surge Tank:
A jacketed vessel of one liter capacity.
It was

placed on a magnetic stirrer and its temperature was maintained a few degrees higher than that of the saturator.

(ii) M-Roy Pump: Maximum capacity of 6.2 gallons per hour, used to circulate 11quid through the apparatus.

(iii) Precooler: A Graham condenser whose temperature was kept the same as the saturator. The solution inlet was connected to the pump and solution outlet to the bottom of the saturator.

(iv) Saturator: A jacketed cylinder whose temperature was kept constant by circulating water. A 150 Tyler mesh screen was mounted at the bottom which supported rasching rings and borax crystals packed to three-fourths of the internal volume. A thermometer was inserted through an opening in the top. The solution outlet was connected to the sterilizer.

(v) Sterilizer: A Graham Condenser maintained at the same temperature as the surge tank. The sterilizer function was to dissolve any crystal dust being carried away from the saturator.

(vi) Filters: Two set's of Ultipor Pall Filters were inserted in-line to ensure a clean particle feed to the crystallizer. A first set of 3 


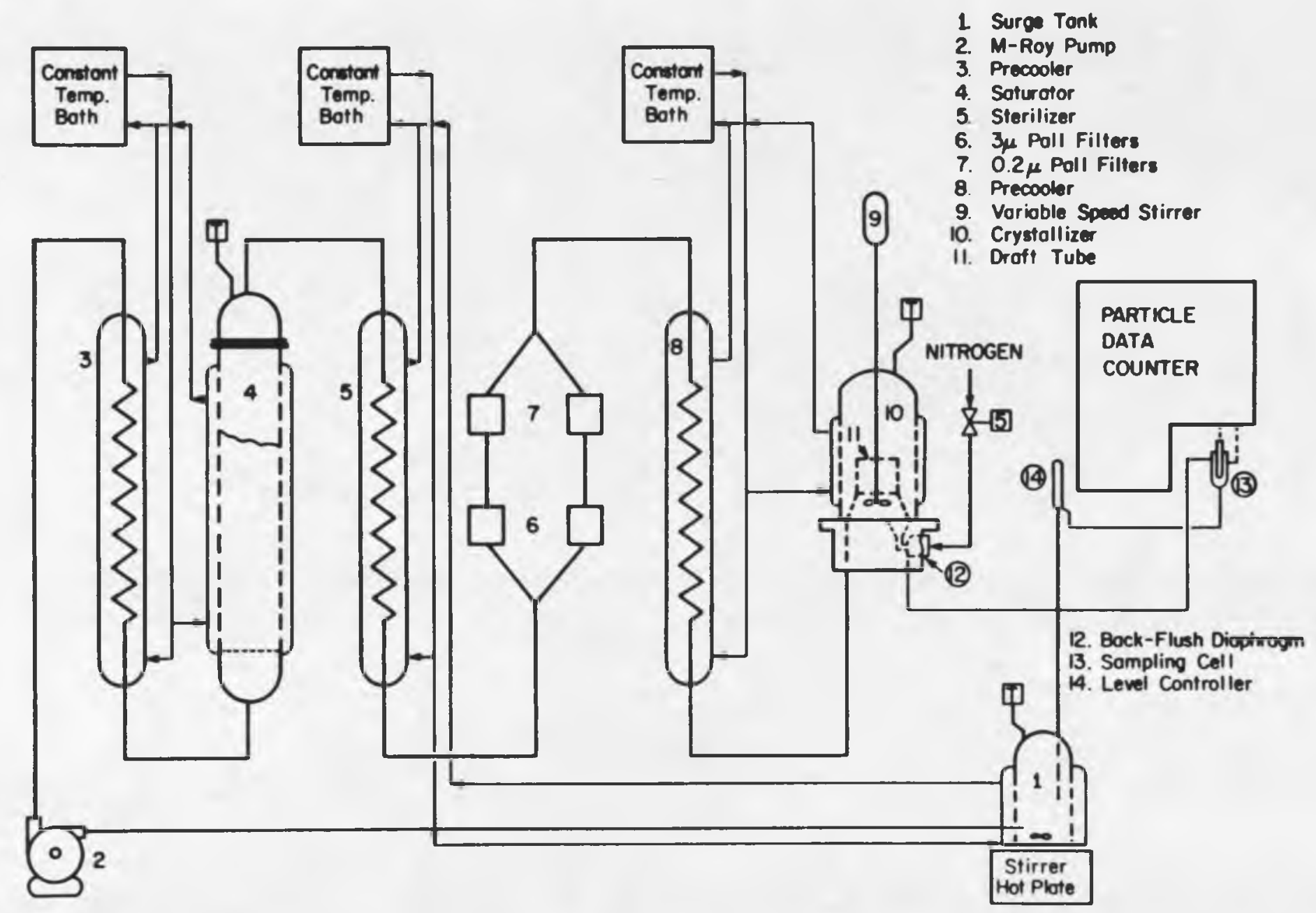

Figure 2. Schematic Diagram of Crystallization Apparatus 
micron (nominal) filters was followed by a 0.2 micron (nominal) set. (vii) Precooler: A graham condenser kept at the temperature of the crystallizer to pre-cool entering feed.

(vili) Crystallizer: A one-liter jacketed vessel with glass baffles formed from the inside wall. The feed input and the effluent from the crystallizer are through the ports at the base. Total retention of parent seeds in the crystallizer is accomplished by removing the discharge flow through a 100 mesh screen. A variable RPM motor is used to drive the stirrer. A center draft tube is used to insure complete mixing. There are three openings at the top of the vessel, two of which are used for a thermometer and for seed introduction, respectively.

The effluent from the crystallizer passes through a concentric sampling cell. surrounding the Particle Data Counter sample proble. Outlet from the cell' returns to the surge tank via an overflow which controls liquid level in the crystallizer. The time constant of the crystallizer is large compared to the time constant of the cell, so samples of nucleiladen effluent are considered to be representative of conditions existing in the crystallizer. A 190 micron orifice counting probe was used throughout this study which could span a size range of approximately 4 to 75 microns.

\section{Particle Data Counter}

The Particle Data Counter works on the electrolytic zone sensing principle. A suspension of particles in their electrolytic mother liquor is drawn through the orifice using vacuum. Each particle in traversing the orifice causes a momentary resistance change proportional 


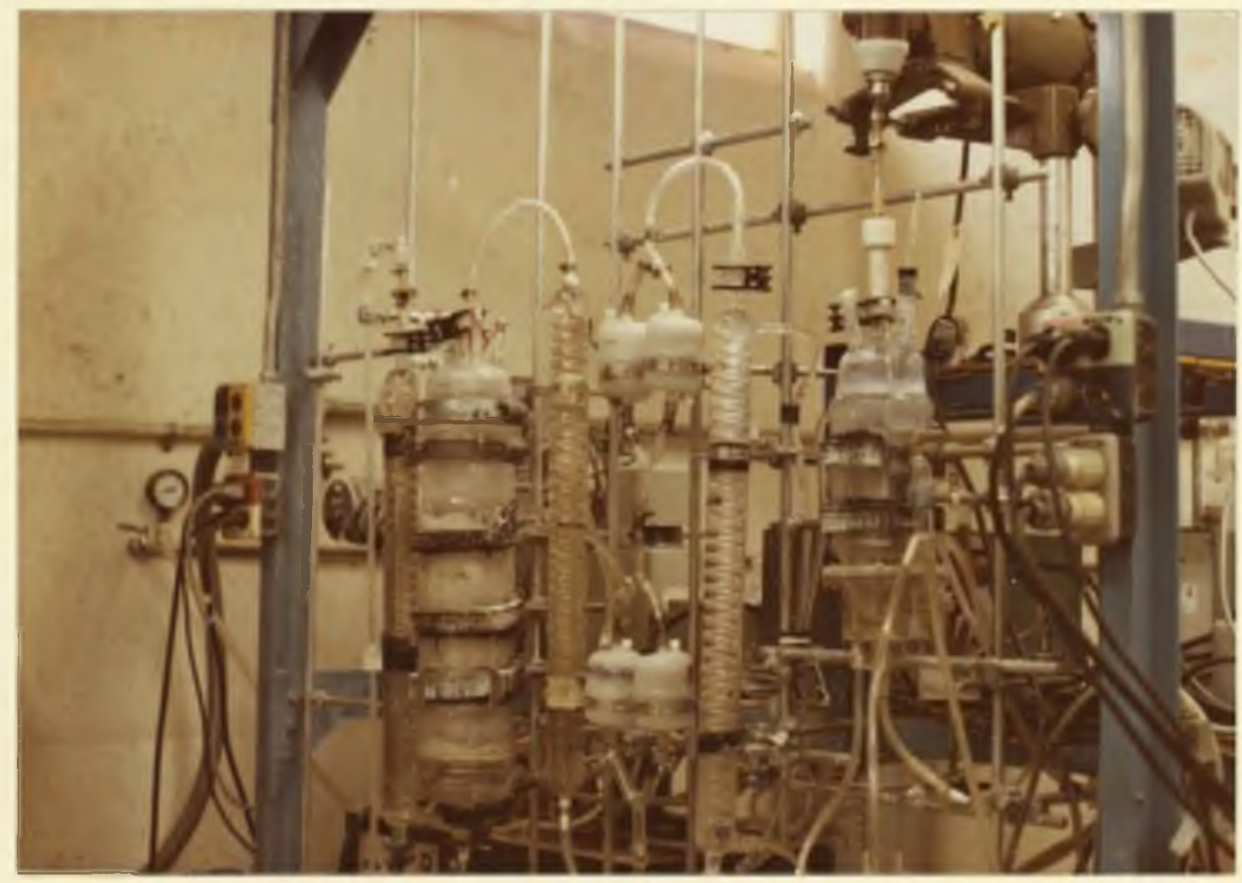

Figure 3. Front view of Crystallization Research Apparatus. 
to particle volume. The resultant sequence of electric particle pulses is then amplified, scaled and counted or otherwise electronically processed to yield a particle count and size distribution.

The counter can measure size ranges from about one to several hundred microns. A given orifice can measure $2 \%$ to $40 \%$ of the orifice diameter. Flow velocity through the orifice is of the order of 5 meters/ second and the instrument can count at a frequency of several thousand particles per second.

The counter assembly consists of a sampling cell, orifice, hydropulser diaphragm, and a regulated vacuum supply. Figure (4) shows the front view of Particle Data Counter. The counter was hooked to an oscilloscope to observe the size distribution and to a PDP8A computer and a Decwriter to print out a copy of the results.

\section{Auxiliary Equipment}

(i) An Allen-Bradley Sonic Sifter Model L3P was used to size parent seed crystals before a run.

(i1). An AO-Spencer Microstar Series 10 Microscope was used to measure the size of the crystals. This microscope was attached to a Polaroid camera so that photomicrographs could be taken.

(iii) A Mettler Balance Series number 63600 was used to weigh the crystals and the additives with an accuracy of four decimal places. Supersaturation was not measured in this study. 


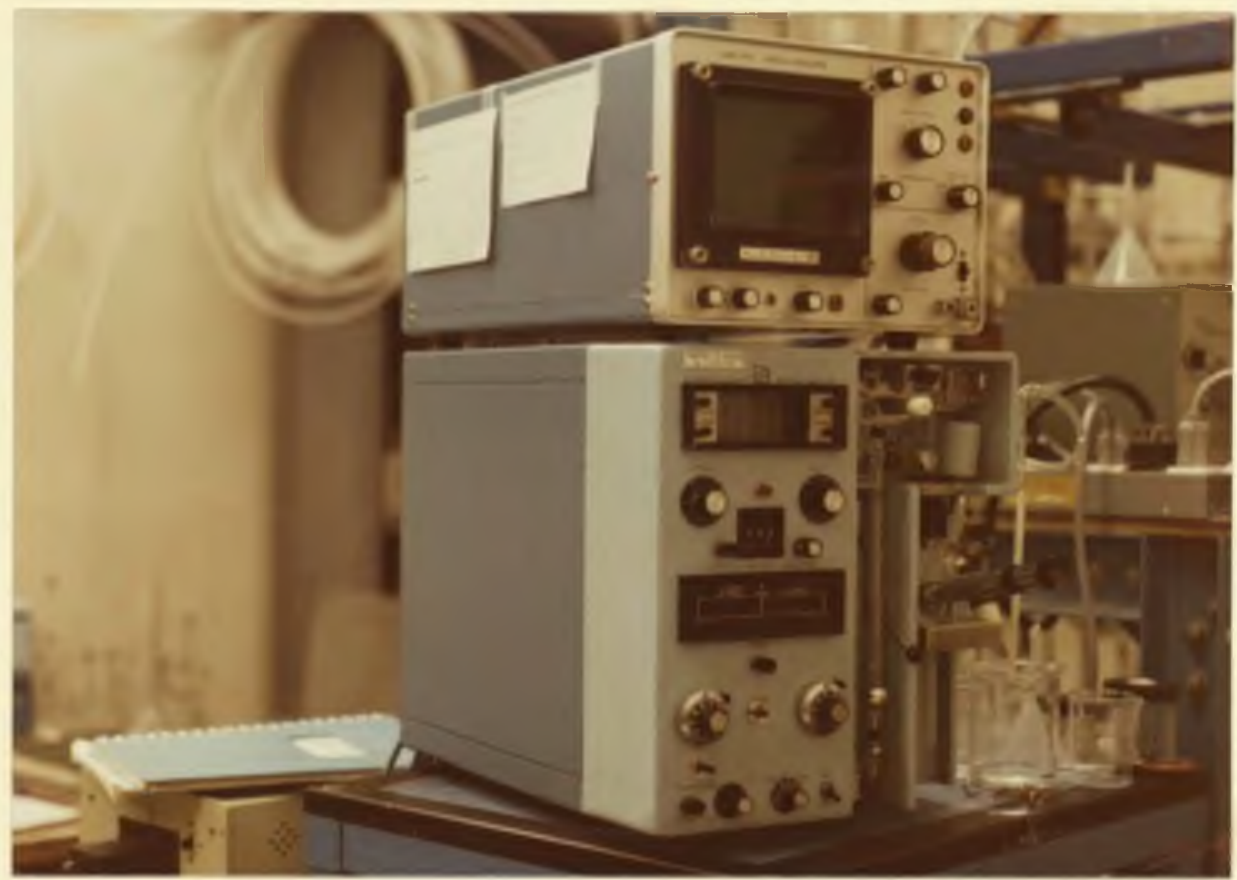

Figure 4. Front view of Particle Data Counter. 
CHAPTER 5

EXPERIMENTAL PROCEDURE

The entire experimental procedure constituted of four steps (a) Calibration, (b) Preparation of Solutions, (c) Preparation of Seeds, and (d) Nucleation Experiments.

\section{Calibration}

Several calibration experiments were carried out. These included calibration of the crystallizer fluid volume, stirrer RPM, thermometers and Particle Data Counter.

The crystallizer volume was calibrated for volume holdup by closing the inlet and outlet ports of the base plate and adding $100 \mathrm{c} . \mathrm{c}$. of water at a time to the crystallizer while making a mark on the meniscus on the outside of the crystallizer. After 600 c.c. of water was added, the stirrer agitator was turned on to about 400 RPM and the addition of water was continued. This procedure gave a dynamic volume holdup.

The two ASTM thermometers used to measure temperatures of the saturator and the crystallizer were calibrated against each other. The results indicated that these thermometers measured the same temperatures under similar environments.

The stirrer agitator was first calibrated with a tachometer. The exact RPM was determined with a General Radio Type 1531-AB Strobotac electronic stroboscope in the range of 350 to 1000 RPM. 
The Particle Data Counter was calibrated for an orifice of 190 microns. The counter was first normalized to its internal standard signal and the current and gain settings. were then adjusted to place the largest particle pulse near the full scale. The current was set as high as thermal noise limitations permitted and the gain was set as low as allowed by span coverage requirements. The current and gain settings for this instrument were $2 \mathrm{M}$-Amps and $2 \frac{1}{8}$ hundreds, respectively. Operation of the counter was made in logarithmic mode to cover an 8-fold span of linear size.

Since the log scales show the proportions of ratios between values, it requires the calibration of two points. These two points were established in calibration range one with the following procedures.

A suspension of 19.5 micron ragweed pollen was placed on sample stand, the current and gain settings were adjusted at 2 and $2 \frac{1}{8}$, and the 'ANALYSE' command was entered followed by particle counting to form a unimodal number-size histogram. Next the 'MARK' command was given and a marker dot placed on the curve peak. Following an escape from 'MARK' command, 'CALIB PT' command ' $\mathrm{IH}$ ' was entered with 19.5 and 'ESC' then typed. To establish calibration point ' $I L$ ', the above procedure was repeated with current and gain settings at $\frac{1}{8}$ and $2 \frac{1}{8}$ with the particle diameter recorded as 7.75 microns. These two points then established the logarithmic calibration line.

A detalled description of the calibration of the Particle Data Counter can be found in the Particle Data Inc. manual. 


\section{Preparation of Solutions}

Saturated solutions at room temperature were prepared in one gallon bottles by dissolving borax in distilled water. The contents of the bottles were treated with activated charcoal to adsorb any surfactant or organic additive present in the borax. The contents were left overnight and then filtered through a one micron millipore filter. The filtered solution was then used for a set of additive experiments.

\section{Preparation of Seeds}

The seed crystals were obtained by sieving a sample of borax crystals through Allen-Bradley sieves. The sieve fraction $-50+60$ mesh was used throughout this study. It was observed in some early experiments that introduction of the dry seeds to the crystallizer produced enormous amounts of nuclei, which were washed out in about half an hour. To avoid such initial breeding the seed crystals were ripened for about one hour in a slightly unsaturated solution before being added to the crystallizer.

\section{Nucleation Experiments}

The types of experiments performed in this study can be summarized as:

(1) Borax-water experiments: The primary objective of these experiments was to study secondary nucleation behavior of the borax-water system. These experiments were conducted at an average temperature of $31.4^{\circ} \mathrm{C}$ with a supersaturation range of $2.8^{\circ} \mathrm{C}$ to $3.7^{\circ} \mathrm{C}$. The stirrer RPM was varied between 380 and 550. An average residence time of 4 minutes was employed in all experiments. 
(ii) Borax-Water-Impurity Experiments: These experiments were designed to study the effect of impurities on the nucleation rate and habit of borax crystals and were similar to the former experiments except for the addition of a known amount of impurity. These impurity experiments were carried out in two fashions.

The first type of experiments was applicable only to organic additives. An ISCO metering pump Model 312, accurate to $0.1 \mathrm{cc} / \mathrm{hr}$, was installed to meter the additive into the main circulating line just before entering the crystallizer. Food solutions had a surfactant concentration of $0.5 \mathrm{gm} / 100 \mathrm{ml}$. The first $(3 \mathrm{micron})$ and the second $(0.2$ micron) ultipor filters were packed with activated carbon. The carbon bed adsorbed all additives in the effluent stream, thus permitting closed loop circulation of borax solution and open loop addition of additives. These experiments had a limitation in that the carbon bed acted as a chromatograph. Thus the adsorbed layer of additive moved upward with the elapse of time and after about one hour the entire additive was eluted from the carbon bed. This difficulty caused the technique to be abandoned and the additive was merely added to the entire circulating solution with no carbon bed in the system.

An experiment was first performed with the pure borax-water system and then stoichiometric proportions of the additive were introduced into the surge tank (the apparatus was allowed to run for about 10 hours to distribute the additive uniformly). Further experiments with increased concentration of additive were carried out in a similar procedure. 
These experiments were performed with the following experimental conditions. Average temperature: $31.4^{\circ} \mathrm{C}$; supersaturation range: 3.1 to $3.7^{\circ} \mathrm{C}$; RPM range: 470 to 500 ; average residence time: $4 \mathrm{~min}-$ utes.

A typical procedure can be described in the following manner. First, the thermostatic temperature baths were switched on. The crystallizer circulation loop was brought to a steady flow condition. A constant level of solution in the crystallizer was achieved by adjusting the level controller tube. The stirrer agitator and the back pressure flushing device were turned on. The temperatures of the saturator and the crystallizer were adjusted to obtain the desired $\Delta T$. The flow rate of solution was recorded to enable computation of the average residence time. The Particle Data counter was switched on when all the settings were at desired levels. No nucleation was observed for about three hours. Ripened seed crystals, weighing 0.2 to 0.207 gram were introduced into the crystallizer to induce secondary nucleation.

During the experiments, frequent particle counts were taken at intervals at approximately ten minutes. The temperatures and RPM readings were also recorded during the runs.

The runs were terminated when (i) sufficient amounts of data were collected, (ii) a steady state was achieved, (iii) Particle concentration became too large to enable reliable counts by the Particle Data Counter or (iv) the discharge screen was plugged by buildup of macrocrystals. At the end of the experiment, the inlet to the crysta11izer was connected directly to the surge tank. The contents of the crystallizer were drained into a beaker and were immediately filtered 
through a vacuum. The parent seed crystals were washed, dried and weighed.

Before switching to another additive, the whole apparatus was cleaned by circulating water and the saturator charge replaced with new borax crystals.

Borax crystals were obtained from Kerr-McGee Chemical Company, Trona, California. Sodium dodecylbenzene sulfonate was obtained from Continental 0il Company as a technical slurry with about $40 \%$ active concentration by weight. Sodium oleate was obtained from J.T. Baker Chemical Company. Sodium lauryl sulfate was obtained from Alcolac, Inc. Sodium chloride and magnesium chloride were obtained from Allied Chemical and Dye Corporation and Mallinckrodt, Inc., respectively. 


\section{CHAPTER 6}

\section{EXPERIMENTAL DATA AND OBSERVATIONS}

The main purpose of this study was to investigate the effect of impurities on the crystallization of borax from aqueous solutions. Several experiments were designed to achieve this goal. First, a few experiments were performed with the borax-water system to study the kinetics of the system without additives. These kinetic runs were conducted at different levels of temperature, supersaturation and stirrer RPM. Typically 0.20 to 0.25 gram of seed crystals were added in about $1000 \mathrm{ml}$ of solution in the crystallizer. An average residence time of 4 minutes was employed in all the experiments.

Organic and inorganic impurities were used to illustrate the influence of two completely different types of additives. The organic impurities used were sodium dodecylbenzene sulfonate, sodium oleate and sodium lauryl sulfate, whereas the inorganic impurities were sodium chloride and magnesium chloride. For each impurity, three or four experiments were carried out under similar experimental conditions, but at different levels of impurity concentration. Nucleation was not observed in any of the above experiments until the seed crystals were added.

\section{Borax-Water System}

Figure (5) shows a plot of log-nucleation rate versus dimensionless time. This figure also shows the effect of stirrer RPM on the 


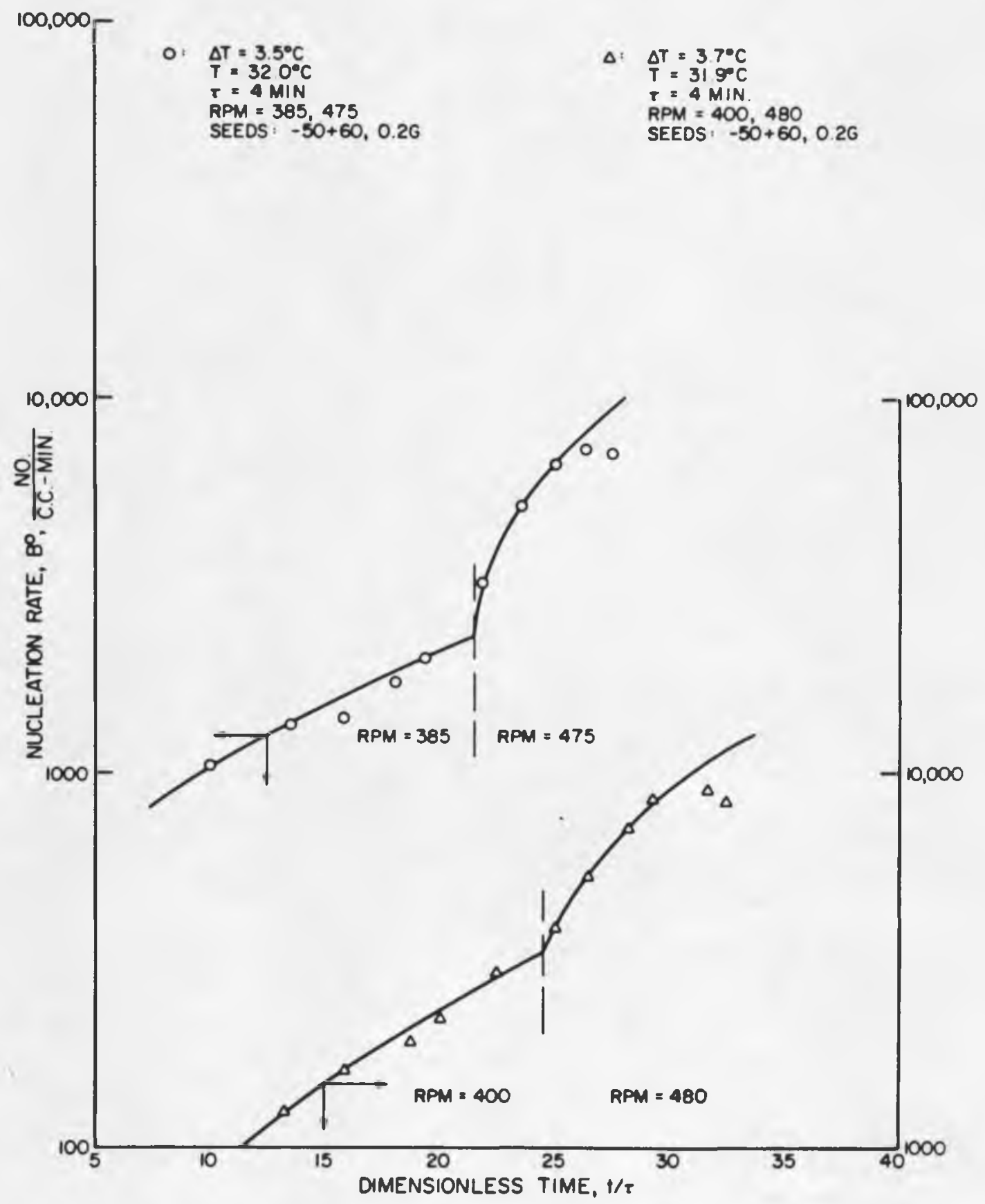

Figure 5. Effect of Sudden Increase of Stirring RPM on Nucleation Rate (Borax-Water System) 
nucleation rate. A sudden change in stirrer RPM at some point during a run caused an instantaneous increase in nucleation rate. This data suggests secondary nucleation by impeller contacts results in direct nuclei formation. This effect of RPM convincingly demonstrates the importance of collision energy and collision frequency in such seçondary nucleation. Higher agitation rates given rise to higher collision energy and more frequent collisions between seed crystals and the impe1ler, resulting in higher nucleation rates.

In Figures (14), (22) and (23) solid lines show a typical set of transient population densities for the pure sodium tetraborate system. Fine crystal $\mathrm{CSD}^{\circ} \mathrm{s}$ were also plotted on log-population density versus size plots. Figures (11), (20) and (21) plot such CSD's (Iines through circles) for pure sodium tetraborate. Except for a few points at the lower size end of the distribution, a satisfactory linear fit was obtained, thus satisfying the quasi-steady-state assumption. Correlation coefficients of a straight line to these data were better than $99 \%$. Such straight line CSD plots verify that the growth rate obeys McCabe's delta $L$ Law, at least in the size range of counting. These straight line log-population density versus size plots can be utilized to analyse CSD data with wel1-known data reduction techniques.

Studies with the pure sodium tetraborate system revealed that the system obeyed a quasi-steady-state and that the nucleation and growth rates are strongly dependent upon experimental conditions, e.g. temperature, supersaturation and stirrer RPM. The habit of borax crystals is also influenced by experimental conditions. A high agitation rate can result in the breakage of crystals and at high RPM the corners can be 
chipped off by crystal-wall, crystal-crystal and crystal-impeller collisions. Moreover, different temperature and supersaturation levels resulted in different velocities of growth steps and hence a changing habit.

\section{Borax-Water-Impurity System}

Three levels of each impurity were studied. Organic impurities were found to be effective at the ppm level. It was observed that the organic additives behaved in a different manner than that of inorganic additives. Thus, the effect of these two kinds of Impurities is discussed separately.

\section{Organic Additives}

Nucleation rates were plotted versus dimensionless time, i.e. by dividing time by retention time. These dimensionless time plots of nucleation were found to be qualitatively similar for both the pure and impure borax runs, as shown in Figures (6), (7) and (8). The nucleation rate was found to increase with time in all cases due to the increase in suspension density with time. Another observation which can be drawn from these plots is that in spite of the increase in nucleation rate with time, a considerable decrease in nucleation was observed with an increase in additive concentration. Few nuclei were formed with 16 ppm (i.e. 6.4 ppm effective) concentration of sodium dodecylbenzene sulfonate or $6 \mathrm{ppm}$ concentration of sodium oleate. These observations are in agreement with the results obtained by Randolph and Koontz (1976).

The test of any experimental data lies in their reproducibility. Experiments with $5 \mathrm{ppm}$ and 6 ppm concentration of sodium oleate were repeated; similar results were obtained. Sodium dodecylbenzene 


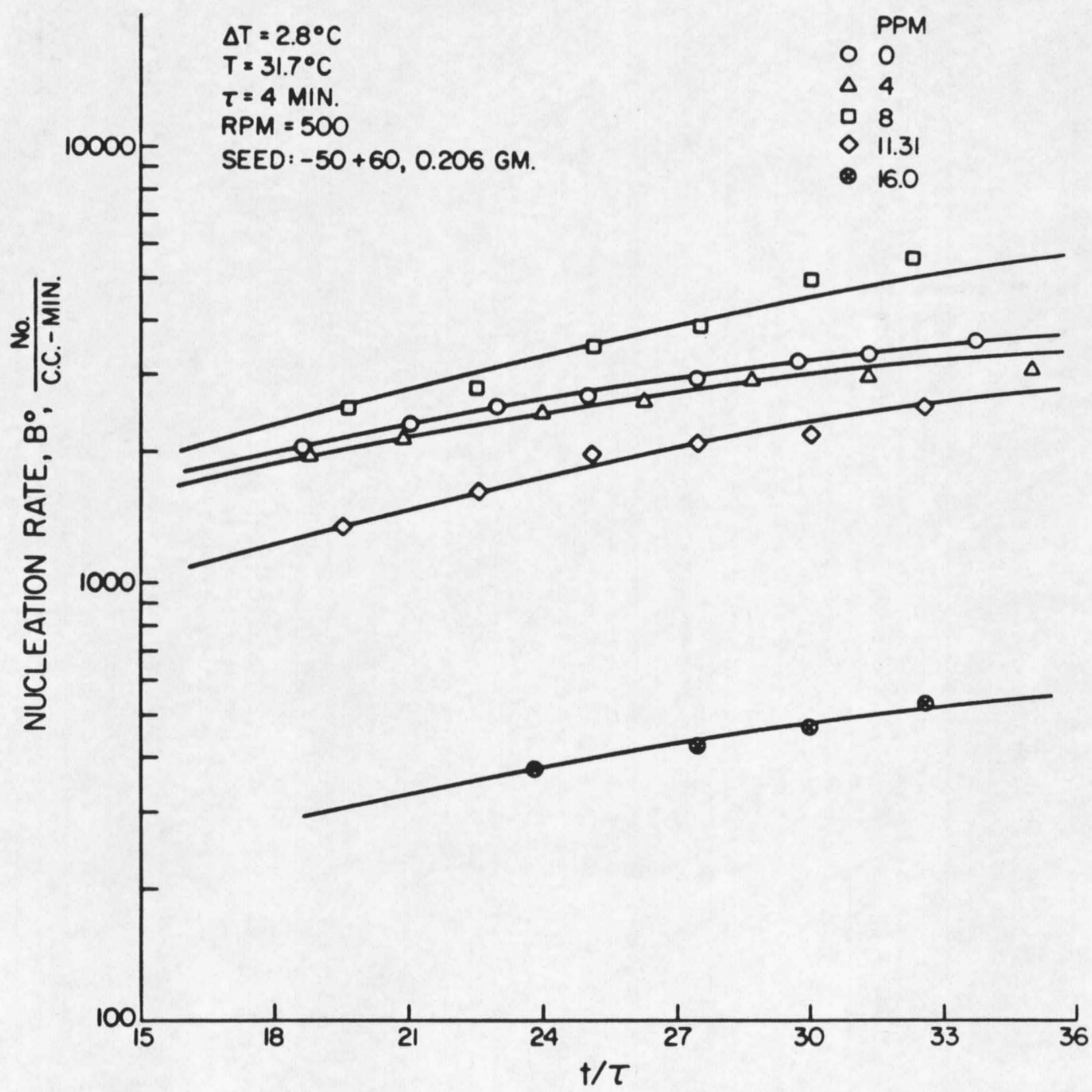

Figure 6. Nucleation Rate Data for Surfactant Sodium Dodecylbenzene Sulfonate Runs. 


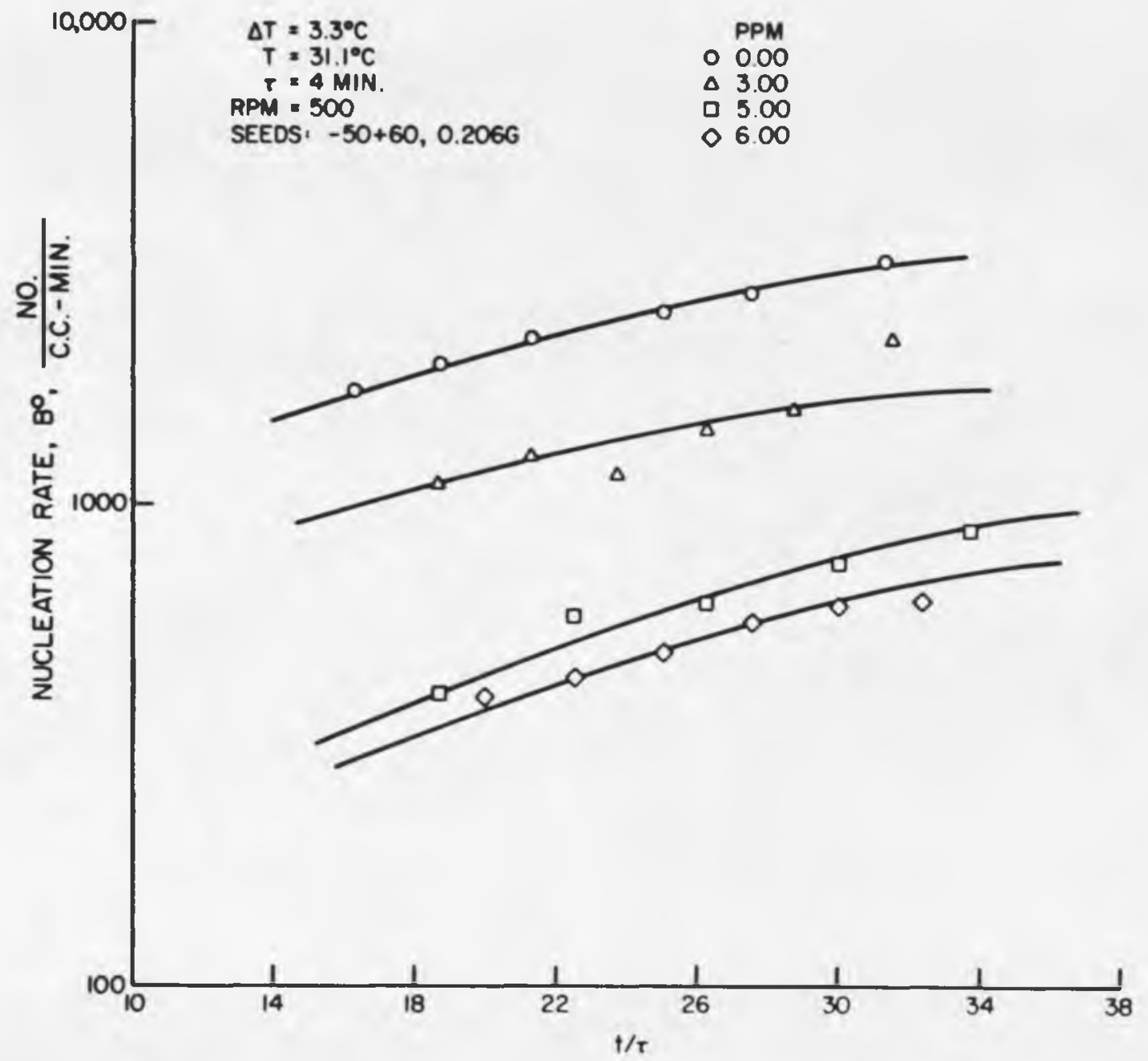

Figure 7. Nucleation Rate Data for Sodium 0leate Runs. 


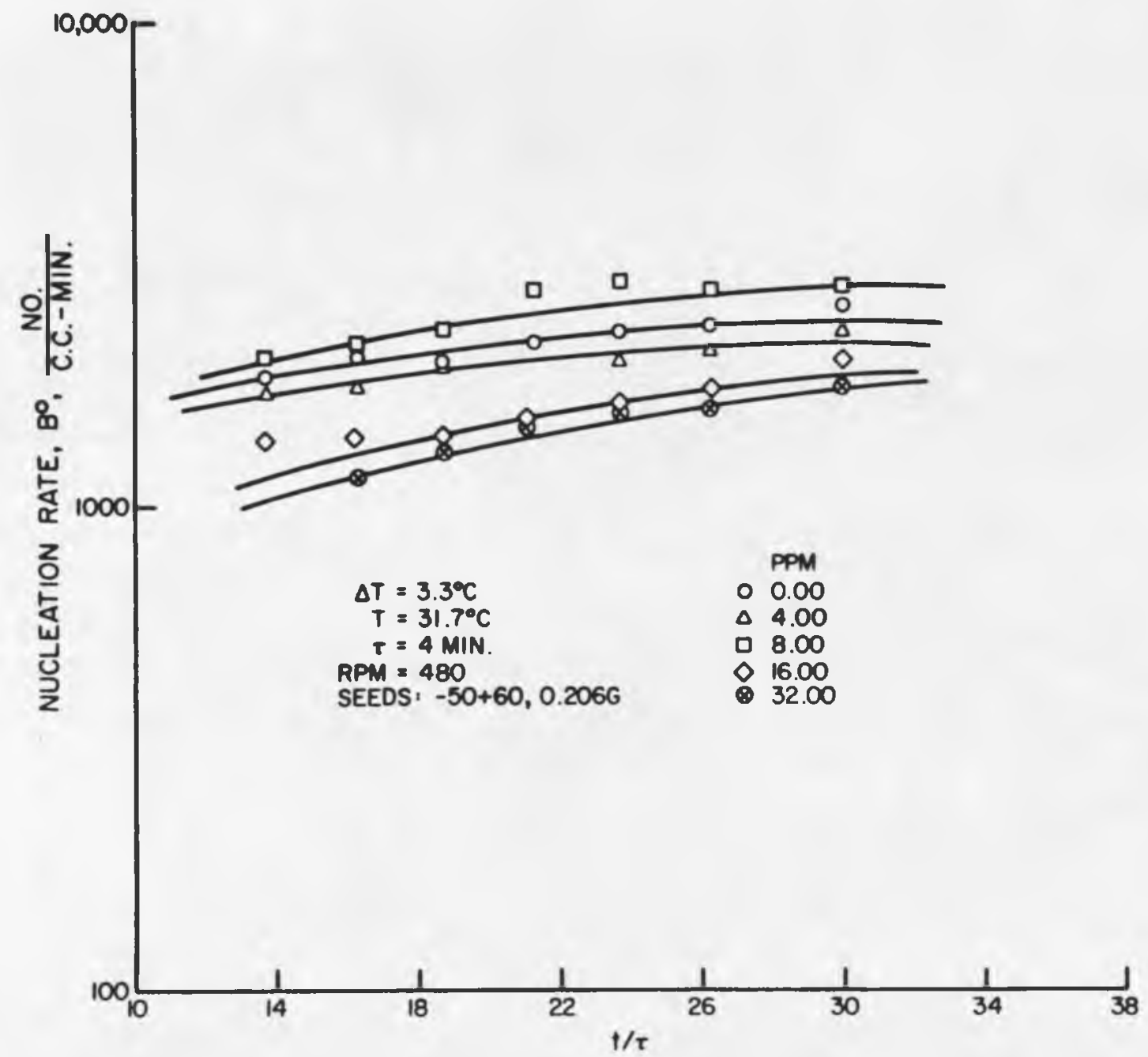

Figure 8. Nucleation Rate Data for Surfactant Sodium Lauryl Sulfate Runs. 
sulfonate experiments were also performed with open loop addition of the additive. The nucleation rate data for these experiments are shown in Figure (9). This plot shows an immediate decrease in nucleation after the addition of additive. For $11.31 \mathrm{ppm}$ (i.e. $4.52 \mathrm{ppm}$ effective) concentration level, the instant decrease in nucleation rate was followed by a gradual increase in nucleation as the solids level increased, whereas for $16 \mathrm{ppm}$ the nuclei were reduced to such a small number that accurate counts with the Particle Data Counter were impossible. In effect, nucleation rate was totally inhibited above $16 \mathrm{ppm}$ of this additive.

Initial breeding usually preceeds true secondary nucleation and should show up on a semi-log plot of nucleation rate versus dimensionless time as initially decreasing nucleation rate followed by a gradual Increase as secondary nucleation takes over. However, forty minutes was required in all the experiments for sufficient nuclei to be generated to get an accurate reading with the Particle Data Counter. The absence of initial breeding was a result of pretreatment of the seed crystals in a slightly undersaturated solution which dissolved loose crystal dust responsible for initial breeding. However, initial breedIng In seeded crystallizers was observed by Randolph and Sikdar (1976) and Randolph and Cise (1972) for the $\mathrm{K}_{2} \mathrm{SO}_{4}$ system. These authors did not ripen their seed crystals.

Figures (10) and (11) show the transient fine-crystal CSD for borax containing trace amounts of sodium dodecylbenzene sulfonate and sodium oleate. The straight line behavior of these plots confirms the quasi-steady-state attained during the runs. Furthermore, the crystal 
$0: \Delta T=2.9^{\circ} \mathrm{C}, T=31.9^{\circ} \mathrm{C}, \quad T=4 \mathrm{MIN}, \quad R P M=540$, SEEDS $-60+70$, $0.207 G$, I6PPM ADDITIVE AT $1 / \tau=37.50$

$\Delta: \Delta T=34^{\circ} \mathrm{C}, T=321^{\circ} \mathrm{C}, T=4$ MIN., RPM $=500$, SEEDS $-50+60$, 0.1986, I6PPM ADOITIVE AT $1 / T=28.75$

口: $\Delta T=3.4^{\circ} \mathrm{C}, T=32.0^{\circ} \mathrm{C}, T=4 \mathrm{MIN} ., R P M=482$, SEEDS : $-50+60$, $0.2046,11.31$ PPM ADDITIVE AT $1 / \mathrm{T}=3000$

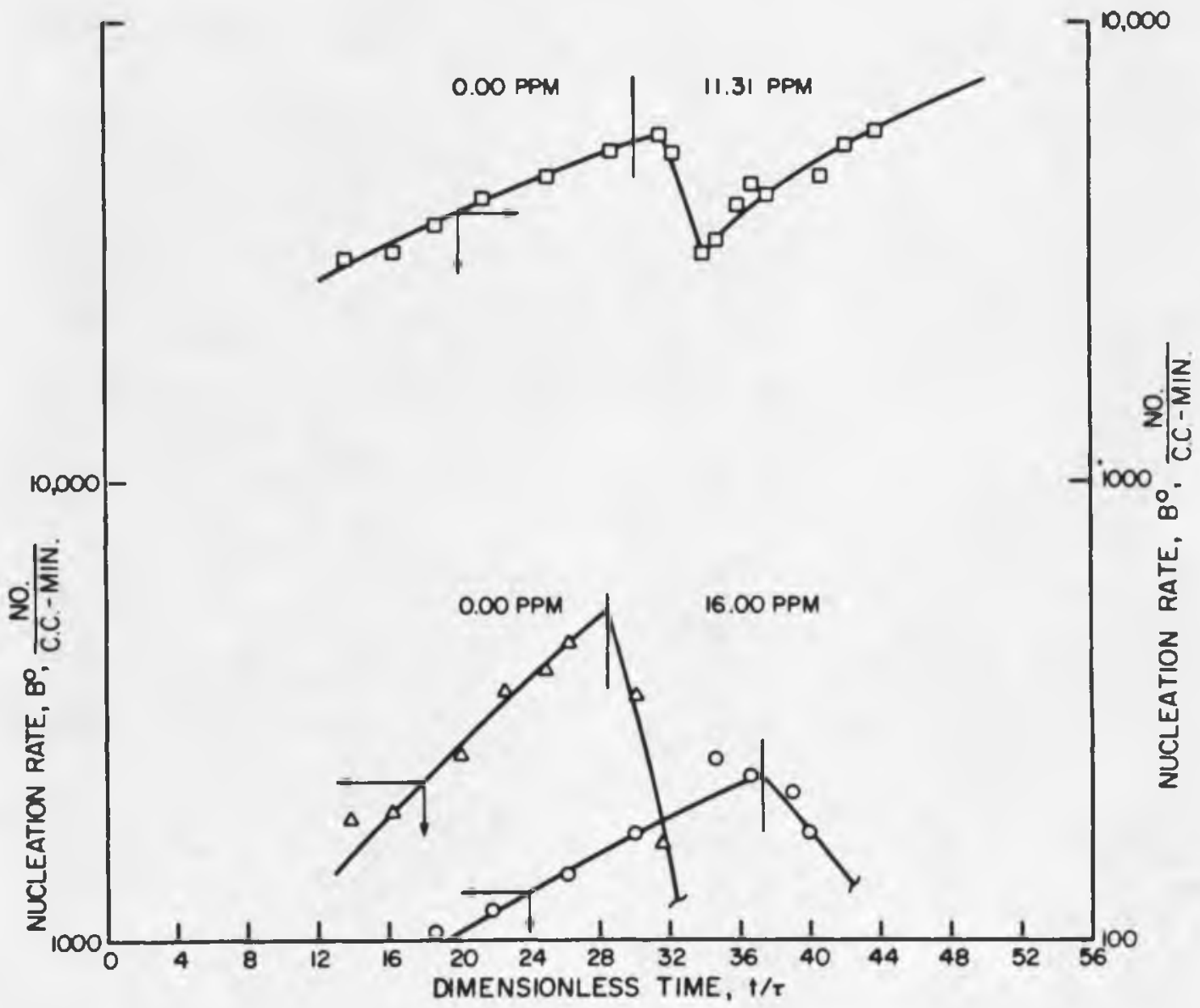

Figure 9. Effect of Surfactant Sodium Dodecylbenzene Sulfonate on Nucleation Rate 


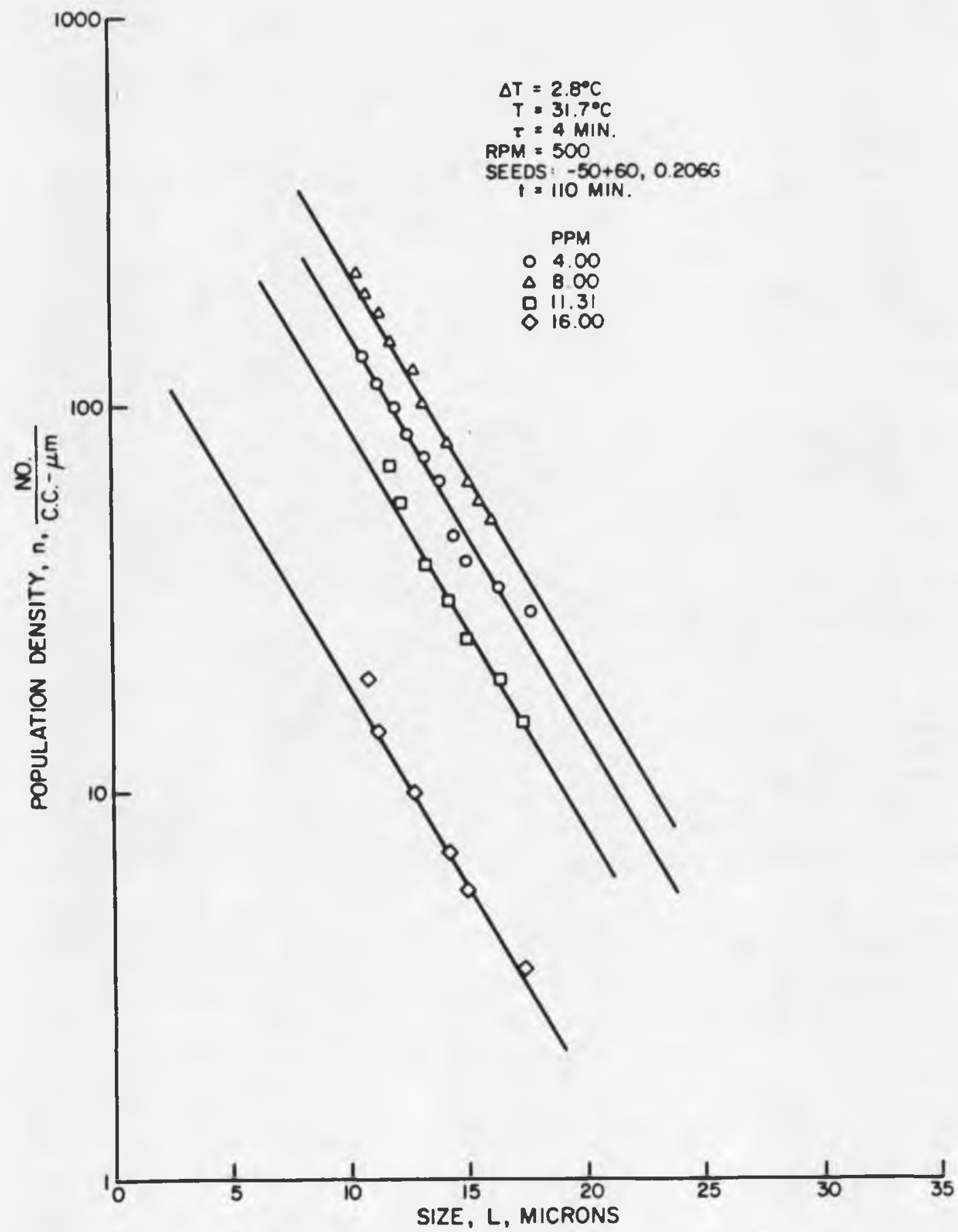

Figure 10. Influence of Surfactant Sodium Dodecylbenzene Sulfonate on the Population Density Distribution of Fine Borax Crystals. 


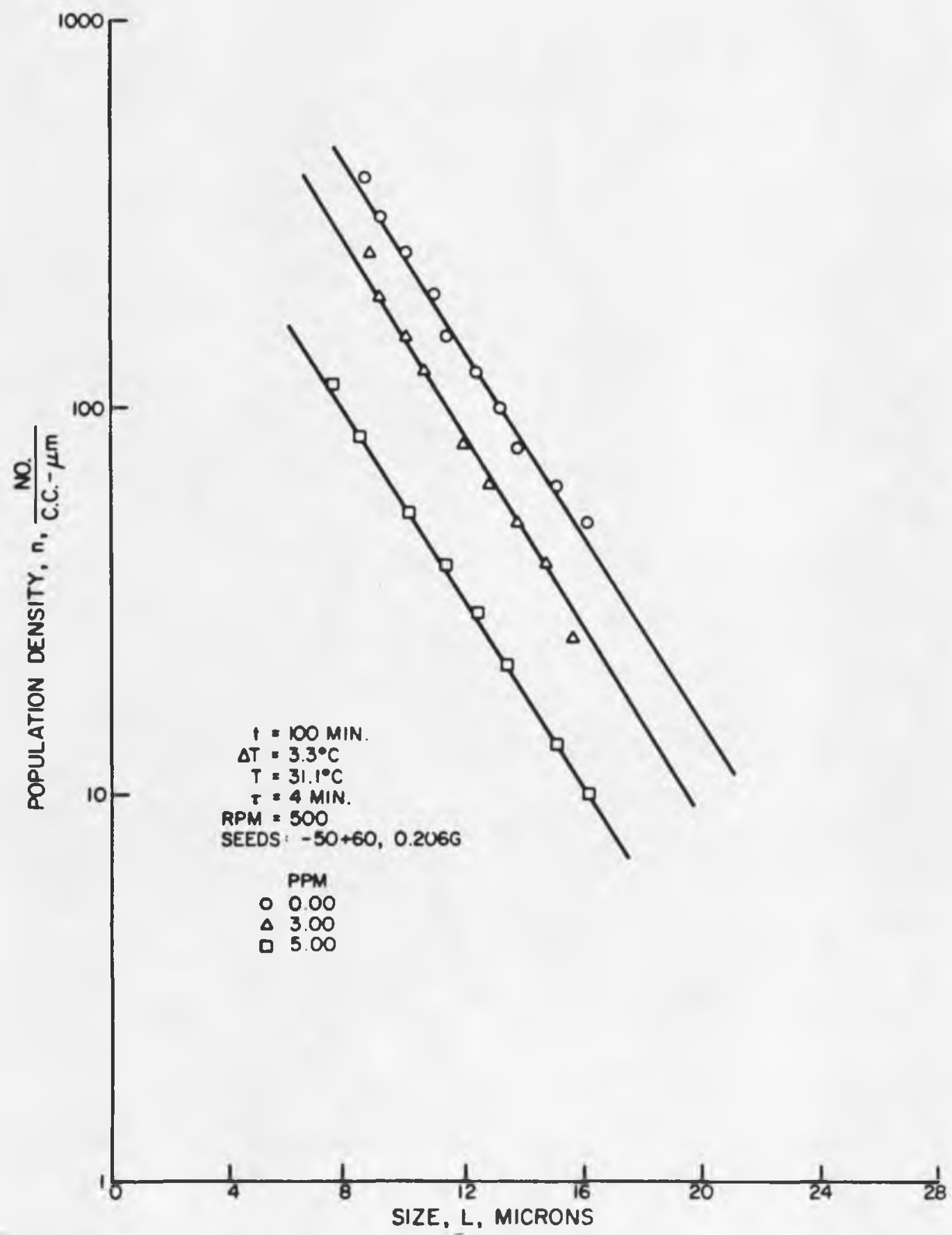

Figure 11. Influence of Sodium Oleate on the Population Density Distribution of Fine Borax Crystals. 
growth rate obeys McCabe's delta L Law, at least in the 7 to $17 \mu \mathrm{m}$ size range studied.

These population density curves shift toward the left as the concentration of organic additive in the solution is increased. Furthermore, these plots indicate that changes in additive concentration produce small changes in fine-crystal growth rate but large changes in the nucleation rate. Thus different concentrations of the organic additives result in sma11 differences in slope but large differences in the intercept. This conclusion was also drawn by Randolph and Koontz (1976) for the same system.

The previous discussion indicates that nucleation rate decreases with increases in additive. If marginal changes (decrease) in finecrystal growth rate (with changes in additive concentration) are not significant enough to alter the nuclei density, then the intercept on CSD plots should have lower values at higher additive concentrations. Population density versus size plots show such behavior. In all the cases, the intercept at high concentration of impurity is less than at low impurity concentration.

Population densities were plotted against time on semi-log paper for a11 runs. Figure (12) shows the variation of population density with time for a typical run with $5 \mathrm{ppm}$ of sodium oleate. Figures (13) and (14) give a comparison between population densities of various sizes of pure borax and when the solution contained $4 \mathrm{ppm}$ (1.6 ppm effective) and $32 \mathrm{ppm}$ of sodium dodecylbenzene sulfonate and sodium laury1 sulfate, respectively. As expected, population densities were found to decrease 


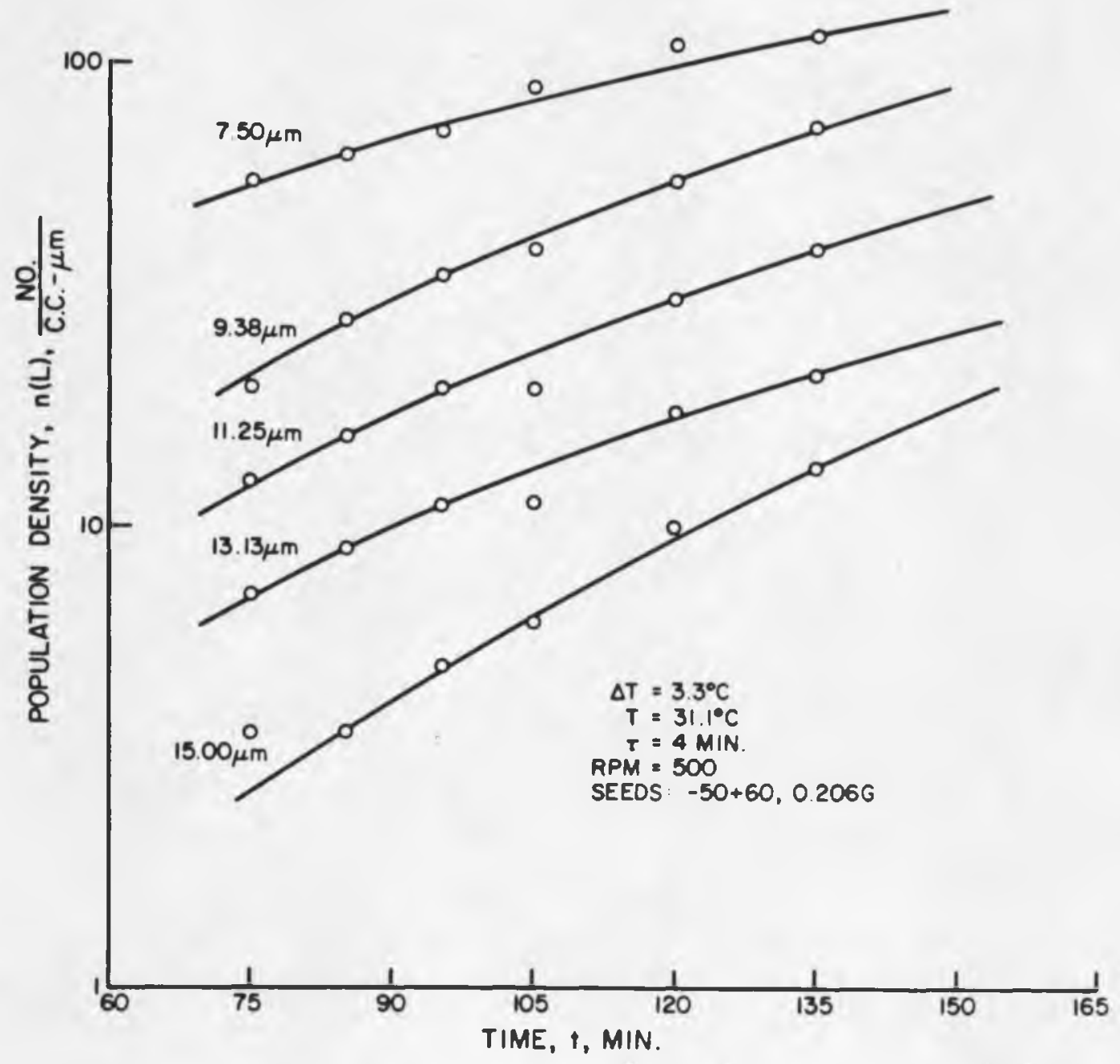

Figure 12. Transient Population Densities of Fine Borax Crystals for a Typical Run with 5 ppm Sodium Oleate. 


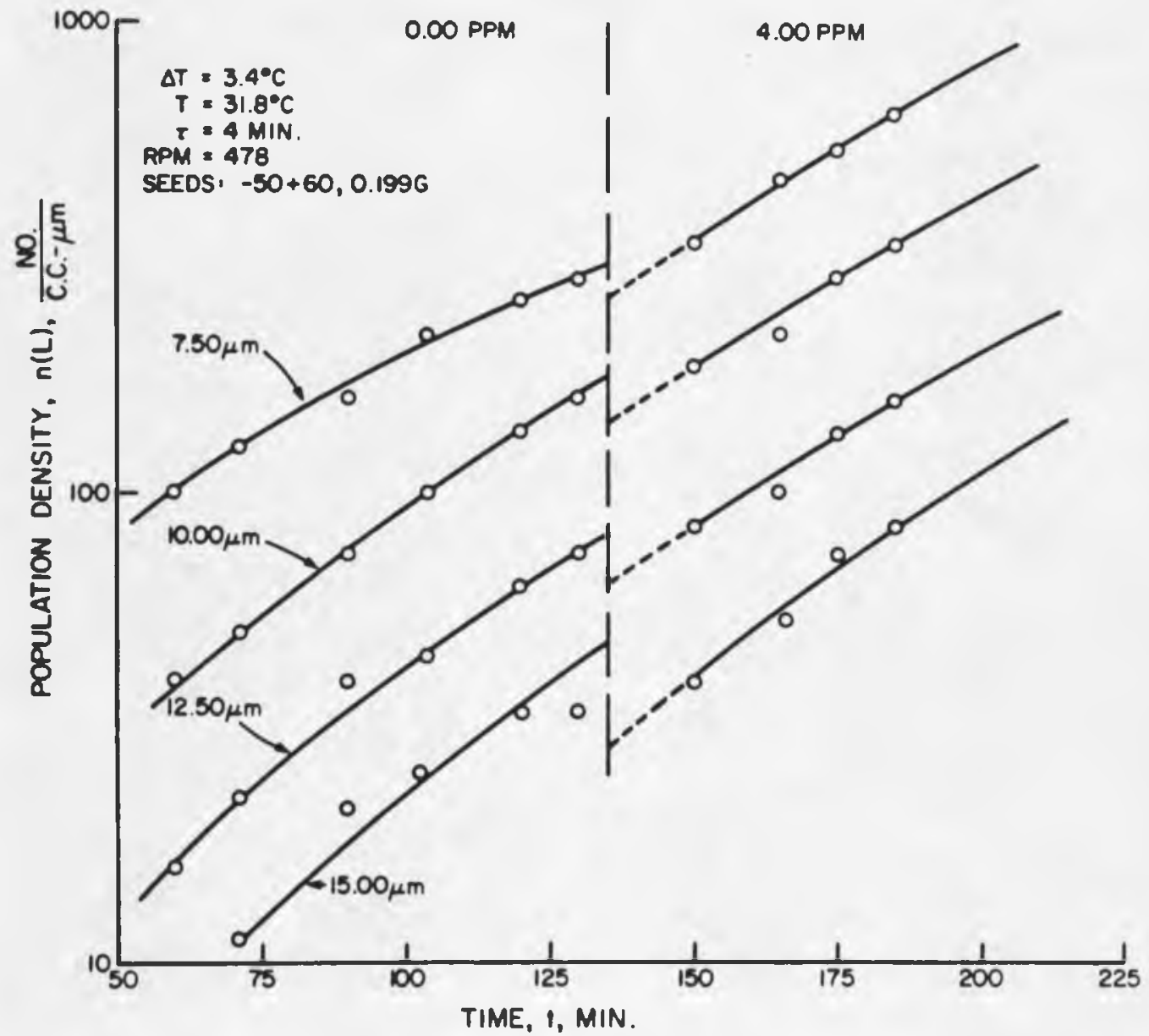

Figure 13. Effect of Surfactant Sodiun Dodecylbenzene Sulfonate on the Dynamic Population Densities of Fine Borax Crystals. 


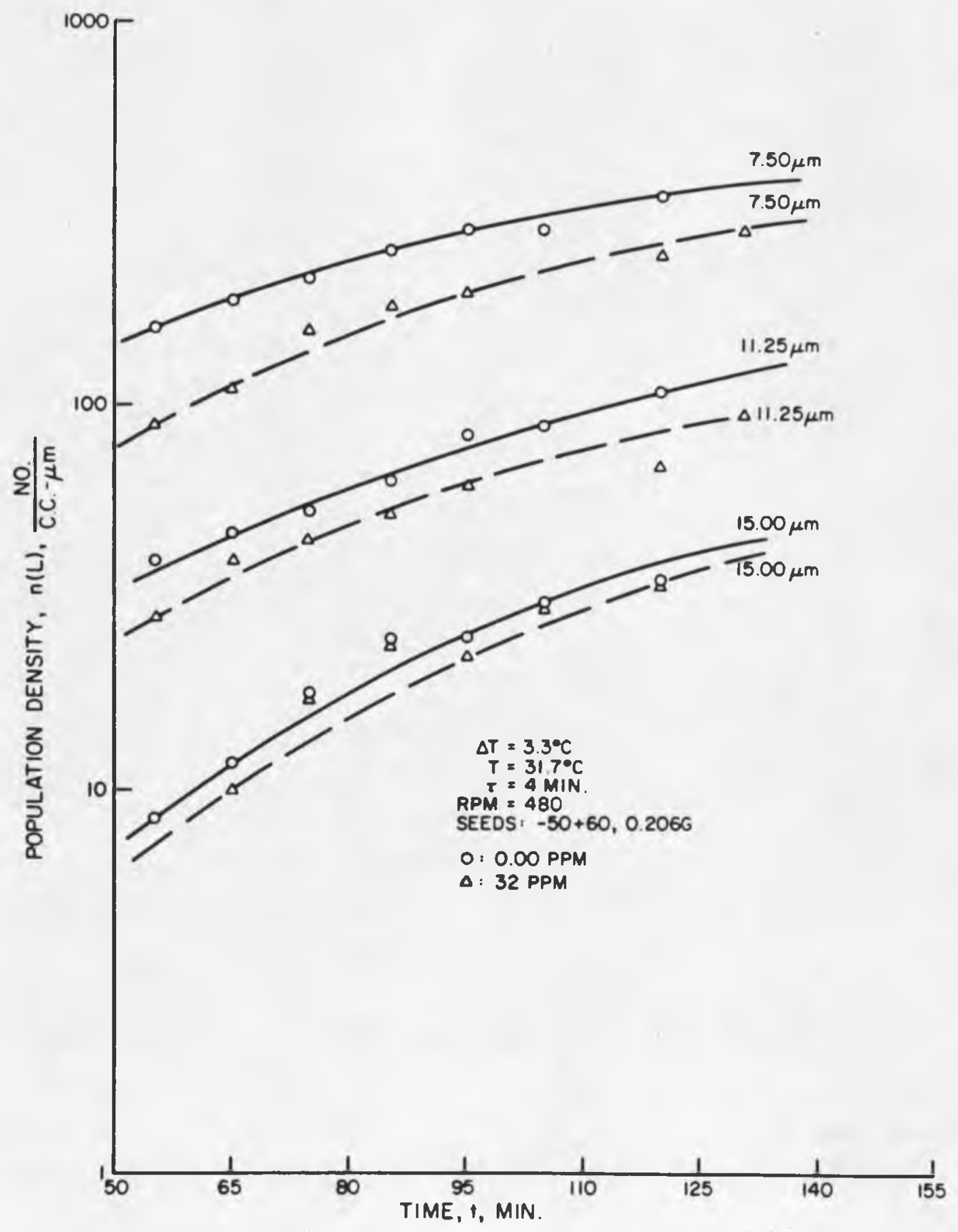

Figure 14. Effect of Surfactant Sodium Lauryl Sulphate on the Transient Population Densities of Fine Borax Crystals. 
with additive. This confirms that additive influences nucleation rate more than fine-crystal rate.

The average seed crystal growth rate was determined by subtracting the volumetric average size of initial seed from that of the product seed and dividing by the length of time the crystals were retained in the crystallizer. These seed crystal growth rates decreased with increased concentration of organic additive. Consequently smaller crystals were obtained at higher organic additive concentrations. These seed crystal growth rates obtained from microscopic measurement were. two to three times larger than the fine-crystal growth rates obtained from the slope of CSD plots. A similar result was observed by Sikdar (1975) using the potassium sulfate-water system. Sikdar concluded that fine-crystal growth rates vary linearly with supersaturation $\mathrm{s}$ whereas product crystal growth rate vary approximately with $\mathbf{s}^{2}$. Another plausible explanation could be that the seed crystals might have size dependent growth rate. The seed crystal growth rates for various runs are listed in Table 1.

Changes in the crystal habit are shown in the photomicrographs of Figures (15), (16) and (17). Figure (16) show the consistent decrease in the amount of multi-crystal growth of borax crystals with increased concentration of sodium oleate. The reduction in growth rate can also be seen by noticing the decreased size of crystals at the larger ppm of additive.

\section{Inorganic Additives}

Unlike organic, inorganic additives gave a significant increase in nucleation rate as the additive level was increased. Figures (18) 
Table 1. Seed Crystal Growth Rate Data for Organic Additives

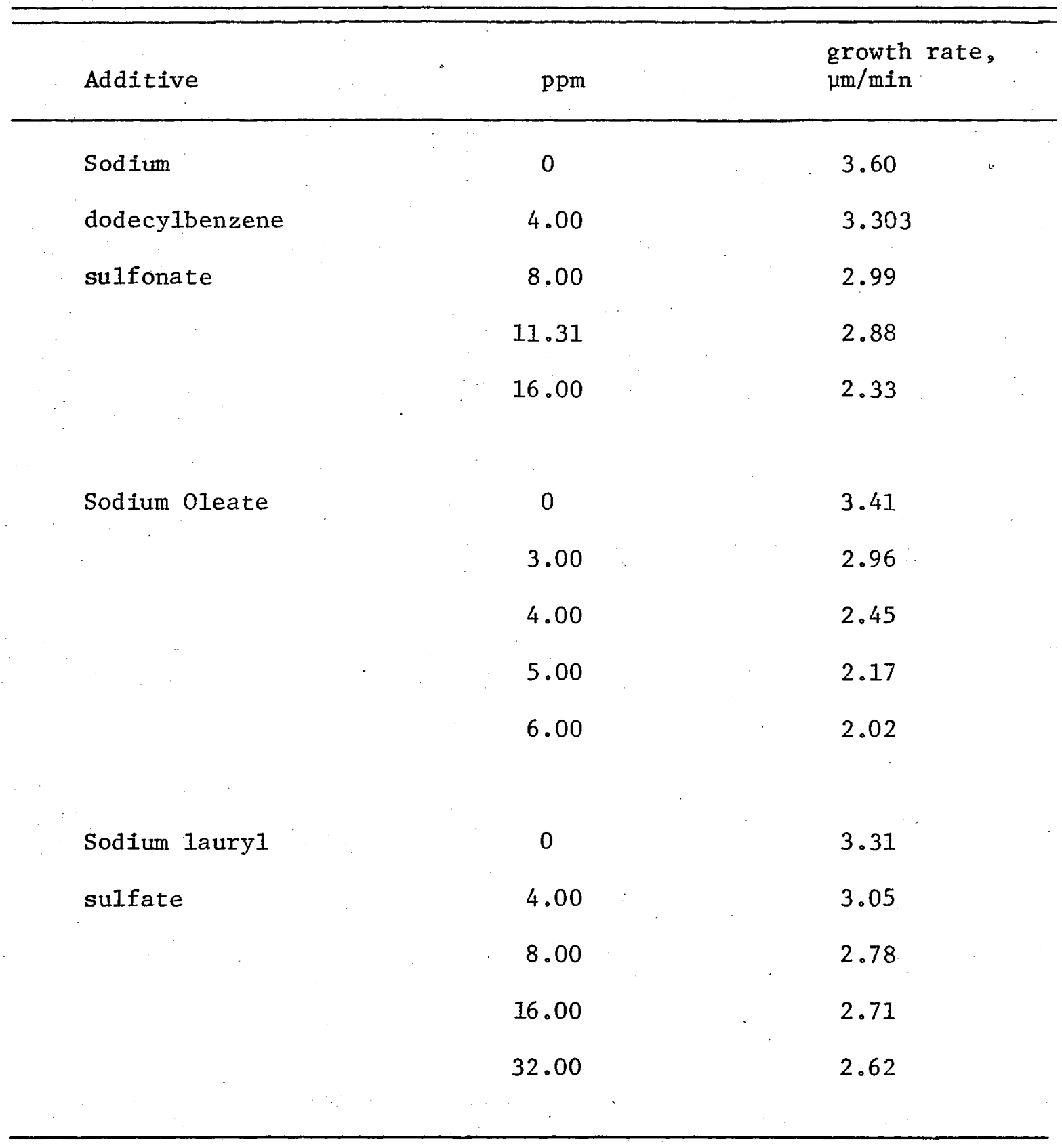




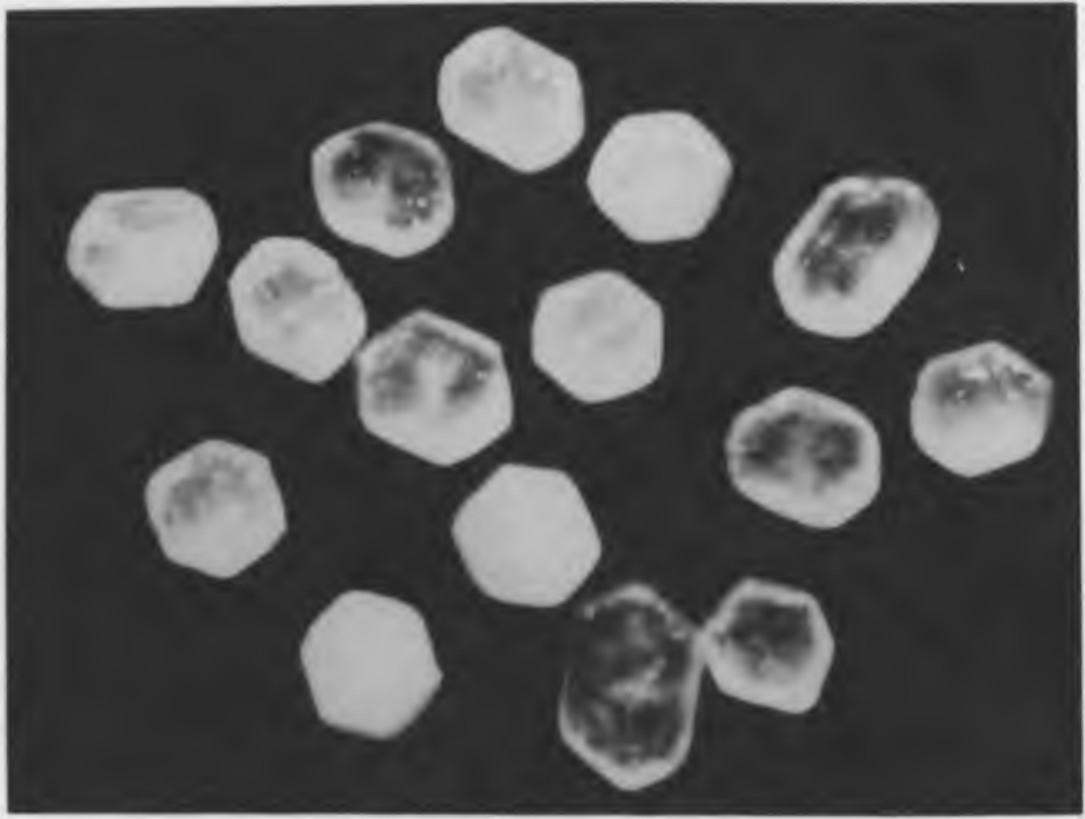

(a)

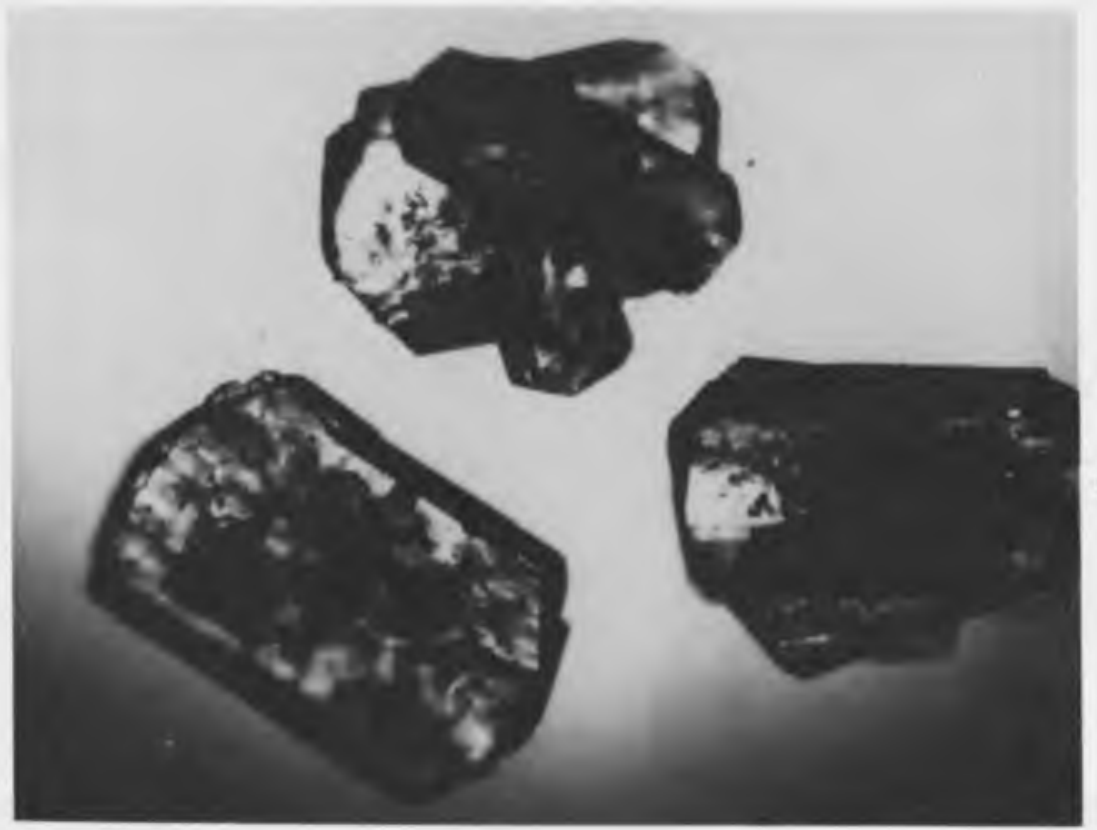

(b)

Figure 15. Borax Crystals (40 times magnification)

(a) $-50+60$ initial seeds.

(b) Product Crystals from Run 2 (Pure Borax Run) withdrawn after 140 minutes. 


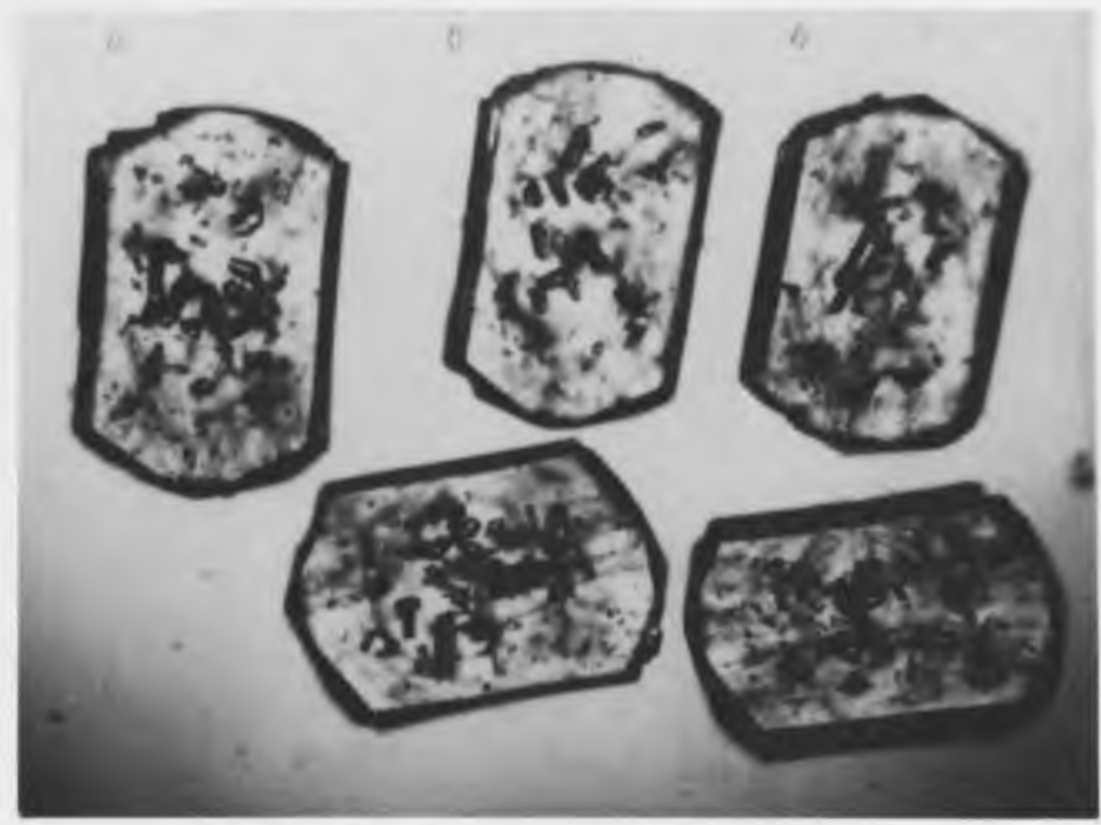

(a)

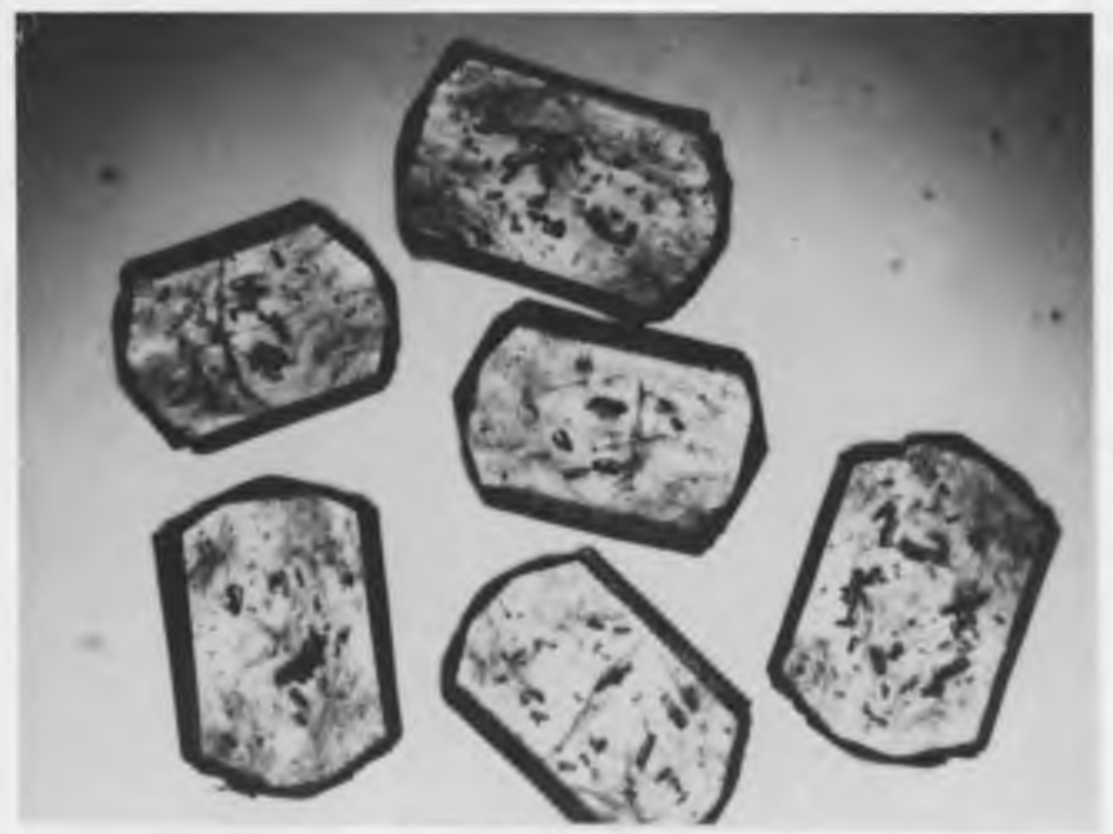

(b)

Figure 16. Borax Crystals (40 times magnification)

Product Crystals from (a) Run 15 ( 3 ppm Sodium Oleate in Solution)

(b) Run 16 (5 ppm Sodium 0leate In Solution) withdrawn after 150 minutes. 


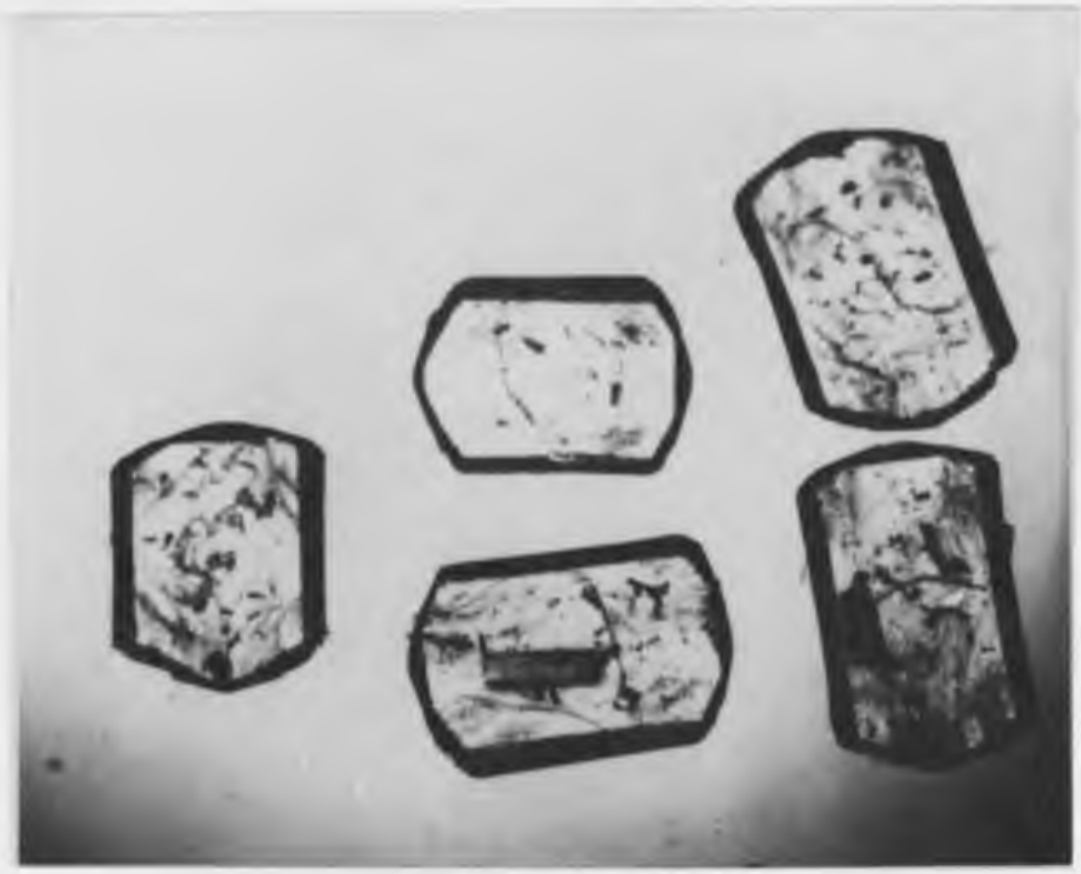

(a)

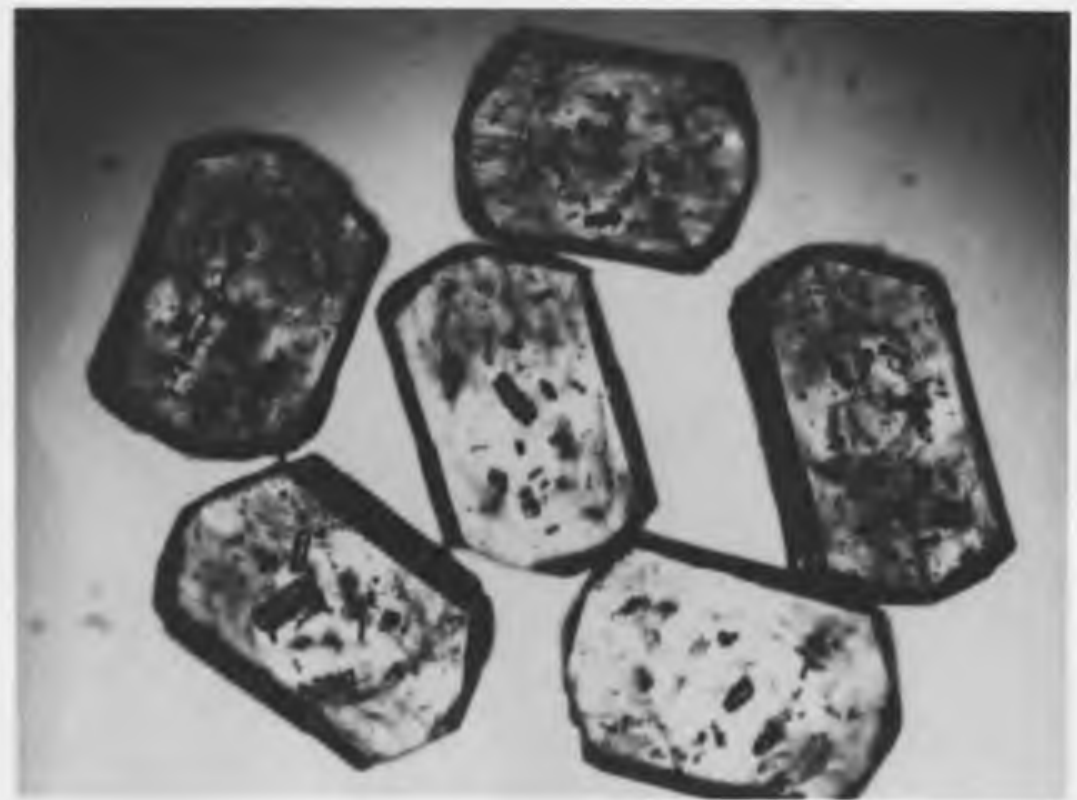

(b)

Figure 17. Borax (irystals (40 t tmes magnification)

Product Crystals from (a) Run 13 (16 ppm C-560 in Solution)

(b) Run 20 (8 ppm Sodium Lauryl Sulphate in Solution) withdrawn after 165 and 145 minutes, respectively. 


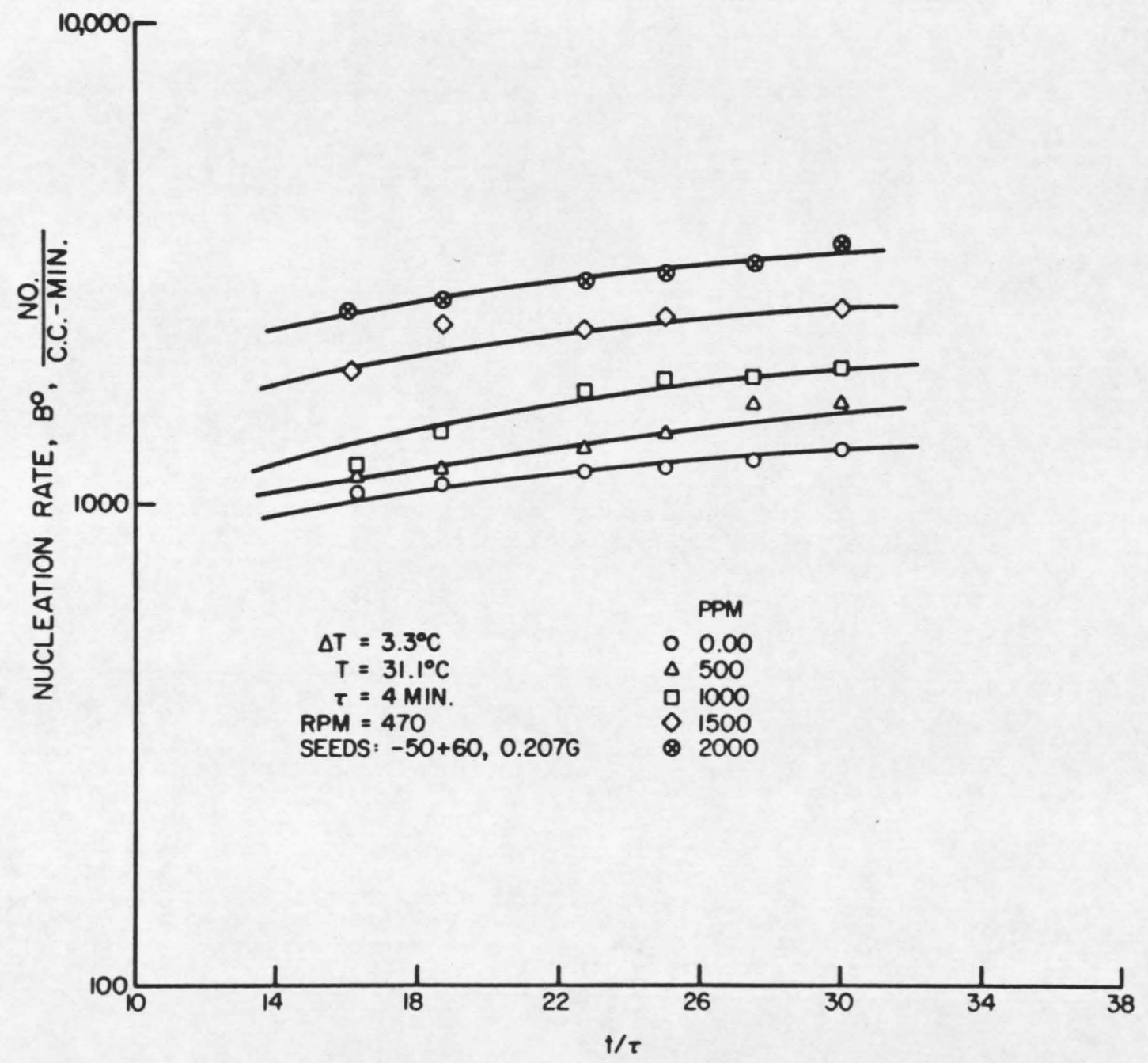

Figure 18. Nucleation Rate Data for Sodium Chloride Runs. 
and (19) plot the nucleation rate of borax when sodium chloride and magnesium chloride were used as an impurity. The consistent increase in nucleation rate with time for a particular run showed that initial breeding was absent.

Fine crystal growth rates were again decreased with increased ppm of ionic impurities. Figures (20) and (21) show the effect of sodium chloride and magnesium chloride on the CSD of fines of sodium tetraborate. Again, these straight line plots show the validity of the quasi-steady-state assumption. As the level of impurity in the solution is increased these population density versus time plots shift towards the right as expected from the nucleation and growth rate data. Transient population densities for fine crystals were plotted versus time in Figure (22) and (23). The presence of ionic impurities increased the population density and is accounted for by an increase in nucleation rate and decrease in fine-crystal growth rate.

Parent seed crystal growth rates were also inhibited in the presence of ionic impurities. Table II shows seed crystal growth rate data. The multicrystal habit of product crystals was reduced (as with organic additives) but this effect was not as pronounced as with organics. Figure (24) illustrates the habit changes of borax crystals when sodium chloride and magnesium chloride were used as impurities. 


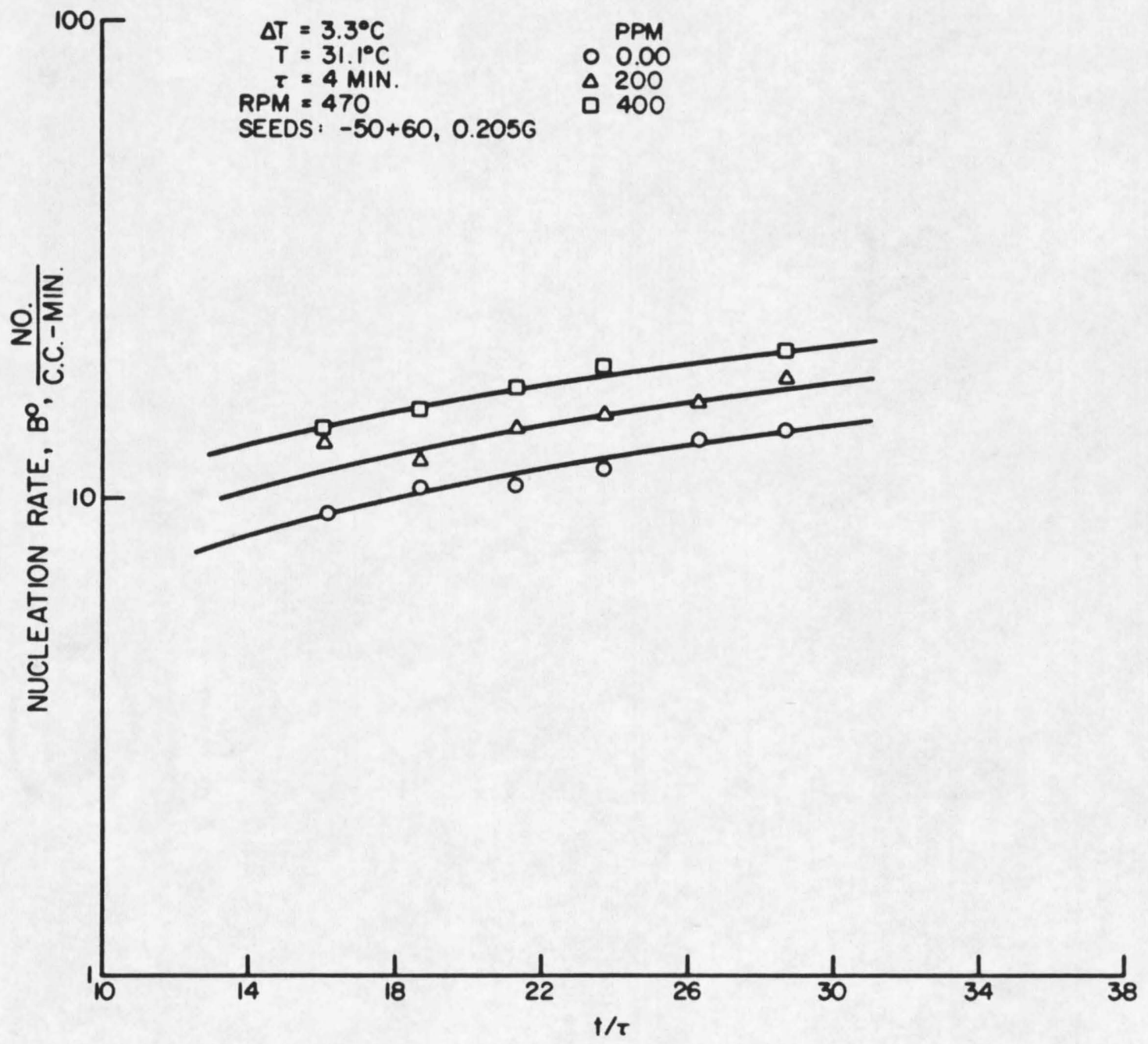

Figure 19. Nucleation Rate Data for Magnesium Chloride Runs 


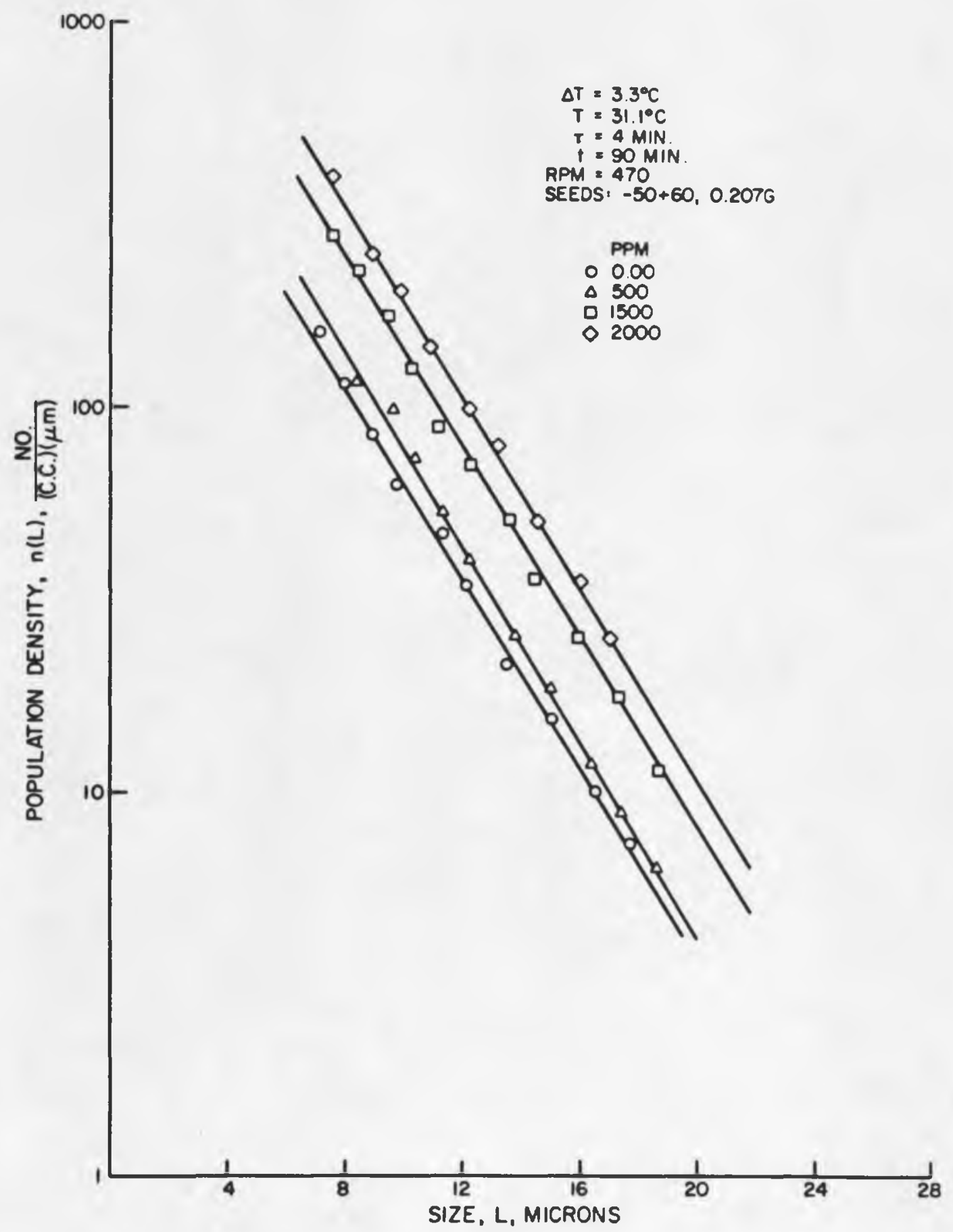

F1gure 20. Effect of Sodium Chloride on the Population Density Distribution of Fine Borax Crystals. 


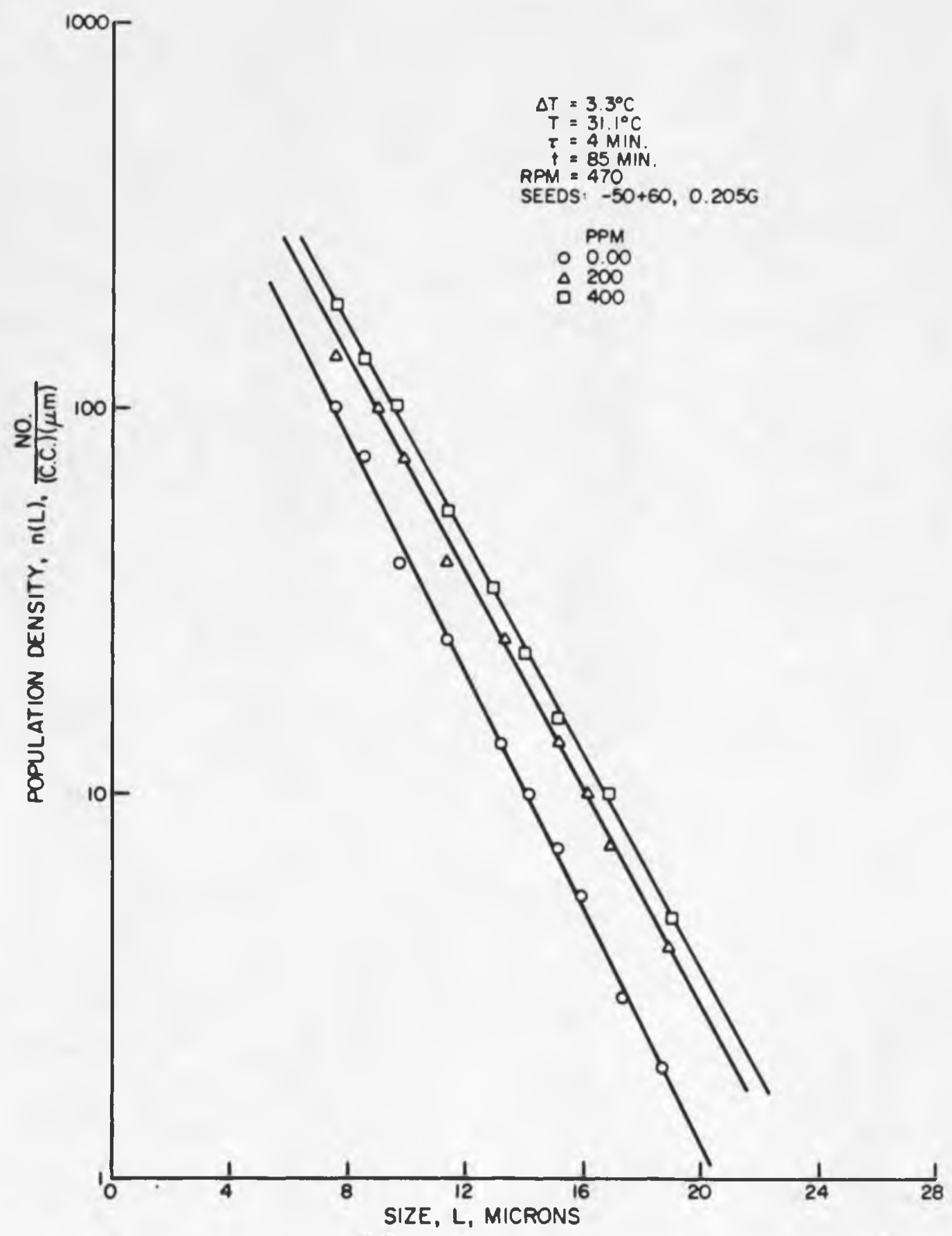

Figure 21. Effect of Magnesium Chloride on the Population Density Distribution of Fine Borax Crysta]s. 


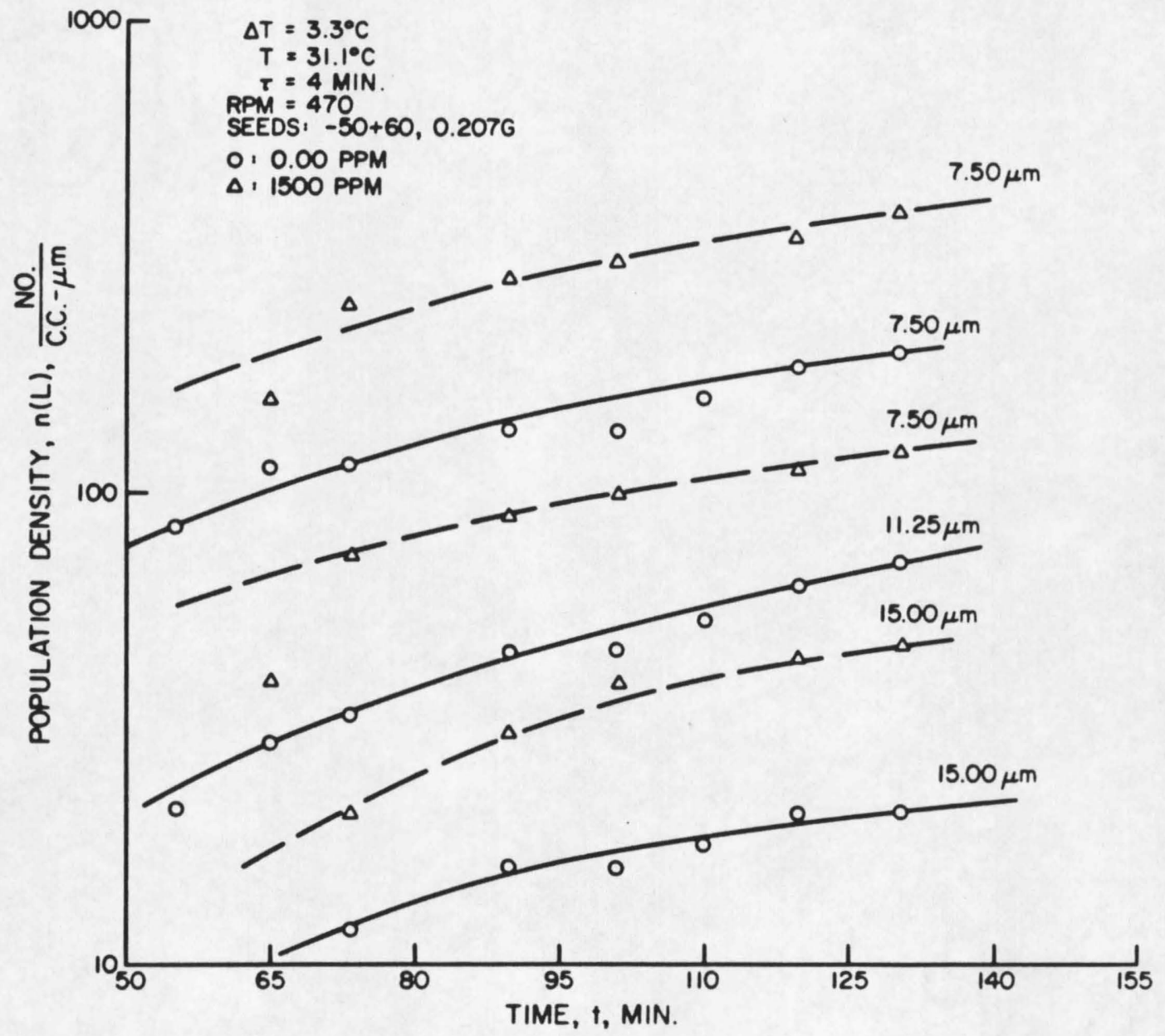

Figure 22. Influence of Sodium Chloride on the Transient Population Densities of Fine Borax Crystals. 


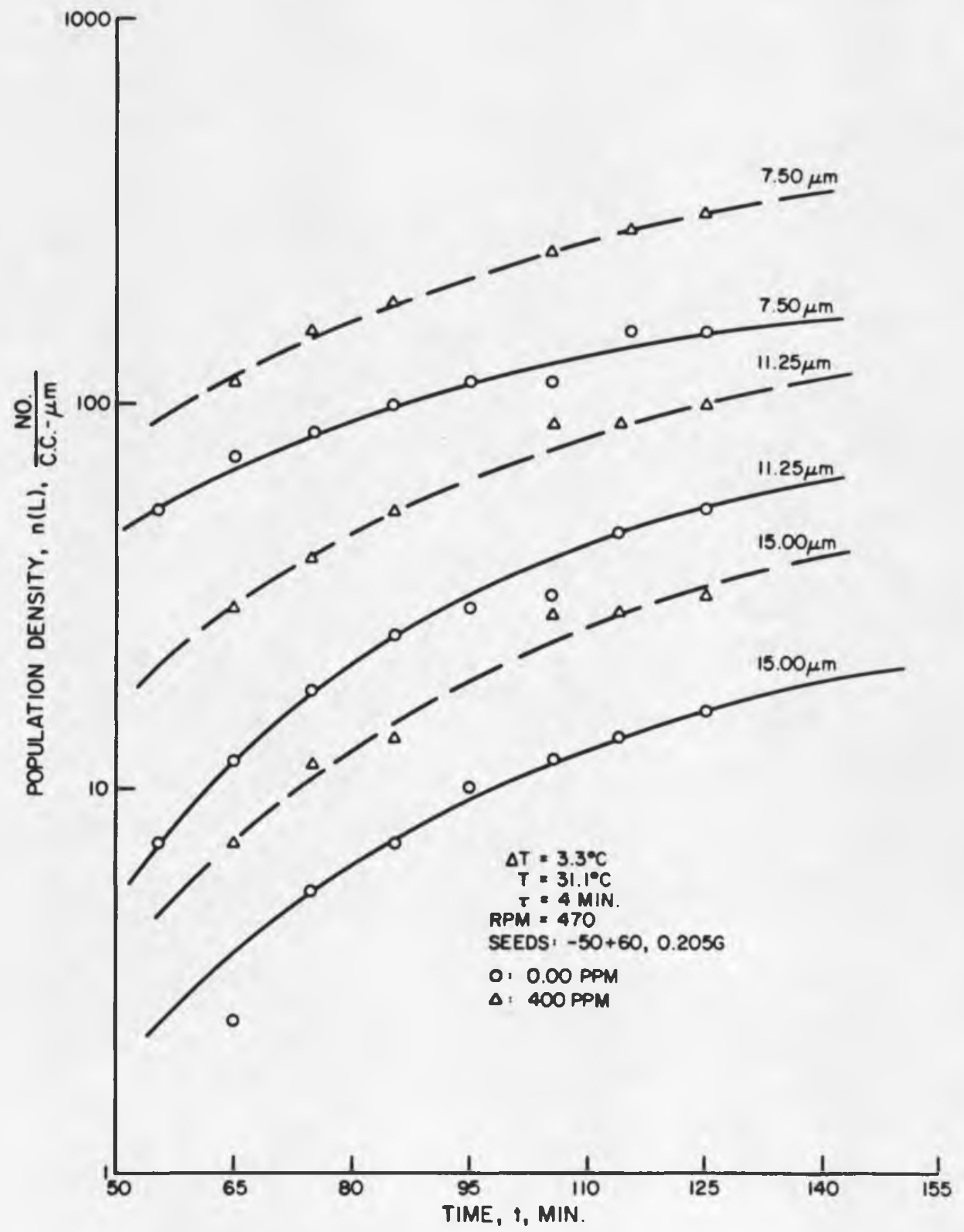

Figure 23. Influence of Magnesium Chloride on Dynamic Population Densities of Fine Borax Crystals. 
Table 2. Seed Crystal Growth Rate Data for Inorganic additives

Additive

ppm growth rate, $\mu \mathrm{m} / \mathrm{min}$

2.95

2.71

2.52

2.68

2.85

3.10
2.64

400

2.83

600

Magnesium Chloride

200

2.57 


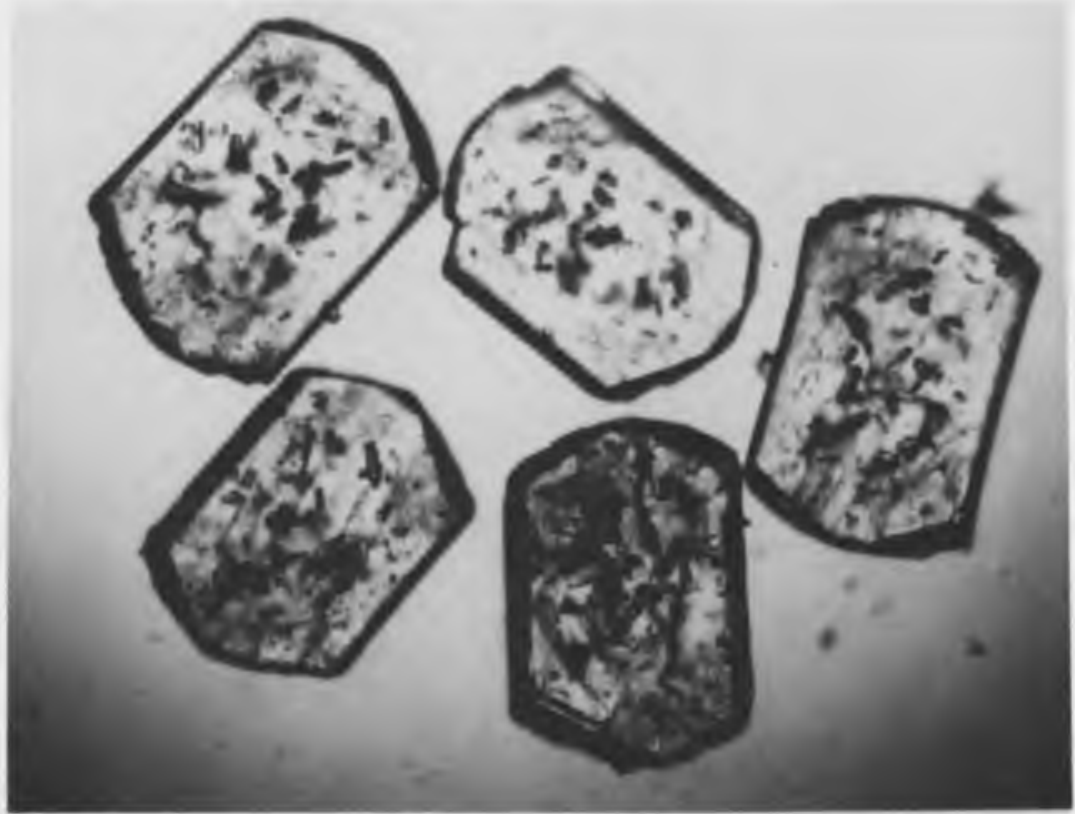

(a)

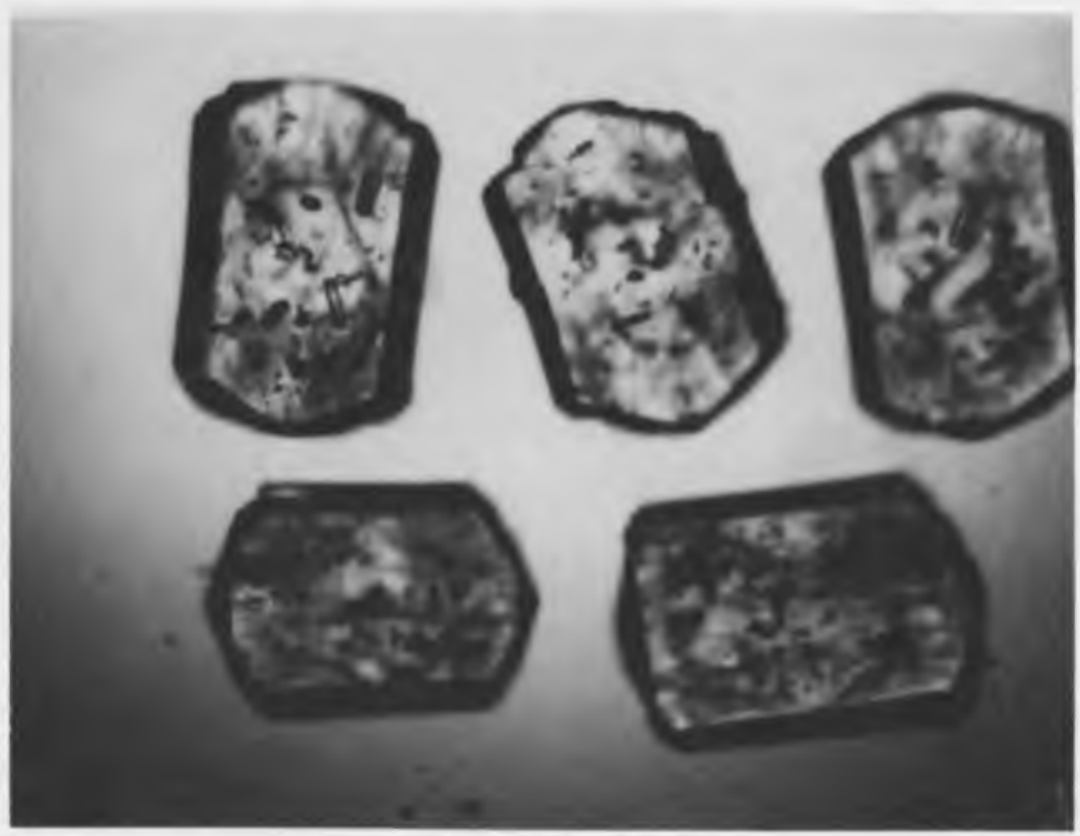

(b)

Figure 24. Borax Crystals (40 times magnification)

Product Crystals from (a) Run 26 (1500 ppm NaCl tn Solution) (b) Run 29 (200 ppm $\mathrm{MgCl}_{2} \cdot 6 \mathrm{H}_{2} \mathrm{O}$ in Solution) withdrawn after 145 and 140 minutes, respectively. 
CHAPTER 7

DATA REDUCTION AND RESULTS

Chapter 6 discussed the effect of impurities on nucleation rate, growth rate and habit of borax crystals. A subsequent goal is to quantitatively relate these effects using appropriate nucleation/growth rate kinetic expressions.

\section{Method of Data Reduction}

The borax system produced straight line population density versus size plots which leads to the conclusion that the rate of increase in population density at any time was. slow, even though the system was dynamic due to continued growth of nuclei-spawning parent crystals. Least squares stralght lines of log population density versus size were drawn through the observed data points and estimates of fine-crystal growth and nucleation rates were obtained from slopes and intercepts of these plots. The nucleation rates thus obtained were correlated with operating variables as well as seed crystal growth rates obtained from microscopic measurements.

The power law form of size independent growth rate in pure solutions is given by Equation (11) as

$$
\mathrm{G}=\mathrm{ks}^{\mathrm{a}}
$$

Equation (12) illustrates a possible model to represent growth rates when the crystallizing solution contains dissolved impurities. 


$$
G_{i}=k\left[s / c_{i}^{b}\right]^{a}
$$

This model suffers from the drawback that the pure system growth rate is unbounded, which obviously is not true. An improved form of the above model was suggested by Davey and Mullin (1973). Thus

$$
G_{i}=\mathrm{ks}^{\mathrm{a}} \mathrm{C}_{i}^{\mathrm{b}}
$$

This relationship can be made to fit data but it predicts zero growth rates in pure solutions, also an impossible conclusion. Equation (16) was modified in the present study as

$$
G_{i}=k s^{a} \exp \left(b C_{i}\right)
$$

Combining Equation (11) with Equation (17) one obtains

$$
G_{i}=G \exp \left(b C_{i}\right)
$$

Thus under similar levels of supersaturation a plot of $\log \left(G_{i}\right)$ versus $C_{1}$ should result in a straight line. The intercept of this line can be used directly to calculate the growth rate of crystals in pure solutions at that value of supersaturation.

A power law model for correlating the nucleation rate as described in chapter 3 is

$$
B^{\circ}=k_{N} G^{i} M_{T}^{j}(R P M){ }^{k} \exp \left(l \times C_{i}\right)
$$

The suspension density, $M_{T}$, is the only unknown variable in the above equation. Values of $\mathrm{M}_{\mathrm{T}}$ were obtained from the third moment of the seed crystals interpolated to the time instant at which $B^{\circ}$ values were obtained. The moments of the seed crystals were calculated from the dynamic moment equations as written below. 


$$
\begin{gathered}
\frac{d m_{j}}{d t}+m_{j} \frac{d(\log V)}{d t}=j G\left(m_{j-1}+a m_{j}\right)+o^{j}{ }^{o}-\sum_{k} \frac{Q_{k} m_{j, k}}{V}+\bar{B}-\bar{D} \\
\mathbf{j}=0,1,2,
\end{gathered}
$$

Using the Iimiting approximations of constant total volume, single mixed discharge, no breakage, unseeded inlet liquor and $G \neq G(L)$, Equation (20) reduces to

$$
\frac{d m_{j}}{d t}+\frac{m_{j}}{\tau}=j \mathrm{Gm}_{j-1} \quad, \quad j=0,1,2,
$$

subject to the initial condition

$$
m_{j}^{o}=m_{j}(0)=\left[\frac{W_{i}}{b k_{v}\left(\bar{L}_{v, i}\right)^{3}}\right]\left(\bar{L}_{v, i}\right)^{j}, \quad j=0,1,2,
$$

where the term in brackets represents the number of parent crystals.

As the seed crystals were tota11y retained in the crystallizer, the washout term in Equation (21) can be eliminated giving the resultant equation

$$
\frac{\mathrm{dm}_{j}}{\mathrm{dt}}=j \mathrm{Gm}_{j-1} \quad, \quad j=0,1,2,
$$

Equations (23) form a simple first order differential equation set and can be solved for values of $j$ to get the 0 th, 1 st, 2 nd and $3 \mathrm{rd}$ moments of the seed crystals at any instant of time. The solution for the third moment obtained from Equation (23) is as follows.

$$
m_{3}(t)=m_{0}(G t)^{3}+3 m_{1}(0)(G t)^{2}+3 m_{2}(0)(G t)+m_{3}(0)
$$

Rearranging Equation (24) and further simplifying by utilization of initial condition leads to Equation (25).

$$
\frac{m_{3}(t)}{m_{3}(0)}=\left(\frac{\bar{L}_{v, i}+G t}{\bar{L}_{v, i}}\right)^{3}
$$


Suspension density at any instant was then calculated from the above equation by multiplying the third moment by $\rho k_{v}$. The volumetric shape factor, $k_{v}$, was taken as $\pi / 6$. Thus

$$
M_{T}(t)=\rho k_{v} m_{3}(0)\left[\frac{\bar{L}_{v_{2} i}+G t}{\bar{L}_{v_{,} i}}\right]^{3}
$$

After obtaining the $M_{T}$ values from Equation (26), the nucleation rate data can then be correlated using Equation (19).

\section{Growth and Nucleation Kinetics}

For each impurity a semi-log plot of growth rate versus the impurity concentration was made. These plots are shown in Figures (25), (26), (27), (28) and (29). Reasonable straight lines are observed. The slopes and intercepts of these graphs were then calculated to fit the data to Equation (18). The correlated values of $G_{i}$ with $C_{i}$ for various impurities are listed below for a constant subcooling of $2.8^{\circ} \mathrm{C}$ to $3.7^{\circ} \mathrm{C}$.

For sodium dodecylbenzene sulfonate:

$$
G_{i}=3.6 \exp \left(-0.047 \times C_{i}^{*}\right)
$$

where $C_{i}^{*}$ is the active concentration of sodium dodecylbenzene sulfonate and is equal to $0.4 \times \mathrm{C}_{i}$.

For sodium oleate:

$$
G_{i}=3.5 \exp \left(-0.0918 \times C_{i}\right)
$$

For sodium lauryl sulfate:

$$
G_{i}=3.26 \exp \left(-0.0133 \times C_{i}\right)
$$

For sodium chloride: 


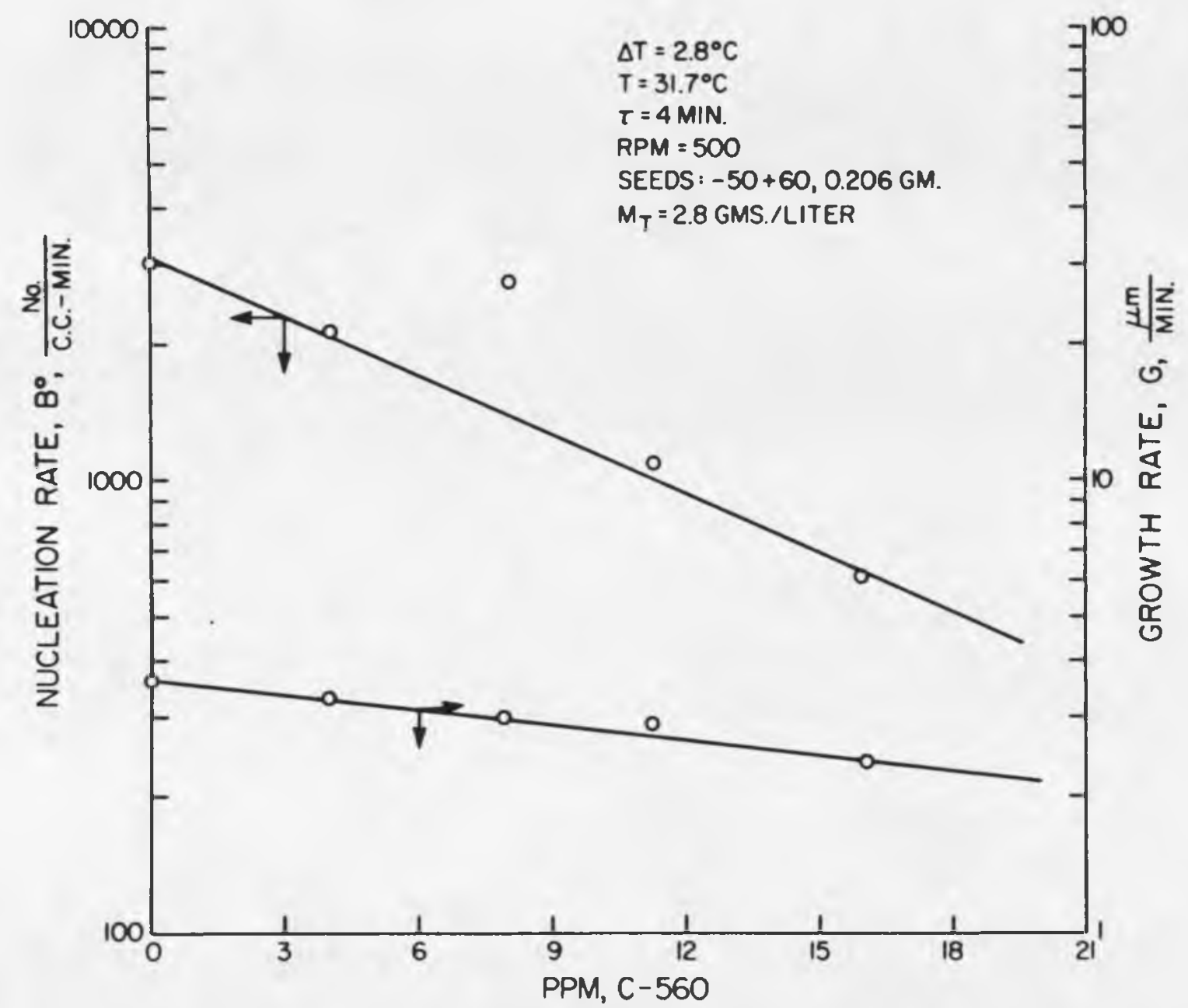

Figure 25. Effect of Surfactant Sodlum Dodecylbenzene Sulfonate on Nucleatlon and Growth Rate of Borax System at Run Time Giving Constant Suspension Density. 


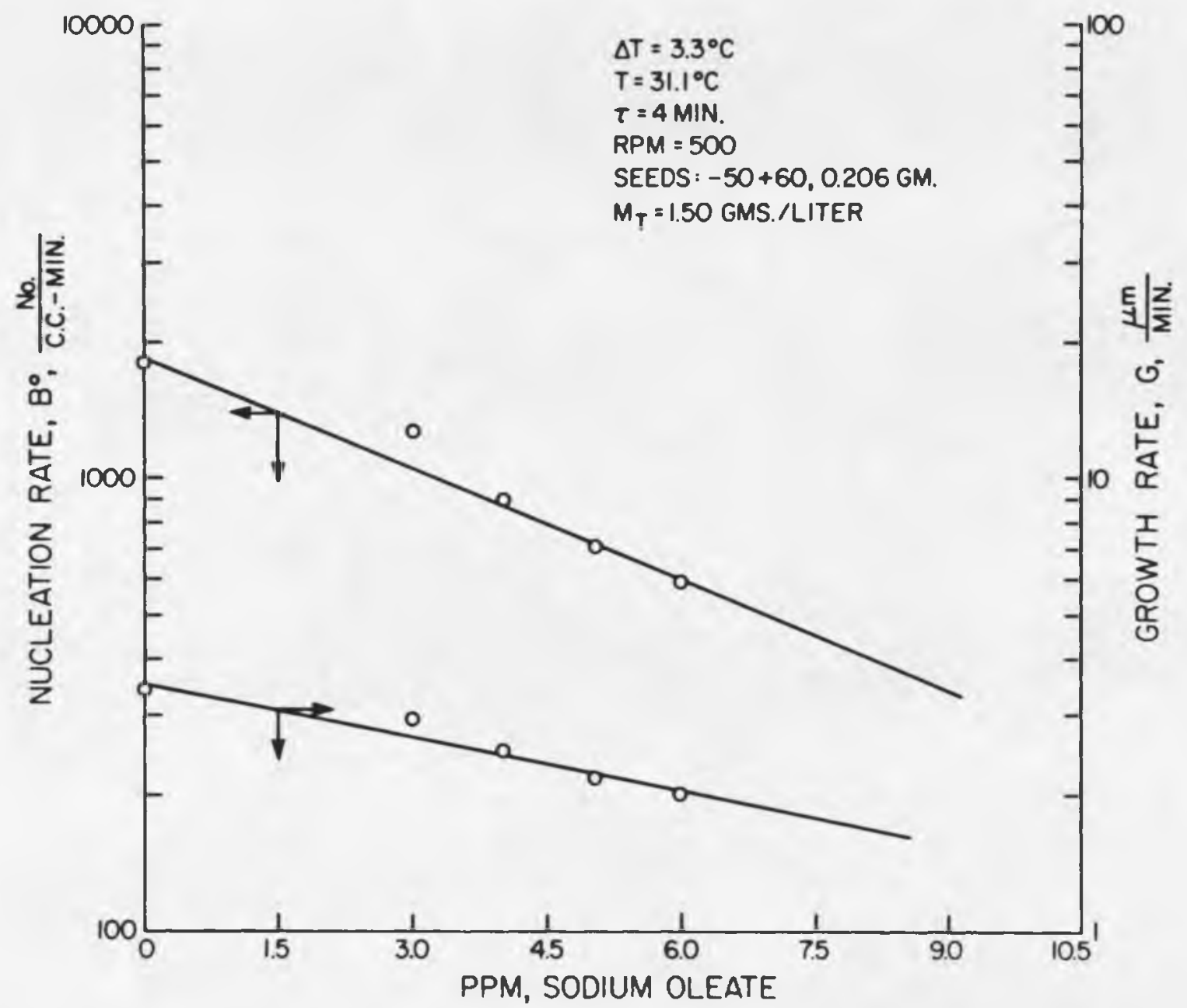

Figure 26. Effect of Sodium 0leate on Nucleation and Growth Rate of Sodium Tetraborate System at Run Time Giving Constant Suspension Density. 


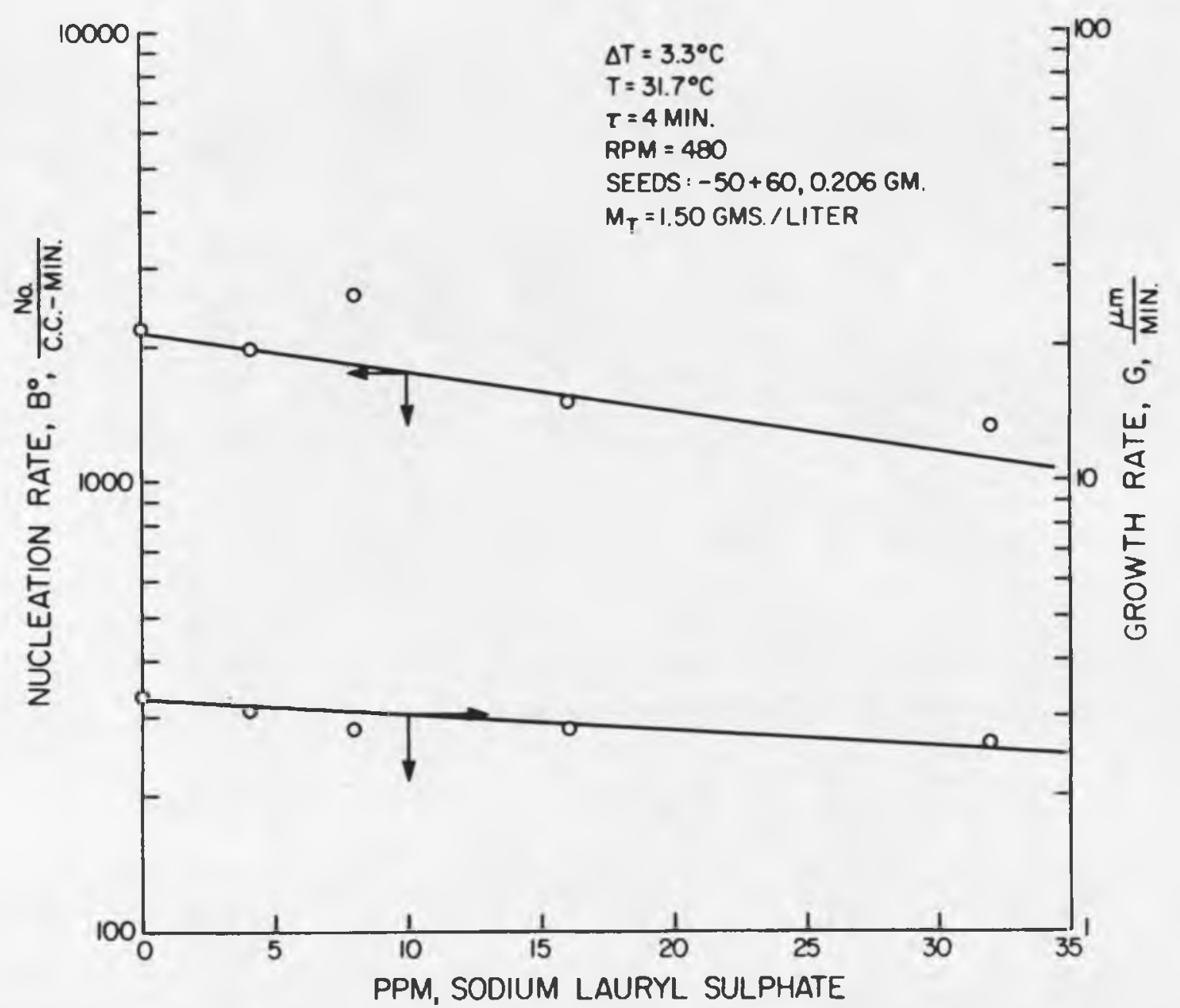

Figure 27. Effect of Surfactant Sodium Lauryl Sulfate on Nucleation and Growth Rate of Sodium Tetraborate System at Run Time Giving Constant Suspension Density. 


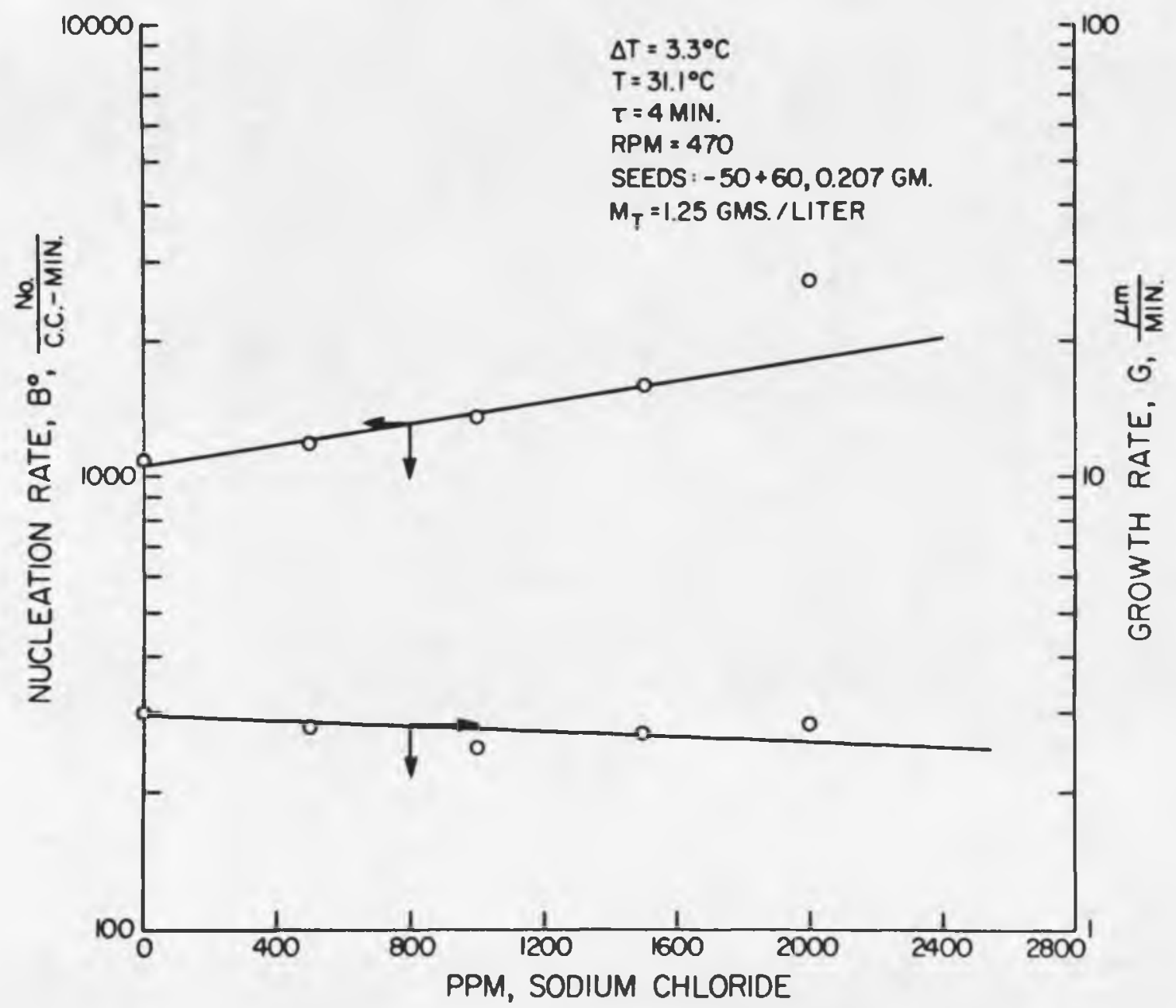

Figure 28. Effect of Sodium Chlorfde on Nucleation and Growth Rate of Sodfum Tetraborate System at Run Time Giving Constant Suspension Density. 


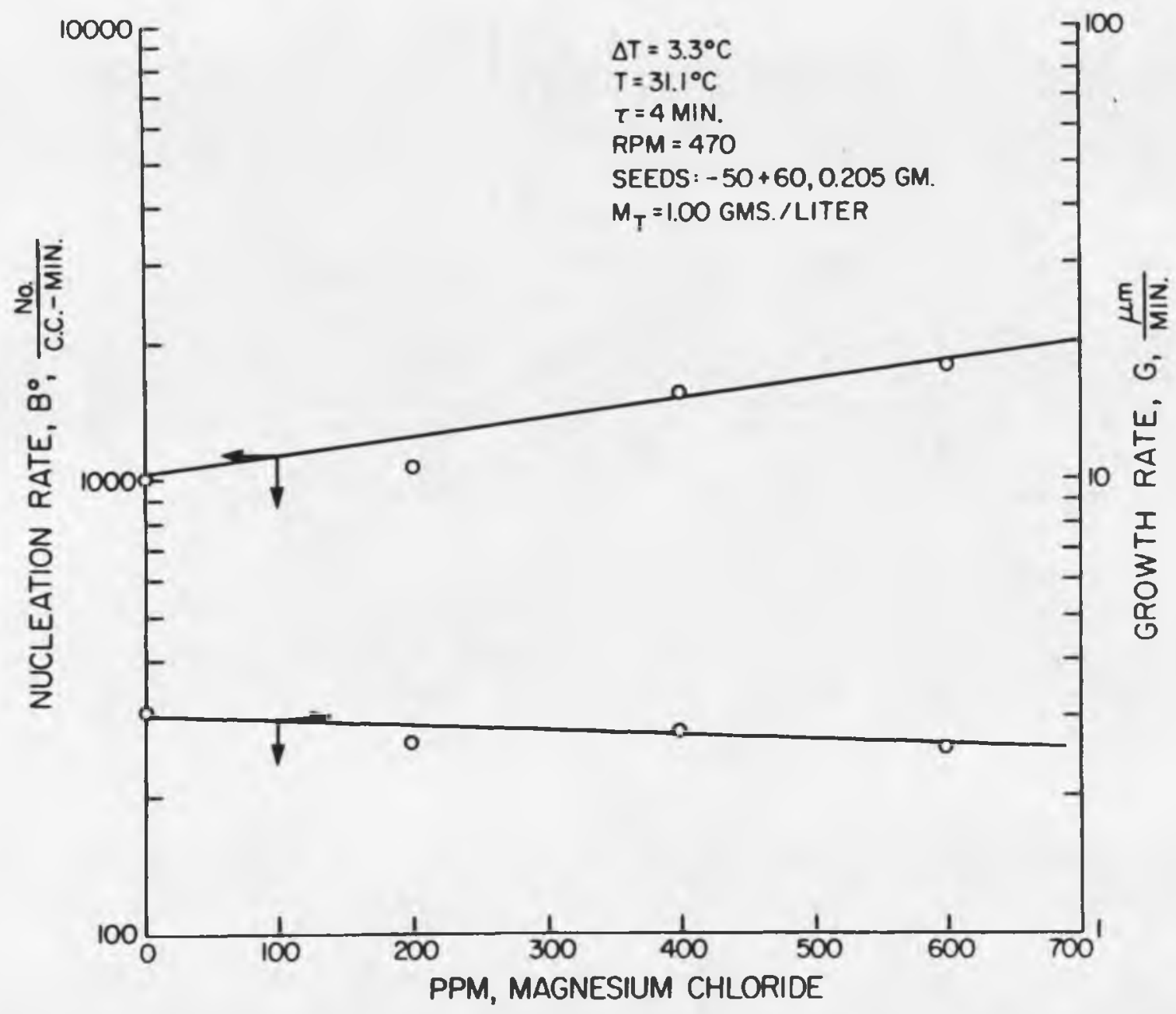

Figure 29. Effect of Magnesium Chlorfde on Nucleation and Growth Rate at Run Time Giving Constant Suspension Density. 


$$
G_{i}=2.90 \exp \left(-0.000077 \times C_{i}\right)
$$

For magnesium chloride:

$$
G_{i}=2.90 \exp \left(-0.00026 \times C_{i}\right)
$$

The different values of pure growth rates, $G$, in the above expressions correspond to different levels of supersaturations employed. Figures (25) to (29) also plot nucleation rate versus ppm additive at constant suspension density $\mathrm{M}_{\mathrm{T}}$. Figure (25) shows an increase of nucleation rate at $8 \mathrm{ppm}$ (i.e. $3.2 \mathrm{ppm}$ active ingredient) concentration of sodium dodecylbenzene sulfonate. Figure (27) shows a similar increase at $8 \mathrm{ppm}$ concentration of sodium laury1 sulfate. The same result was also obtained by Randolph and Koontz (1976) for the same system using sodium dodecylbenzene sulfonate. This anomalous increase at small addition levels has not been explained.

These data were also fit to a power-law nucleation kinetics model (Equation 19). The correlation of data to this multivariable nucleation kinetics expression was performed using a multiple linear regression program on file at the University of Arizona computer center, code named MLR. This program fit the data to the linearized (1ogarithmic) form of the model and calculates statistical properties of interest. The power law model for nucleation rate described by Equation (19) was linearized by taking logarithms of both sides.

The effectiveness of the correlation was judged by the value of the square of the correlation coefficient obtained from the MLR computer program. The correlation coefficient, $R$, represent the fraction of the total variance contributed by independent variables. It is defined mathematically as 


$$
\mathrm{R}^{2}=1-\frac{\Sigma\left(y-\mathrm{y}_{\mathrm{c}}\right)^{2}}{\Sigma \mathrm{y}^{2}}
$$

where $\mathrm{y}$ is the observed value of the dependent quantity and $\mathrm{y}_{\mathrm{c}}$ is the value of the dependent variable calculated from the regression equation. This difference between calculated and actual values decreases as the fit of the data improves, thus the value of $R$ approaches unity. A complete discussion of the statistical tests performed by MLR may be found in a book on statistics by Neville and Kennedy (1964).

A nucleation kinetics expression for the pure sodium tetraborate system was obtained by using both the seed and fine-crystal growth rates. The correlation using seed crystal growth rate is

$$
\mathrm{B}^{0}=7.096 \times 10^{12}(\mathrm{G})^{3.85}\left(\mathrm{M}_{\mathrm{T}}\right)^{0.44}(\mathrm{RPM}){ }^{1.38} \quad \mathrm{R}^{2}=0.918
$$

The units of the variables in this equation are listed in the nomenclature section. If fine-crystal growth rates obtained from the slope of the CSD plots are used, the relationship for $\mathrm{B}^{\circ}$ becomes

$$
\mathrm{B}^{0}=5.10 \times 10^{-1}\left(\mathrm{G}_{\mathrm{f}}\right)^{1.30}\left(\mathrm{M}_{\mathrm{T}}\right)^{0.46}(\mathrm{RPM})^{3.25} \quad \mathrm{R}^{2}=0.823
$$

where $G_{f}$ is the growth rate of fines. A comparison of Equations (33) and (34) indicates that the kinetic order $j$ for slurry density remains the same irrespective of the source of growth rate used to predict $\mathrm{B}^{\circ}$. The power-law model of Equation (34) well agrees with the therortical collision nucleation model, developed by Ness and White (1974). This theoretical model equation is

$$
B^{\circ} \alpha s^{i} \cdot M_{T}(R P M)^{3}
$$


The exponent, $i$, is a characteristic of the crystallizing system and usually varies between one and two. However, in the present case the supersaturation was replaced by growth rate. The observed dependence on stirrer speed and growth rate is almost the same as predicted in the theoretical model.

The observed dependence of secondary nucleation rate on suspension density is less than proportional as predicted in Ness' theoretical model, Equation (35). Cayey and Estrin (1967) have reported that only particles above a certain minimum size contribute to the collision nucleation process. This critical size was about $200 \mu \mathrm{m}$ for magnesium sulfate crystallization. Because some crystal mass is present at the smaller size distribution, the kinetic order of slurry density can be expected to be less than unity. The observed value of 0.44 for the borax system is reasonable for inorganic systems (e.g. Sikdar, 1975; Randolph et a1.,1977).

Figures (30) and (31) show the comparison between the experimental and predicted nucleation rates for both of the models represented by Equations (33) and (34).

Nucleation kinetics in the presence of additives were determined using Equation (19). The various correlations obtained with different impurities using either $G$ or $G_{f}$ to represent supersaturation driving forces are as follows:

For sodium dodecylbenzene sulfonate:

$$
\mathrm{B}^{0}=2.20 \times 10^{5}(\mathrm{G})^{1.70}\left(\mathrm{M}_{\mathrm{T}}\right)^{0.62}(\mathrm{RPM})^{1.38} \exp \left(-0.139 \times \mathrm{C}_{\mathrm{i}}^{*}\right) \mathrm{R}^{2}=0.687
$$




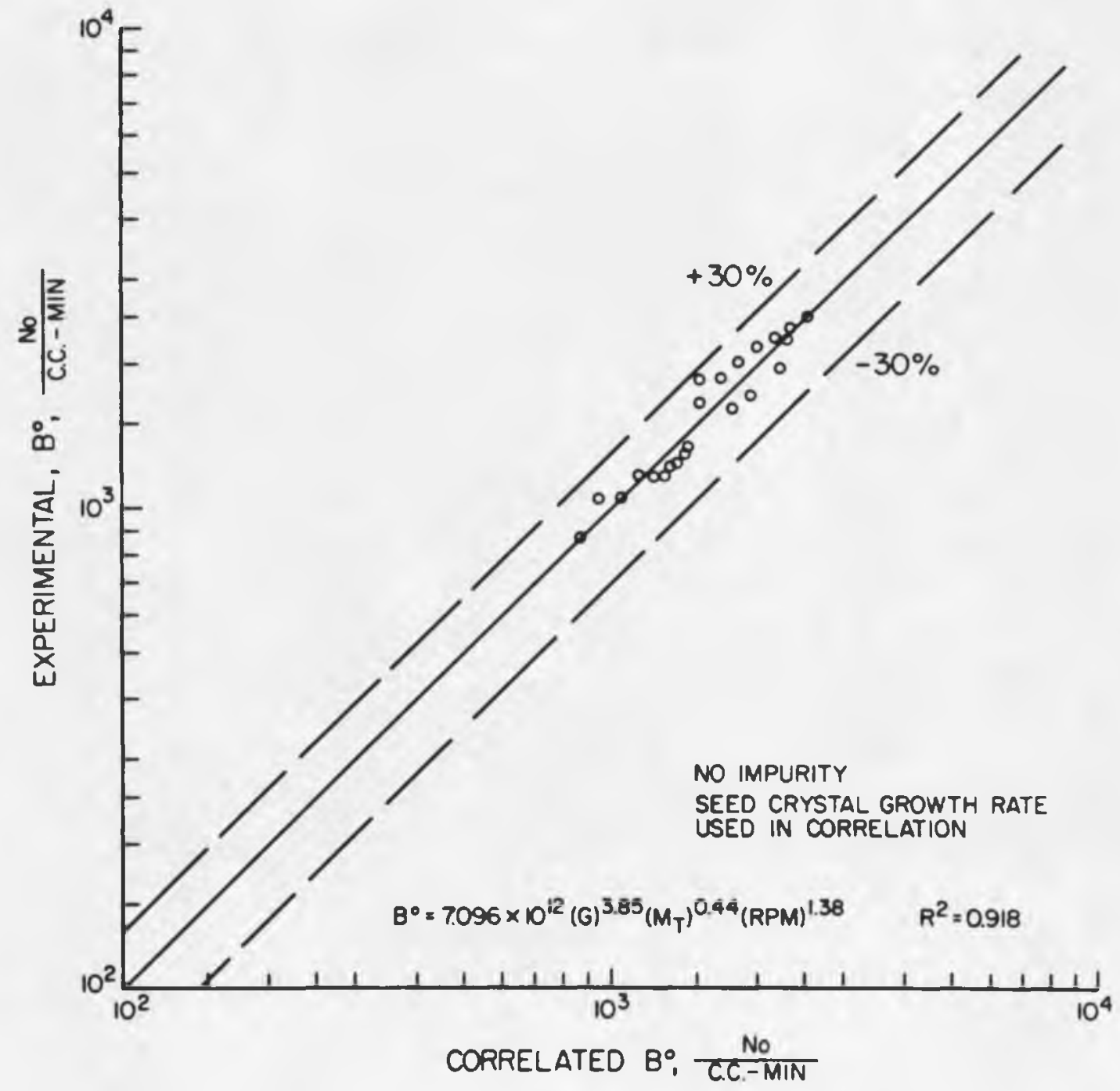

Figure 30. Comparison Between Experimental and Correlated Nucleation Rates (pure borax system). 


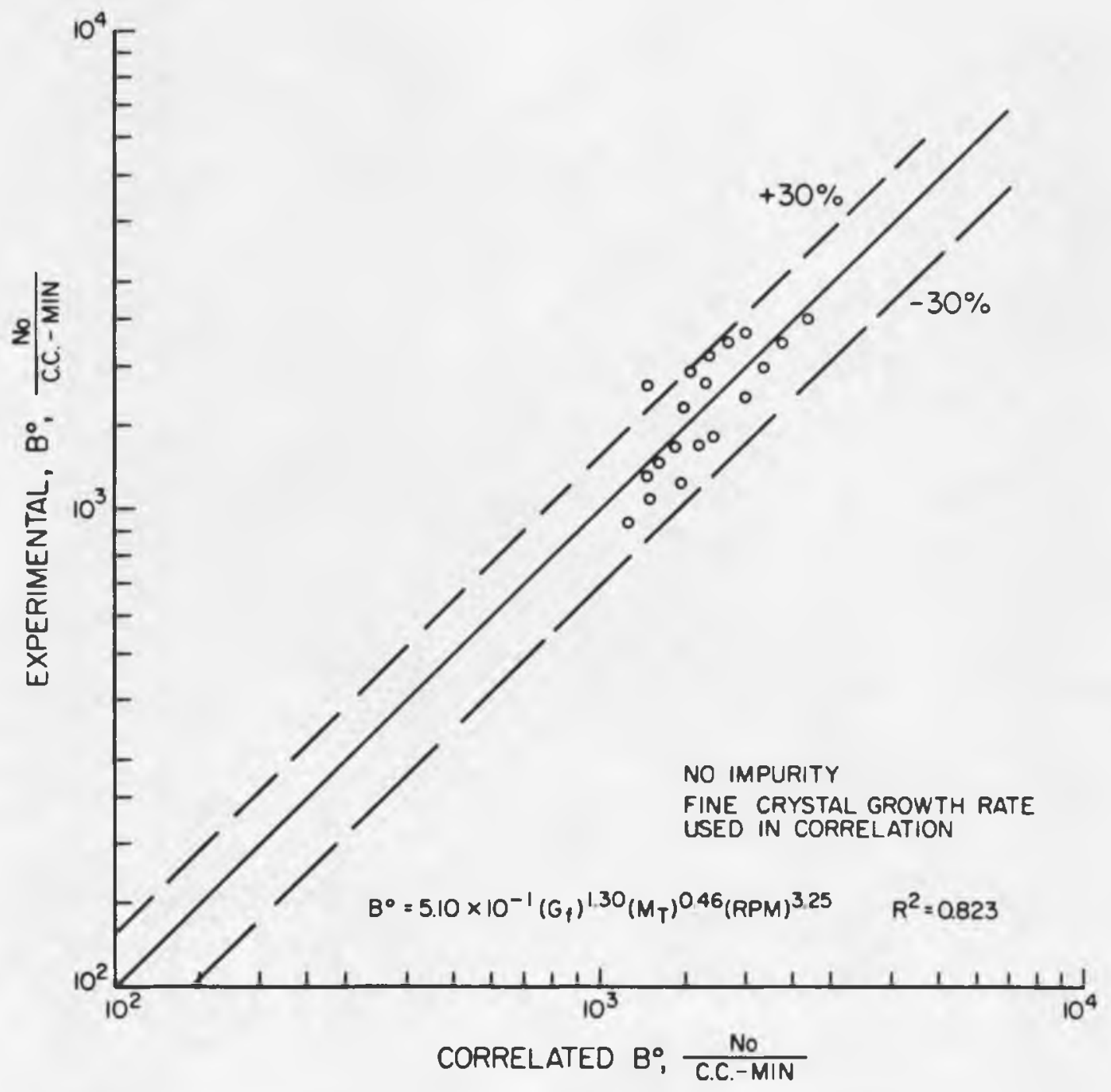

Figure 31. Comparison Between Experimental and Correlated Nucleation Rates (pure borax system). 
$\mathrm{B}^{0}=2.66 \times 10^{4}\left(\mathrm{G}_{\mathrm{f}}\right)^{1.50}\left(\mathrm{M}_{\mathrm{T}}\right)^{0.66}(\mathrm{RPM})^{3.25} \exp \left(-0.197 \times \mathrm{C}_{i}^{*}\right) \quad \mathrm{R}^{2}=0.710$ (37) For sodium oleate:

$B^{0}=2.02 \times 10^{5}(G)^{1.70}\left(M_{T}\right)^{0.67}(R P M)^{1.38} \exp \left(-0.038 \times C_{i}\right)^{-} R^{2}=0.892$

or.

$\left.B^{0}=0.26 \times 10^{1}\left(G_{f}\right)^{1.50}\left(M_{T}\right)^{0.83}(R P M)\right)^{3.25} \exp \left(-0.171 \times C_{i}\right) \quad R^{2}=0.949$

For sodium laury1 sulfate:

$B^{0}=3.03 \times 10^{5}(G)^{1.70}\left(M_{T}\right)^{0.38}(R P M){ }^{1.38} \exp \left(-0.0022 \times C_{i}\right) \quad R^{2}=0.690(40)$

or

$B^{0}=0.43 \times 10^{1}\left(G_{f}\right)^{1.50}\left(M_{T}\right)^{0.38}(R P M){ }^{3.25} \exp \left(-0.0093 \times C_{i}\right) \quad R^{2}=0.780$

For sodium chloride:

$\mathrm{B}^{0}=1.96 \times 10^{5}(\mathrm{G})^{1.70}\left(\mathrm{M}_{\mathrm{T}}\right)^{0.43}(\mathrm{RPM})^{1.38} \exp \left(0.00052 \times \mathrm{C}_{i}\right) \quad \mathrm{R}^{2}=0.896(42)$

or

$B^{0}=0.26 \times 10^{1}\left(G_{f}\right)^{1.50}\left(M_{T}\right)^{0.40}(R P M)^{3.25} \exp \left(0.00048 \times C_{i}\right) R^{2}=0.794$ (43)

For magnesium chloride:

$B^{0}=1.90 \times 10^{5}(G)^{1.70}\left(M_{T}\right)^{0.40}(R P M)^{1.38} \cdot \exp \left(0.0015 \times C_{i}\right) \quad R^{2}=0.67$

or

$B^{0}=0.29 \times 10^{1}\left(G_{f}\right)^{1.50}\left(M_{T}\right)^{0.43}(R P M)^{3.25} \exp \left(0.0013 \times C_{i}\right) R^{2}=0.92$

The dependence of RPM on nucleation rate was fixed in the above impurity correlations. An important conclusion that can be drawn from the above correlations is that the nucleation rate kinetics order with respect to growth rate, slurry density and $R P M$ remains almost constant 
irrespective of the type and amount of impurity present in the system. This fact was also observed by Shor and Larson (1971) for the potassium nitrate system in the presence of several ionic and surface active agents. Shor and Larson also employed a MSMPR crystallizer to study the effect of additives on potassium nitrate crystallization. A comparison of the above correlations indicates that the correlation coefficient is usually better when fine-crystal growth rate is used to express the data. Values of $\mathrm{G}_{f}$ were measured with more precision than the crude microscopic estimates for $G$.

A master correlation of nucleation kinetics for organic addi- . tives was also obtained. The effect of organic additives in these master correlations was expressed as a ratio of active concentration $C_{i}^{*}$ (ppm) and the molecular weight of the additive. The ratio of active concentration $\mathrm{C}_{i}^{*}$ and the molecular weight of the additive brought the effect of sodium dodecylbenzene sulfonate and sodium oleate on the nucleation rate of sodium tetraborate to the same level. The molecular weight of sodium dodecylbenzene sulfonate is greater than sodium oleate whose molecular weight is in turn greater than sodium lauryl-sulfate. The inclusion of sodium lauryl sulfate data in these master correlations for organic additives decreased the correlation coefficient to 0.30 . This implies that sodium lauryl sulfate is not as effective in decreasing the nucleation rate as are sodium dodecylbenzene sulfonate and sodium oleate which fact is immediately obvious from the raw data. Thus nucleation was totally inhibited above $16 \mathrm{ppm}$ concentration (i.e.6.4 ppm active concentration) of sodium dodecylbenzene sulfonate and above $6 \mathrm{ppm}$ 
concentration of sodium oleate, whereas sufficient numbers of nuclei were produced even at 32 ppm concentration of sodium lauryl sulfate.

The master correlation using seed crystal growth rate for organic additives is

$B^{0}=2.47 \times 10^{5}(G)^{1.70}\left(M_{T}\right)^{0.42}(R P M)^{1.38} \exp \left(-0.0022 \times \frac{C_{i}^{*}}{M_{. W}}\right) \quad R^{2}=0.894$

Figure (32) shows a comparison between experimental and predicted values of $\mathrm{B}^{\circ}$ obtained from Equation (46). If fine-crystal growth rate is used, the master correlation for the organic additive becomes

$B^{0}=0.33 \times 10^{1}\left(G_{f}\right)^{1.53}\left(M_{T}\right)^{0.80}(R P M)^{3.25} \exp \left(-0.0044 \times \frac{C_{i}^{*}}{M \cdot W_{0}}\right) R^{2}=0.895$

Figure (33) shows a comparison between experimental and predicted values of $\mathrm{B}^{\circ}$ obtained from Equation (47). 


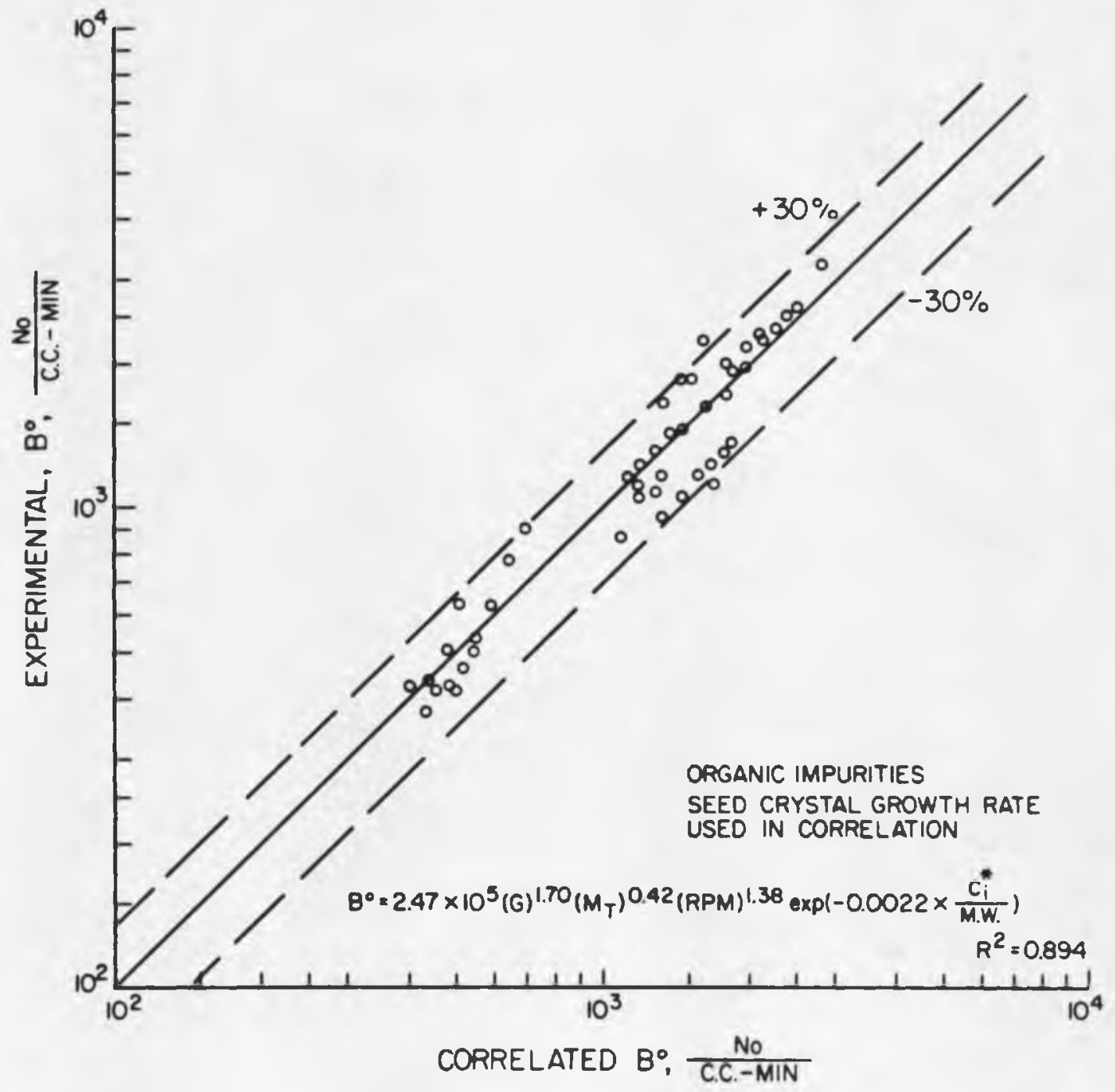

Figure 32. Comparison Between Experimental and Correlated Nucleation Rates for Organic Additives. 


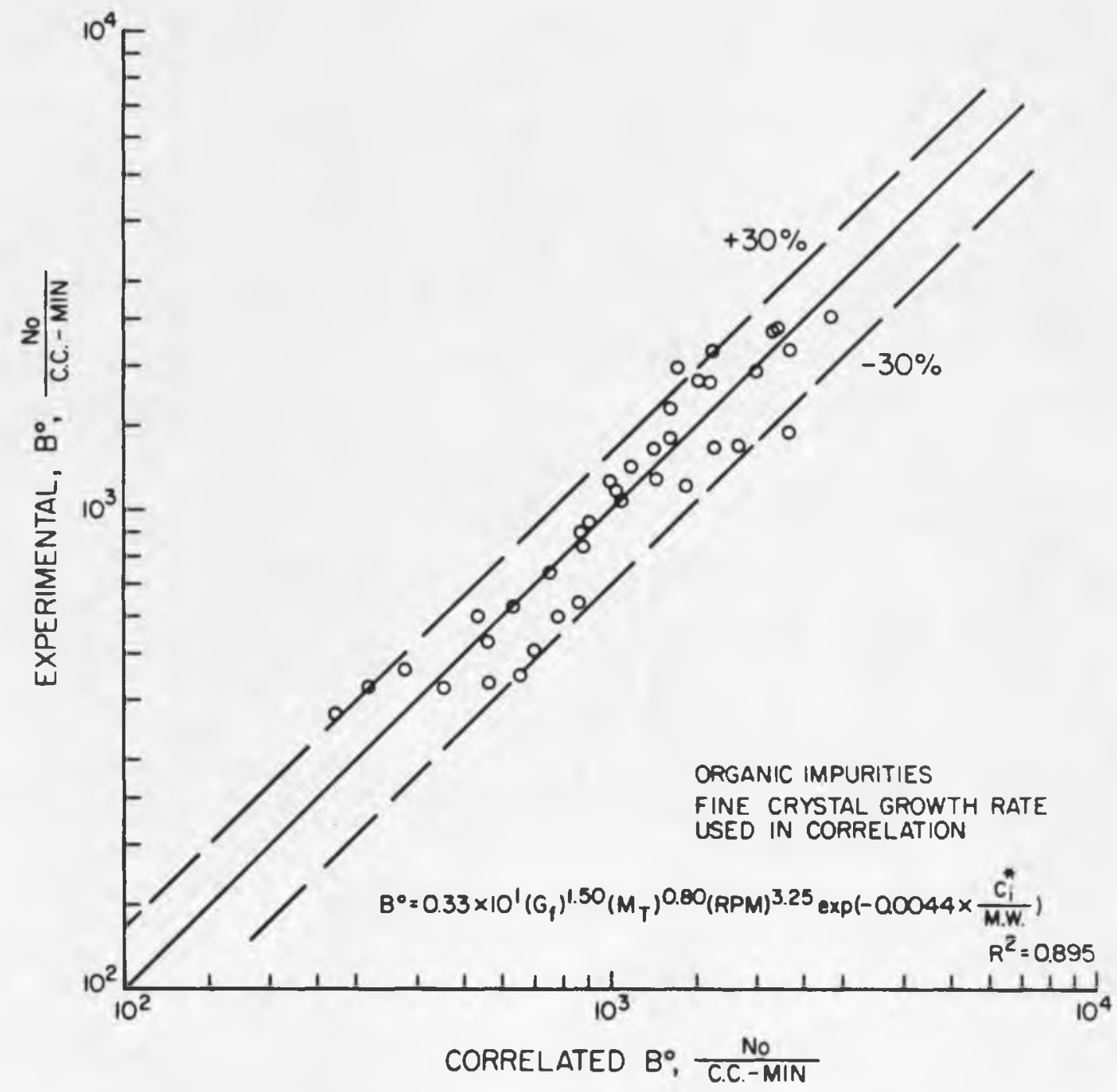

Figure 33. Comparison Between Experimental and Correlated Nucleation Rates for Organic Additives. 
CHAPTER 8

\section{DISCUSSION OF RESULTS}

An attempt was made in this study to obtain the nucleation and growth rate kinetics of sodium tetraborate crystallized from solutions containing trace organic and inorganic impurities. Simultaneously, the effect of these additives on the crystal habit was observed. Nucleation rates and fine-crystal growth rates were obtained from the intercept and slope of population density versus size plots. Fine-crystal growth rates were obtained in the range of 7.50 to 17.34 microns and were found to be size-independent. However, seed-crystal growth rates obtained from microscopic measurements of initial and final seeds gave values 2-3 times the fine-crystal growth rates. The habit of crystals was observed from photomicrographs taken at the end of the experiment.

It was found that the presence of organic additives decreased nucleation rate whereas inorganic additives increased nucleation rate. Fine-crystal as well as seed-crystal growth rates were decreased in both cases. An improvement of habit of product crystals was also observed in both cases, $i_{. e}$. the extent and fraction of multi-crystal growth was reduced.

Seed-crystal growth rates were found to depend on impurity levels In a negative exponential manner. These growth kinetics relationships for various impurities are given by Equations (27) to (31). Two important conclusions can be derived from these relationships: 
(i) The presence of an impurity in a crystallizing solution decreases the growth rate and the modified growth rate $\left(G_{i}\right)$ depends upon the impurity level present in the solution.

(ii) Different growth kinetics for different additives indicate that the growth rate $\left(G_{i}\right)$ in the presence of impurities also depends upon type of impurity. Thus, organic additives were found to be effective at a lower concentration leve1, typically 3 to $30 \mathrm{ppm}$, as opposed to 200 to $2000 \mathrm{ppm}$ effectiveness level for inorganic additives. Shor and Larson (1971) arrived at the same conclusion for the potassium nitrate system in the presence of various impurities. They also demonstrated that different impurities alter the growth rate to different extents. They found that surface active agents decreased the growth rate of potassium nitrate crystals whereas inorganic impurities increased the growth rate. However, their results were constrained by an over-all mass balance/yield relationship whereas the crystallizer of the present study operated as a differential reactor. Thus in Shor's crystallizer, if $\mathrm{B}^{\circ}$ increased then $G$ must decrease (and vice-versa) to achieve an over-all mass balance. Liu and Botsaris (1973) concluded that the presence of lead ions in the crystallizing solution of sodium chloride decreased the growth rate of sodium chloride crystals and the new growth rate $\left(G_{i}\right)$ bears a simple power relation with impurity concentration $\left(C_{i}\right)$.

The results of this study as well as those of Liu and Botsaris were found to be consistent with the we11-known observation that dissolved impurities decrease growth rate. Shor and Larson explained the alteration in growth rate in the presence of impurities as a change in supersaturation. This explanation cannot hold for the present study as 
the crystallizer acted as a differential reactor, $i . e$. there was no perceptible difference in the concentration of solute in input and output streams. This can be shown by a simple mass balance across the MSMPR crystallizer. The assumptions and the constraints previously mentioned in the population balance still apply.

The rate at which solute is lost from the mother liquor is equal to the rate at which mass is gained by the solid phase. Thus,

$$
\bar{Q}_{i} C_{i}-\bar{Q}_{0} C_{0}=\bar{Q}_{0}\left[\left(M_{T}\right)_{n u c l e i}+\left(\Delta M_{T}\right)_{\text {seed }}\right]
$$

where $\bar{Q}_{i}, \bar{Q}_{0}$ are the volumetric feed and discharge rates

$$
\begin{gathered}
C_{i}, C_{0} \text { are the solute concentrations of feed and mixed suspension } \\
\text { discharge }
\end{gathered}
$$

$\left(M_{T}\right)_{n u c l e i}$ is the slurry density of nuclei
$\left(\Delta \mathrm{M}_{\mathrm{T}}\right)_{\text {seed }} \quad$ is the increase in slurry density of suspended seeds in the crystallizer in one retention time.

The volumetric feed and discharge rates were kept the same, thus Equation (48) simplifies to

$$
C_{i}-C_{0}=\left(M_{T}\right)_{\text {nuclei }}+\left(\Delta M_{T}\right)_{\text {seed }}
$$

$\left(M_{T}\right)_{\text {nuclei }}$ at any instant can be obtained from the fine-crystal nucleation and growth rate data and $\left(\Delta \mathrm{M}_{\mathrm{T}}\right)_{\text {seed }}$ can be obtained from Equation (26). The approximate average values of $\left(M_{T}\right)_{n u c l e i}$ and $\left(\Delta M_{T}\right)_{\text {seed }}$ are $0.0005 \mathrm{~g} / 1$ iter and $0.10 \mathrm{~g} / 1$ iter, respectively. Thus, the drop in concentration of solute across the crystallizer is approximately equal to $0.10 \mathrm{~g} /$ Iiter, which is small compared to the supersaturation level. Nucleation rates were related to impurity concentration in an exponential manner as shown in the nucleation kinetics relationship (36) to (45). A comparison of these relations indicates that though 
impurities have considerable effect on nucleation rate, yet the kinetic order of nucleation rate with respect to growth rate, suspension density and RPM remains nearly the same irrespective of the type and amount of impurity present. Shor and Larson (1971) and Liu and Botsaris (1973) arrived at the same conclusion from their work on crystallization in the presence of impurities. Shor and Larson found that surface active agents increased the nucleation rate and the ionic impurities decreased the nucleation rate whereas the present study showed exactly the opposite trend. Shor and Larson rationalized their surfactant results with classical heterogeneous nucleation theory. A decrease in contact angle between a protonucleus in the growth layer of a crystal and the crystal surface should result in an exponential increase in the heteronucleation rate. However, in the present case nucleation rate (as well as multicrystal growth) was always inhibited in the presence of organic additives. The effect of ionic impurities were rationalized by Shor and Larson using an adsorption mechanism. They assumed that highly charged cations adsorb on the nucleation sites on crystals in suspension, thus inhibiting solute nucleation by blocking the sites. Furthermore, they assumed that the presence of highly charged ions could upset the charge balance. This would lead to the formation of some complex compounds which would decrease the tendency of ions to be attracted to each other and possibly decrease nucleation rate. Nucleation rate in the present study was always increased in the presence of singly-charged sodium ionic impurity as well as with doubly charged $\mathrm{Mg}$. A direct comparison with Shor's work is not possible because of the difference in operation of the two MSMPR systems. 
Crystals grown under similar experimental conditions in this study were better formed, $i . e$. less multi-crystals in the presence of impurities. The effect of additives on crystal quality can possibly be explained by the mechanism of dendritic whisker growth. The rate of initiation of new growth layers increases with supersaturation to a power greater than unity while the rate of advance of these growth layers across the crystal surface only increases directly with supersaturation (in Michaels and Tausch, 1961). Thus with increasing levels of supersaturation a point will eventually be reached at which the rate of initiation of new layers is faster than the rate of advance of these layers away from the point of initiation. Thus, a layer pile-up occurs which forms a growth protrusion on the surface. Growth of these protrusions at angles different from the main crystal axes by definition result in the observed multi-crystal habit exhibited by borax. Because of the more favorable diffusion environment of this protrusion it will become unstable and grow into solution faster than, and at the expense of, adjacent surfaces. This theory of dendritic growth explains the well-known phenomena of multi-crystal growth at high supersaturations. Since additives were found to improve crystal quality it appears that they must retard initiation of new layers relative to the advance of layers across the crystal surface and/or reduce the levels of supersaturation in the boundary layer immediately adjacent to the crystal surface.

\section{Mechanism of Impurity Effects}

Several conflicting mechanisms have been proposed in the literature to explain the effect of impurities on the crystallization of pure substances. Recent developments in this field have postulated that an 
impurity must adsorb to some extent on the crystal surface in order to decrease the growth rate of a crystal. Thus a crystal face can be considered as a matrix of adsorption sites. It can further be assumed that there is no interaction between adsorbed species on neighbouring sites. If the rate of adsorption of impurity, $q_{a d s}$ is linearly dependent upon the concentration of impurity in the solution and the area of free surface, i.e. the area not covered by adsorbed impurity, one may write

$$
q_{\text {ads }}=k_{a d s}\left(1-A_{i}\right) c_{i}
$$

where $A_{i}$ is the surface coverage of impurity. The rate constant $\mathrm{K}_{\text {ads }}$ is given by an Arhenius expression

$$
K_{\text {ads }}=S \exp \left(-\Delta E_{\text {ads }} / R T\right)
$$

where $S$ is the Arhenius equilibrium constant and $\Delta E$ ads is the activation energy for adsorption. Similarly, the rate of desorption can be considered to depend upon the surface coverage of impurity.

$$
q_{\text {des }}=K_{\text {des }} A_{i}
$$

where the rate constant $\mathrm{K}_{\text {des }}$ is again given by Arhenius expression

$$
\mathrm{K}_{\mathrm{des}}=\mathrm{S} \exp \left(-\Delta \mathrm{E}_{\mathrm{des}} / \mathrm{RT}\right)
$$

$\Delta E_{\text {des }}$ is the activation energy for desorption. At steady state

$$
q_{\text {ads }}=q_{\text {des }}
$$

or

$$
\mathrm{K}_{\mathrm{ads}}\left(1-\mathrm{A}_{i}\right) \mathrm{C}_{i}=\mathrm{K}_{\mathrm{des}^{\mathrm{A}}}{ }_{i}
$$

Rearranging Equation (54) one obtains

$$
A_{i}=\frac{K C_{i}}{1+K C_{i}}
$$


The flux of growth units to a single step in pure solution is

$$
\mathrm{N}=\left(\frac{\mathrm{x}}{\mathrm{t}_{k}}\right)\left(\mathrm{n}_{\mathrm{s}}-\mathrm{n}^{*}\right)
$$

where $\mathrm{x}=$ distance between neighbouring positions on surface

$$
\begin{aligned}
t_{k}= & \text { relaxation time entering a kink } \\
n_{s}= & \text { number of adsorbed growth units per unit area of crystal } \\
& \text { surface } \\
n^{*}= & \text { number adsorbed at equilibrium }
\end{aligned}
$$

The flux of growth units to a single step in impure solution is

$$
N_{i}=\left(\frac{x}{t_{k}}\right)\left(1-A_{i}\right)\left(n_{s}-n^{*}\right)
$$

or

$$
N_{i}=N\left(1-A_{i}\right)
$$

Since the step velocity may be expressed as

$$
\mathrm{v}=2 \mathrm{NF}
$$

where $F$ is the area occupied by one growth unit. If $v$ and $v_{i}$ are the step velocities of a crystal face in pure and impure solutions, then using Equations (58) and (59) one obtains

$$
A_{i}=\frac{v-v_{i}}{v}
$$

Thus Equation (55) becomes

$$
\frac{\mathrm{v}-\mathrm{v}_{i}}{\mathrm{v}}=\frac{\mathrm{KC}}{1+\mathrm{KC}}
$$

Equating the step velocities with the growth rates gives a basis for a theoretical predictive mode1. Thus, Davey and Mullin's model becomes 


$$
\frac{G-G_{i}}{G}=\frac{K C_{i}}{1+K C_{i}}
$$

or

$$
G-G_{i}=\frac{K_{1} C_{i}}{1+K_{2} C_{i}}
$$

or

$$
\frac{1}{G-G_{i}}=\frac{1}{K_{1} C_{i}}+\frac{K_{2}}{K_{1}}
$$

From Equations (62) and (63) one obtains

$$
\mathrm{K}=\mathrm{K}_{2}=\frac{\mathrm{K}_{1}}{\mathrm{G}}
$$

Thus a plot of $\frac{1}{G-G_{i}}$ versus $\frac{1}{C_{i}}$ should result in a straight line if an adsorption mechanism is responsible for the effect of impurities on growth.

For organic impurities good straight line plots were observed, as shown in Figure (34). The values of $K_{1}$ and $K_{2}$ for different impurities calculated from the slopes of these straight lines are as follows:

$$
\text { Impurity }
$$

Sodium dodecylbenzene sulfonate

Sodium oleate

$0.39 \times 10^{-5}$

$0.15 \times 10^{-5}$$$
0.12 \times 10^{-5}
$$

Sodium lauryl sulfate

$$
\frac{\mathrm{K}=\mathrm{K}_{2}\left(\mathrm{~m}^{3} / \mathrm{Kg}\right)}{0.2 \times 10^{2}}
$$

$$
\mathrm{K}_{1}\left(\mathrm{~m}^{4} / \mathrm{Kg} \cdot \mathrm{s}\right)
$$$$
0.68 \times 10^{2}
$$

These data indicate that organic impurities adsorb at the crystal surface and the adsorption on certain sites in a growing crystal results in a reduction of growth rate. Secondary nucleation was shown to be the dominant mechanism of particle formation in this study. Botsaris (1975) postulated that such a mechanism requires new particles 


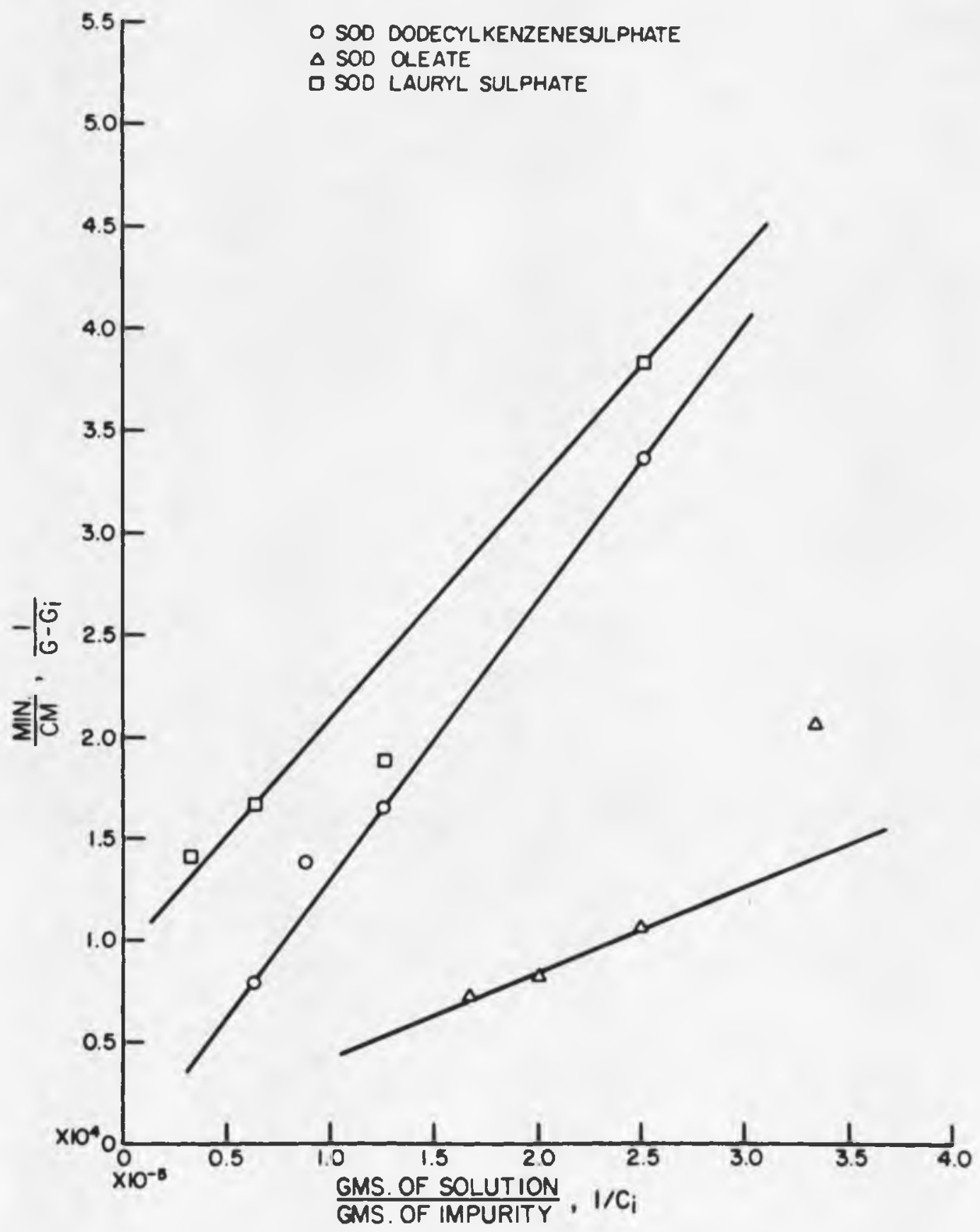

Figure 34. Graph Showing Languir's Adsorption Isotherm for Organic Additives. 
to be formed at active crystal sites. Adsorption of organic impurities causes these sites to be blocked which in turn decreases nucleation rate.

The data for inorganic impurities did not fit Langmuir's isotherm. This is shown in Figure (35). The behavior of inorganic impurities can be explained by collision probability theory. The presence of these singly charged ions might increase the probability of several tve and -ve ions colliding on or near the crystal surface to form a cluster. The increased collision efficiency between ions would then increase the nucleation rate. This mechanism is plausible in view of the high concentration of ions $\left(210^{3} \mathrm{ppm}\right)$ need to influence nucleation.

Moreover, sodium tetraborate is a weak electrolyte. The presence of common $\mathrm{Na}^{+}$(added as sodium chloride) in a crystallizing sodium tetraborate solution will reduce the ionization of sodium tetraborate which will shift the ionic equilibrium of sodium tetraborate to the left. The result will favor the formation of sodium tetraborate and hence provide more chemical driving force for nucleation. 


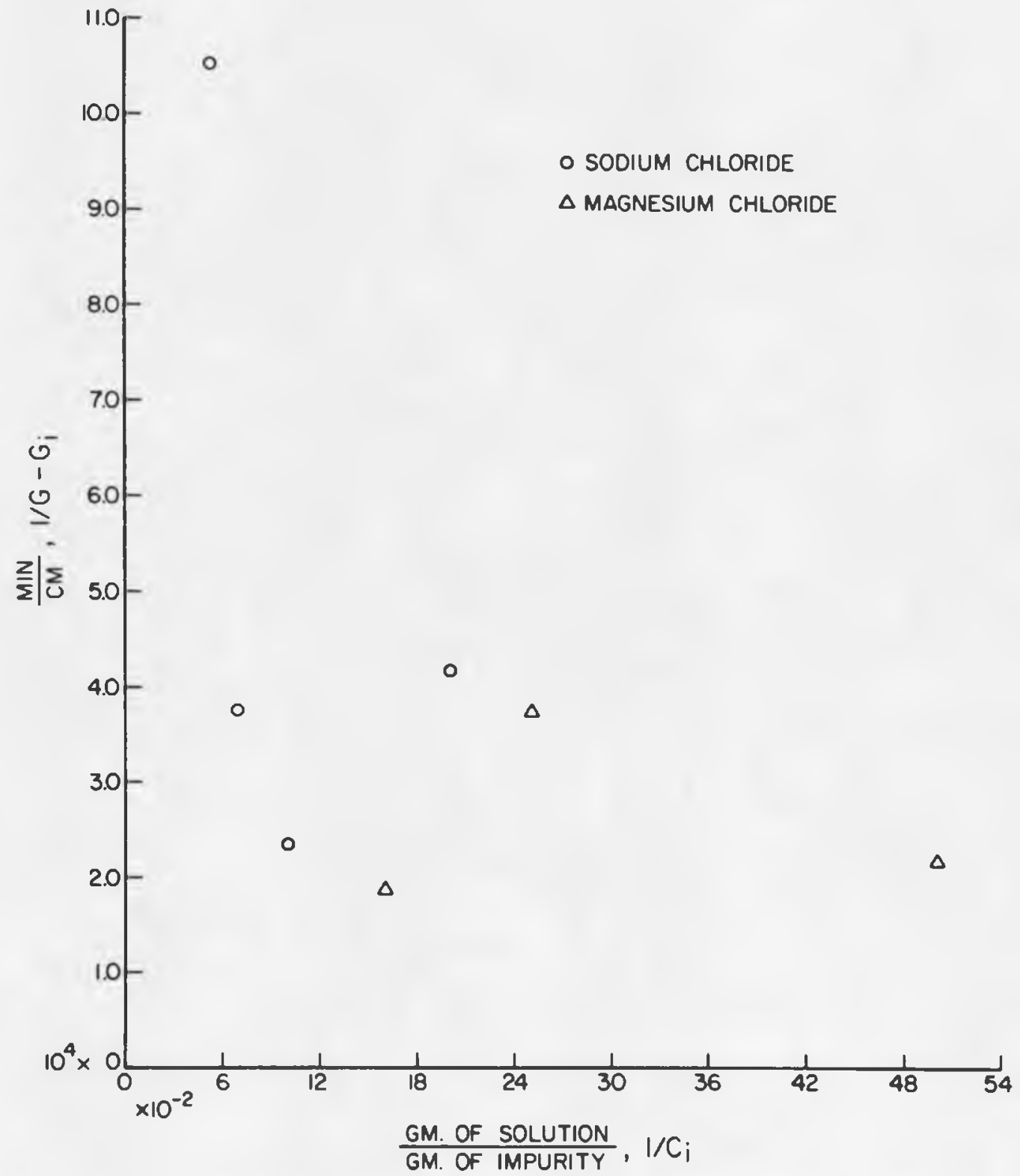

Figure 35. Langmuir's Adsorption Isotherm for Inorganic Impurities. 
CHAPTER 9

SUMMARY AND CONCLUSIONS

1. The crystallization of sodium tetraborate decahydrate in the presence of organic and inorganic impurities was investigated in a one liter stirred crystallizer with retained seeds.

2. The effects of nucleation, growth and crystal habit of the organic additives sodium dodecylbenzene sulfate, sodium oleate and sodium lauryl sulfate (at the $3-30 \mathrm{ppm}$ level) were studied.

3. Inorganic impurities consisting of sodium chloride and magnesium chloride were studied over the concentration range of 200 to 2000 ppm.

4. The sodium tetraborate system exhibits classical magma and RPMdependent secondary nucleation.

5. The presence of organic impurities inhibited the nucleation rate. Nucleation was totally inhibited with $6.4 \mathrm{ppm}$ sodium dodecylbenzene sulfonate and $6 \mathrm{ppm}$ sodium oleate. However, inorganic additives increased nucleation rate.

6. Growth rate of fines as well as of parent seeds were inhibited by both organic and inorganic additives.

7. Al1 of the additives which were studied improved the crystal quality of borax, i.e. fewer multi-crystals were produced in the presence of additive. 
8. The nucleation rate data correlated with growth rate, suspension density, RPM and additive concentration using a generalized powerlaw model. The relative kinetic order of nucleation rate with respect to growth rate, suspension density and RPM remained almost the same irrespective of the type and the amount of impurity present.

9. Seed crystal growth rates were found to depend upon the type and amount of additive concentration. These growth rates correlated with the additive concentration in a negative exponential manner. 10. The effect of organic additives is explained using an adsorption mechanism whereas the effect of inorganic additives is rationalized with collision probability theory. 
APPENDIX A

\section{CALCULATION OF VOLUMETRIC AVERAGE SIZE SHAPE FACTOR}

Consider the crystal to be spherical. Volumetric shape factor for spherical particles is $\pi / 6$. If $w$ is weight of $N$ particles, then

$$
w=N \times \rho \times \frac{\pi}{6} \times\left(\bar{L}_{v}\right)^{3}
$$

or

$$
\bar{L}_{v}=\left(\frac{6 \mathrm{~W}}{N \rho \pi}\right)^{1 / 3}
$$

Experimentally 50 sodium tetraborate decahydrate crystals were weighed. The average length of these crystals was determined from microscopic measurements. Thus

$$
\overline{\mathrm{L}}_{\mathrm{v}}=\left(\frac{6 \times 0.0105 \mathrm{gm}}{50 \times 1.7 \frac{3 \mathrm{gm}}{\mathrm{cc}} \times \pi}\right)^{1 / 3}
$$

or $\overline{\mathrm{L}}_{\mathrm{v}}=0.0616 \mathrm{~cm}$

Average Length, $\overline{\mathrm{L}}=0.0968 \mathrm{~cm}$

Thus, volumetric average size shape factor, $\frac{\overline{\mathrm{L}}}{\overline{\mathrm{L}}}=0.636$ 
APPENDIX B

GENERAL OPERATIONAL CONDITIONS AND

EXPERIMENTAL DATA

The following is a summary of the general operating conditions and the experimental data taken during all the experiments performed in this study. Temperatures are expressed in degree centigrade, and the seed mass is expressed in grams. An average residence time of 4 minutes was employed in all the experiments. Seeds of $-50+60$ mesh size were used in a11 the runs. A $190 \mu \mathrm{m}$ orifice was used in all the experiments and the size range of measurements was 7.50 to $17.34 \mu \mathrm{m}$. The various abbreviations used in this table are defined as follows:

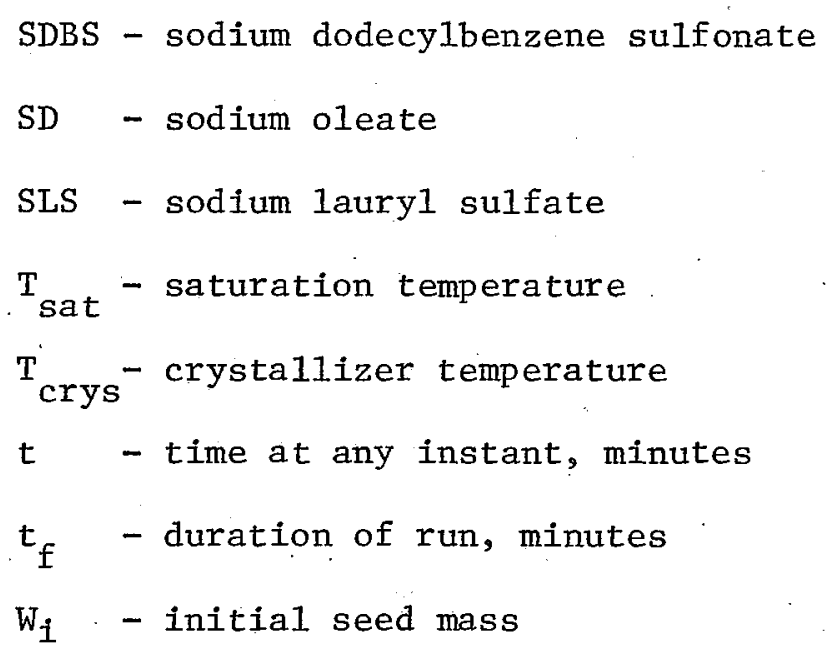




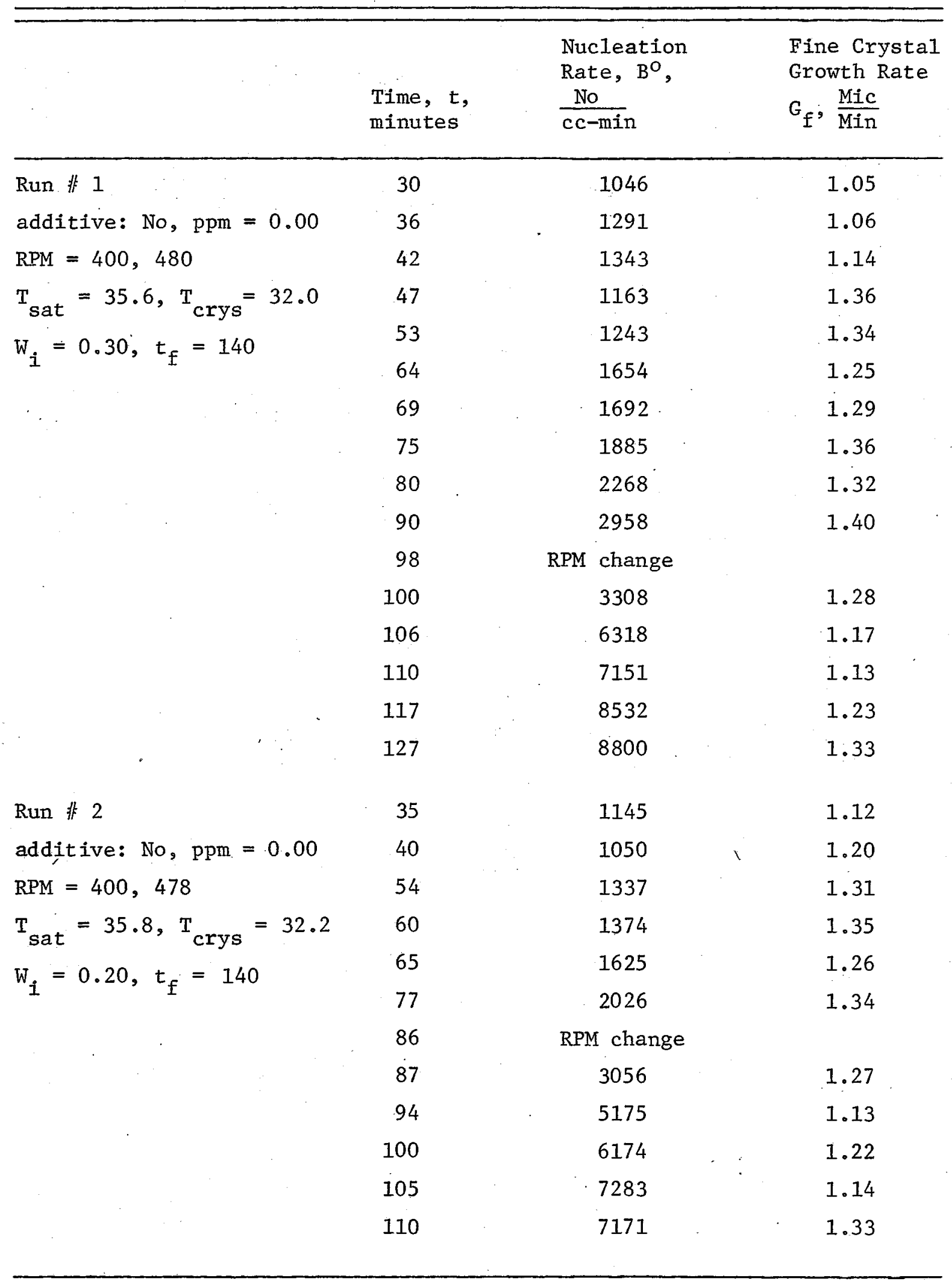




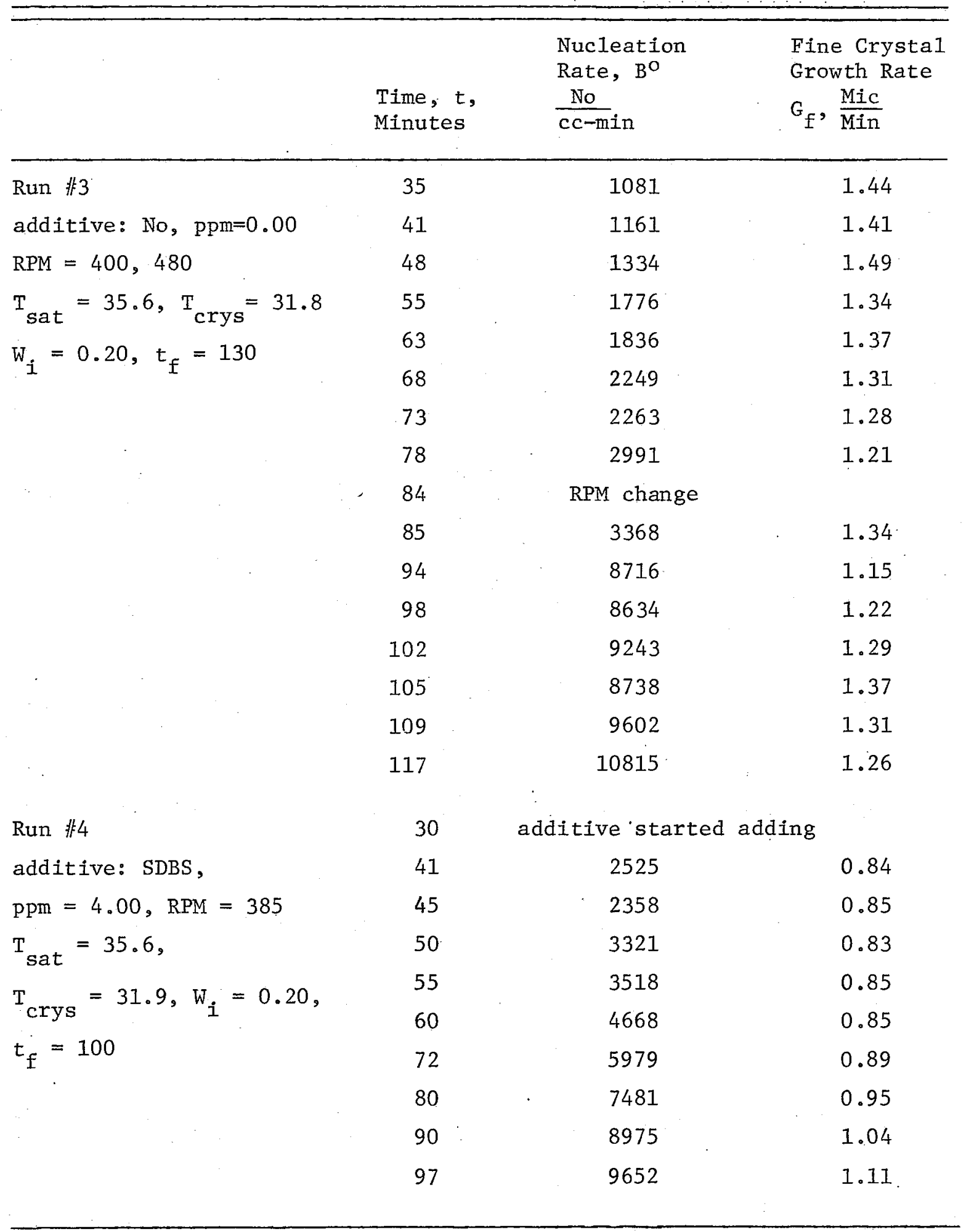




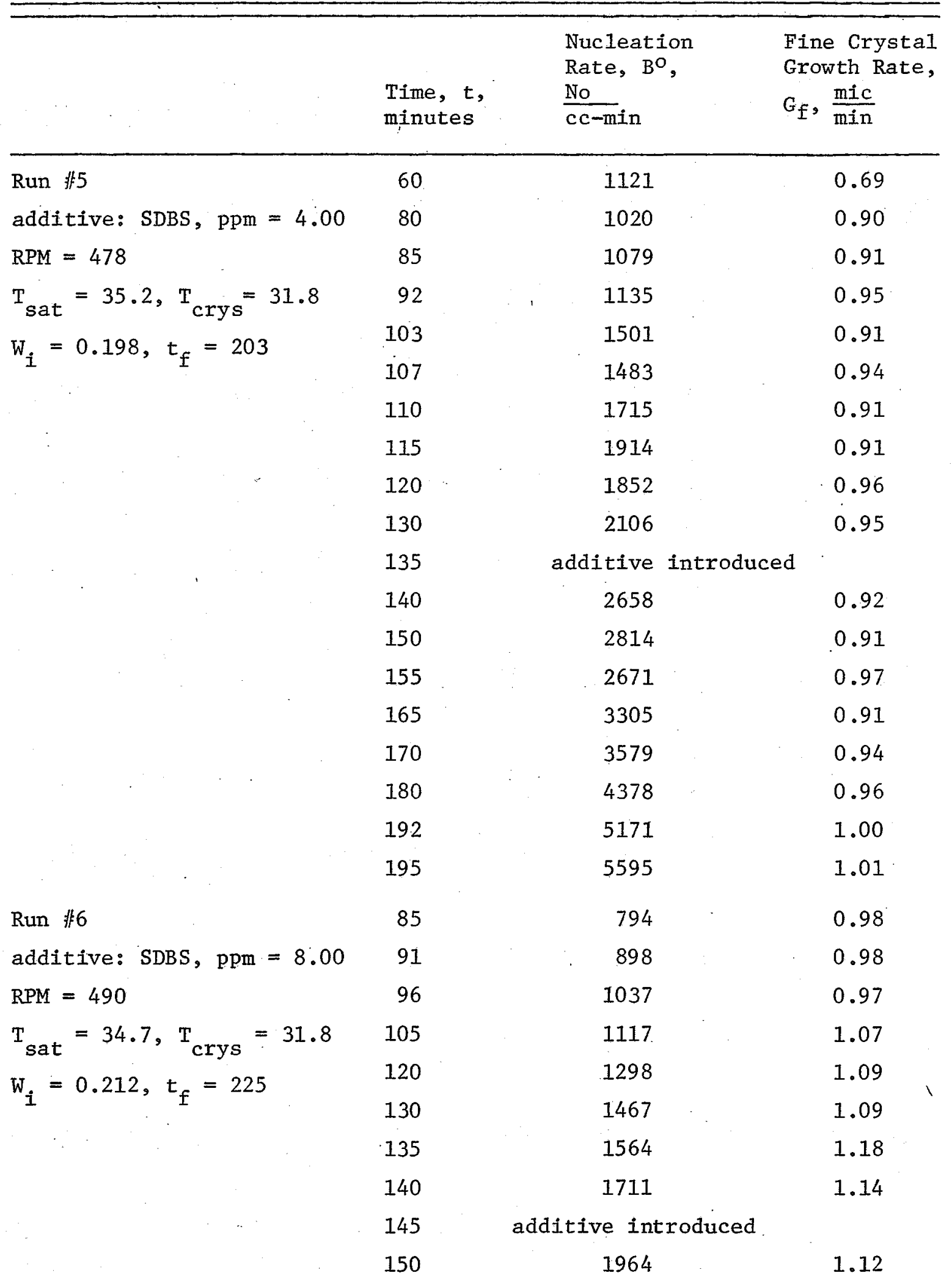




\begin{tabular}{|c|c|c|c|}
\hline & $\begin{array}{l}\text { Time, } t, \\
\text { Minutes }\end{array}$ & $\begin{array}{l}\text { Nucleation } \\
\text { Rate, } \mathrm{B}^{\circ}, \\
\text { No } \\
\text { cc-min }\end{array}$ & $\begin{array}{l}\text { Fine Crystal } \\
\text { Growth Rate, } \\
G_{f}, \frac{\text { mic }}{\min }\end{array}$ \\
\hline \multirow[t]{6}{*}{ Run 非6 Cont. } & 160 & 2270 & 0.98 \\
\hline & 170 & 2557 & 0.97 \\
\hline & 180 & 2671 & 0.94 \\
\hline & 190 & 3433 & 0.97 \\
\hline & 205 & 3630 & 1.10 \\
\hline & 215 & 4058 & 1.03 \\
\hline Run 非 & 48 & 3227 & 0.65 \\
\hline Additive: SDBS, ppm=11.31 & 53 & 3064 & 0.69 \\
\hline $\mathrm{RPM}=482$ & 65 & 3121 & 0.78 \\
\hline $\mathrm{T}_{\text {sat }}=35.4, \mathrm{~T}_{\text {crys }}=32.0$ & $75^{\prime}$ & 3672 & 0.82 \\
\hline \multirow{19}{*}{$\mathrm{w}_{\mathbf{i}}=0.204, \mathrm{t}_{\mathrm{f}}=195$} & 85 & 4193 & 0.84 \\
\hline & 100 & 4628 & 0.88 \\
\hline & 105 & 4571 & 0.88 \\
\hline & 110 & 5059 & 0.88 \\
\hline & 115 & 5274 & 0.88 \\
\hline & 119 & 5736 & 0.88 \\
\hline & 120 & additive introduced & \\
\hline & 125 & 5801 & 0.87 \\
\hline & 129 & 5362 & 0.74 \\
\hline & 135 & 3251 & 0.72 \\
\hline & 139 & 3430 & 0.65 \\
\hline & 143 & 4072 & 0.64 \\
\hline & 147 & 4522 & 0.64 \\
\hline & 150 & 4188 & 0.64 \\
\hline & 163 & 4639 & 0.65 \\
\hline & 168 & 5438 & 0.64 \\
\hline & 175 & 5954 & 0.67 \\
\hline & 179 & 7602 & 0.63 \\
\hline & 185 & $\ldots 9081$ & 0.64 \\
\hline
\end{tabular}




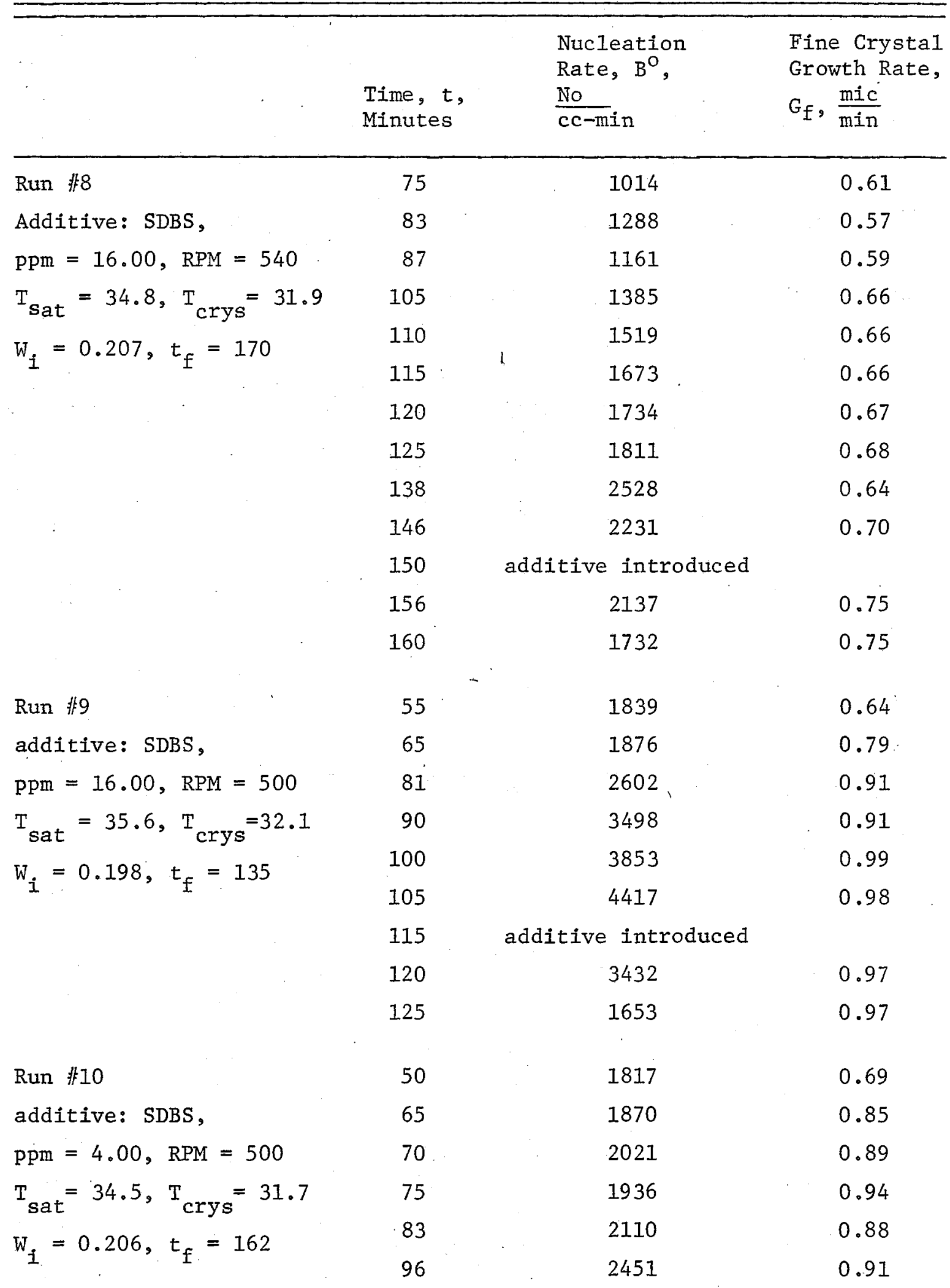




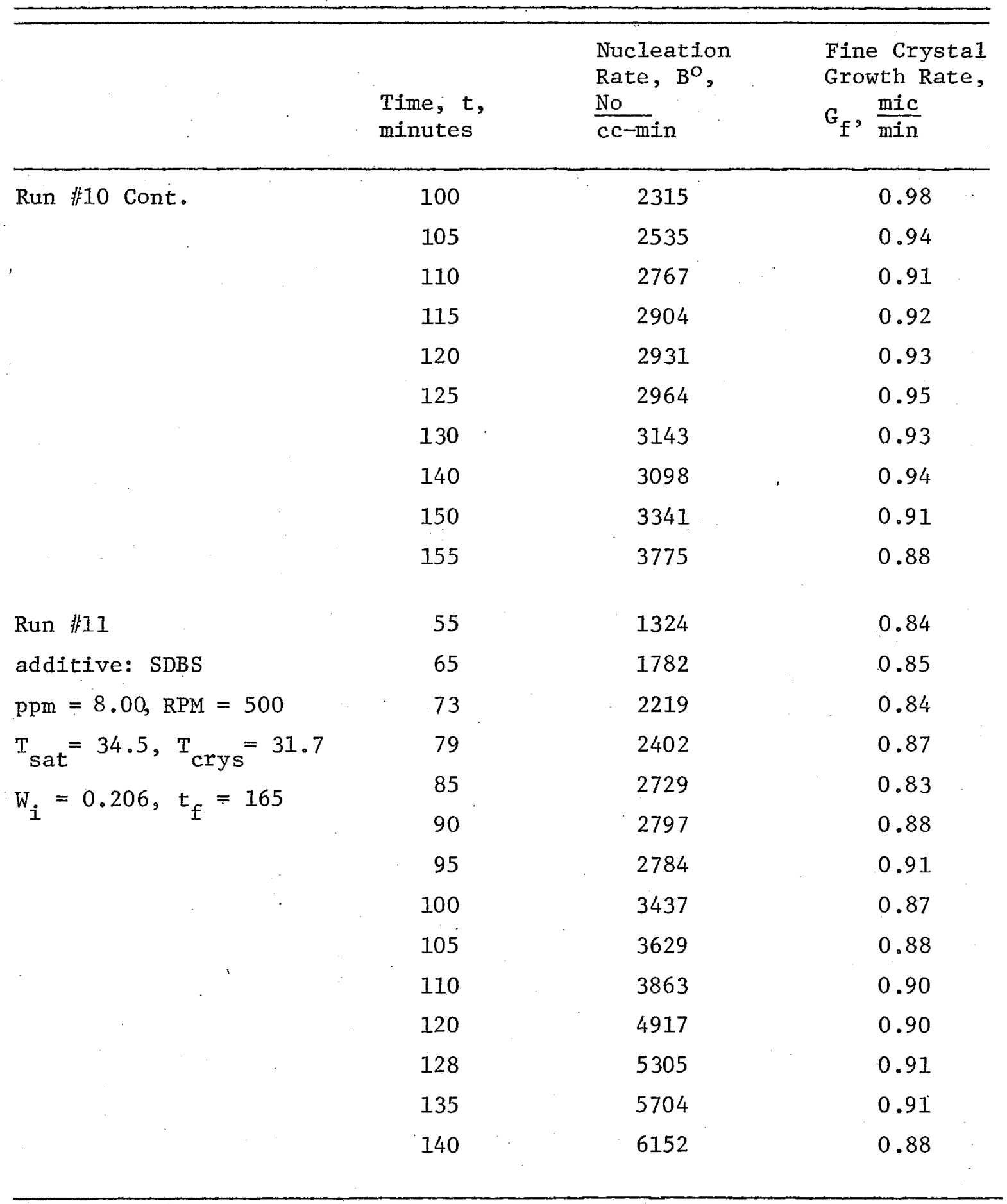




\begin{tabular}{|c|c|c|c|}
\hline . & $\begin{array}{l}\text { Time, } t, \\
\text { minutes }\end{array}$ & $\begin{array}{l}\text { Nucleation } \\
\text { Rate, } B^{\circ} \\
\text { No } \\
\text { cc-min }\end{array}$ & $\begin{array}{l}\text { Fine Crystal } \\
\text { Growth Rate, } \\
G_{f}, \frac{\text { mic }}{\min }\end{array}$ \\
\hline Run 非12 & 60 & 975 & 0.81 \\
\hline additive: SDBS & 78 & 1356 & 0.84 \\
\hline $\mathrm{ppm}=11.31, \mathrm{RPM}=500$ & 83 & 1695 & 0.81 \\
\hline $\mathrm{T}_{\text {sat }}=34.5, \mathrm{~T}_{\text {crys }}=31.7$ & 90 & 1649 & 0.84 \\
\hline \multirow{9}{*}{$\dot{W}_{i}=0.206, t_{f}=162$} & 95 & 1794 & 0.85 \\
\hline & 100 & 1959 & 0.85 \\
\hline & 105 & 1936 & 0.88 \\
\hline & 110 & 2076 & 0.84 \\
\hline & 115 & 2267 & 0.83 \\
\hline & 120 & 2208 & 0.86 \\
\hline & 125 & 2484 & 0.85 \\
\hline & 130 & 2594 & 0.85 \\
\hline & 135 . & 3366 & 0.83 \\
\hline Run \#13 & 95 & 375 & 0.75 \\
\hline additive: SDBS, & 105 & 320 & 0.89 \\
\hline $\mathrm{ppm}=16.00, \mathrm{RPM}=500$ & 110 & 427 & 0.84 \\
\hline $\mathrm{T}_{\text {sat }}=34.5, \mathrm{~T}_{\text {crys }}=31.7$ & 120 & 463 & 0.73 \\
\hline \multirow{3}{*}{$\mathrm{w}_{\mathbf{i}}=0.206, \mathrm{t}_{\mathrm{f}}=165$} & 125 & 609 & 0.72 \\
\hline & 130 & 536 & 0.85 \\
\hline & 135 & 674 & 0.84 \\
\hline Run \#14 & 55 & 1620 & 0.79 \\
\hline additive: $\quad \mathrm{NO}, \mathrm{ppm}=0.00$ & 65 & 1727 & 0.88 \\
\hline $\mathrm{RPM}=500$ & 75 & 1975 & 0.89 \\
\hline $\mathrm{T}_{\text {sat }}=34.4, \mathrm{~T}_{\text {crys }}=31.1$ & 85 & 2253 & 0.94 \\
\hline \multirow{4}{*}{$w_{i}=0.206, t_{f}=145$} & 100 & 2520 & 0.97 \\
\hline & 110 & 2756 & 0.97 \\
\hline & 125 & 3231 & 0.94 \\
\hline & 135 & 3685 & 0.92 \\
\hline
\end{tabular}




\begin{tabular}{|c|c|c|c|}
\hline & $\begin{array}{l}\text { Time, } t, \\
\text { minutes }\end{array}$ & $\begin{array}{l}\text { Nucleation } \\
\text { Rate, } B^{\circ} \\
\text { No } \\
\text { cc-min }\end{array}$ & $\begin{array}{l}\text { Fine Crystal } \\
\text { Growth Rate } \\
G_{f}, \frac{\text { mic }}{\min }\end{array}$ \\
\hline Run 非15 & 70 & 836 & 0.83 \\
\hline additive: $\mathrm{so}, \mathrm{ppm}=3.00$ & 75 & 1110 & $0 . \dot{8} 2$ \\
\hline $\mathrm{RPM}=500$ & 80 & 1079 & 0.86 \\
\hline $\mathrm{T}_{\text {sat }}=34.4, \mathrm{~T}_{\text {crys }}=31.1$ & 85 & 1282 & 0.82 \\
\hline \multirow{6}{*}{$\mathrm{W}_{\mathrm{i}}=0.206, \mathrm{t}_{\mathrm{f}}=145$} & 90 & 1021 & 0.92 \\
\hline & 95 & 1159 & 0.90 \\
\hline & 100 & 1429 & 0.85 \\
\hline & 110 & 1463 & 0.88 \\
\hline & 126 & 2243 & 0.80 \\
\hline & 135 & 2590 & 0.83 \\
\hline Run \#16 & 75 & 411 & 0.76 \\
\hline additive: $\mathrm{so}, \mathrm{ppm}=5.00$ & 85 & 602 & 0.71 \\
\hline $\mathrm{RPM}=500$ & 90 & 596 & 0.72 \\
\hline $\mathrm{T}_{\text {sat }}=34.4, \mathrm{~T}_{\text {crys }}=31.1$ & 95 & 565 & 0.82 \\
\hline \multirow{4}{*}{$w_{i}=0.206, t_{f}=150$} & 105 & 622 & 0.80 \\
\hline & 120 & 778 & 0.87 \\
\hline & 135 & 897 & 0.88 \\
\hline & 145 & 897 & 0.91 \\
\hline Run $k^{\prime} 17$ & 80 & 416 & 0.91 \\
\hline additive: $s 0, p p m=6.00$ & 90 & 444 & 0.98 \\
\hline $\mathrm{RPM}=500$ & 100 & 502 & 0.98 \\
\hline$T_{\text {sat }}=34.4, T_{\text {crys }}=31.1$ & 110 & 598 & 0.98 \\
\hline \multirow{3}{*}{$W_{i}=0.206, t_{f}=145$} & 120 & 638 & 0.98 \\
\hline & 130 & 631 & 1.03 \\
\hline & 140 & 804 & 0.98 \\
\hline
\end{tabular}




\begin{tabular}{|c|c|c|c|}
\hline n & $\begin{array}{l}\text { Time, } t, \\
\text { minutes }\end{array}$ & $\begin{array}{l}\text { Nucleation } \\
\text { Rate, B } \\
\text { No. } \\
\text { cc-min }\end{array}$ & $\begin{array}{l}\text { Fine Crystal } \\
\text { Growth Rate } \\
G_{f}, \frac{\text { mic }}{\text { min }}\end{array}$ \\
\hline Run 非18. & 55 & 1871 & 0.66 \\
\hline additive: No, $\mathrm{ppm}=0.00$ & 65 & 2051 & 0.70 \\
\hline $\mathrm{RPM}=480$ & 75 & 2017 & 0.75 \\
\hline $\mathrm{T}_{\text {sat }}=35.0, \mathrm{~T}_{\text {crys }}=31.7$ & 85 & 2185 & 0.79 \\
\hline \multirow{4}{*}{$w_{i}=0.206, t_{f}=143$} & 95 & 2293 & 0.82 \\
\hline & 105 & 2367 & 0.84 \\
\hline & 120 & 2642 & 0.86 \\
\hline & 130 & 2960 & 0.86 \\
\hline Run 非19 & 55 & 1759 & 0.70 \\
\hline additive: SLS, & 65 & 1761 & 0.84 \\
\hline $\mathrm{ppm}=4.00, \quad \mathrm{RPM}=480$ & 85 & 1971 & 0.87 \\
\hline $\mathrm{T}_{\text {sat }}=35.0, \mathrm{~T}_{\text {crys }}=31.7$ & 95 & 2007 & 0.90 \\
\hline \multirow{3}{*}{$w_{i}=0.206, t_{f}=145$} & 105 & 2169 & 0.89 \\
\hline & 120 & 2388 & 0.90 \\
\hline & 130 & 2695 & 0.90 \\
\hline Run \#20 & 55 & 2023 & 0.60 \\
\hline additive: SLS, $\mathrm{ppm}=8.00$ & 65 & 2193 & 0.64 \\
\hline $\mathrm{RPM}=480$ & 75 & 2382 & 0.71 \\
\hline $\mathrm{T}_{\text {sat }}=35.0, \mathrm{~T}_{\text {crys }}=31.7$ & 95 & 2907 & 0.78 \\
\hline \multirow{3}{*}{$w_{i}=0.206, t_{f}=145$} & 105 & 2861 & 0.83 \\
\hline & 120 & 2818 & 0.89 \\
\hline & 130 & 3193 & 0.87 \\
\hline Run 非21 & 55 & 1387 & 0.62 \\
\hline additive: SLS, $\mathrm{ppm}=16.00$ & 65 & 1530 & 0.64 \\
\hline $\mathrm{RPM}=480$ & 75 & 1402 & 0.73 \\
\hline $\mathrm{T}_{\text {sat }}=35.0, \mathrm{~T}_{\text {crys }}=31.7$ & 85 & 1475 & 0.78 \\
\hline$w_{i}=0.206, t_{f}=143$ & 95 & 1628 & 0.80 \\
\hline
\end{tabular}




\begin{tabular}{|c|c|c|c|}
\hline & $\begin{array}{l}\text { Time, } t, \\
\text { Minutes }\end{array}$ & $\begin{array}{l}\text { Nucleation } \\
\text { Rate, } \mathrm{B}^{\mathrm{O}} \text {, } \\
\text { No: } \\
\text { cc-min }\end{array}$ & $\begin{array}{l}\text { Fine Crystal } \\
\text { Growth Rate, } \\
G_{f}, \frac{\text { mic }}{m i n}\end{array}$ \\
\hline \multirow[t]{3}{*}{ Run 非21 Cont. } & 105 & 1766 & 0.81 \\
\hline & 120 & 1580 & 0.90 \\
\hline & 130 & 2089 & 0.83 \\
\hline Run 非22 & 55 & 714 & 0.85 \\
\hline additive: SLS, & 65 & 1174 & 0.77 \\
\hline $\mathrm{ppm}=32.00, \mathrm{RPM}=480$ & 75 & 1359 & 0.81 \\
\hline $\mathrm{T}_{\text {sat }}=35.0, \mathrm{~T}_{\text {crys }}=31.7$ & 85 & 1561 & 0.82 \\
\hline \multirow{3}{*}{$w_{i}=0.206, t_{f}=145$} & 95 & 1791 & 0.81 \\
\hline & 120 & 1768 & 0.89 \\
\hline & 130 & 2068 & 0.86 \\
\hline Run 非23 & 55 & 861 & 0.70 \\
\hline additive: No, $\mathrm{ppm}=0.00$ & 65 & 1048 & 0.76 \\
\hline $\mathrm{RPM}=470$ & 75 & 1079 & 0.79 \\
\hline $\mathrm{T}_{\text {sat }}=34.4, \mathrm{~T}_{\text {crys }}=31.1$ & 90 & 1139 & 0.84 \\
\hline \multirow{4}{*}{$w_{i}=0.207, t_{f}=145$} & 100 & 1158 & 0.85 \\
\hline & 110 & 1229 & 0.89 \\
\hline & 120 & 1296 & 0.89 \\
\hline & 130 & 1614 & 0.86 \\
\hline Run \#24 & 55 & 1500 & 0.53 \\
\hline additive: $\mathrm{NaCl}$, & 65 & 1189 & 0.69 \\
\hline $\mathrm{ppm}=500, \quad \mathrm{RPM}=470$ & 75 & 1184 & 0.77 \\
\hline $\mathrm{T}_{\text {sat }}=34.4, \mathrm{~T}_{\text {crys }}=31.1$ & 90 & 1284 & 0.86 \\
\hline \multirow{4}{*}{$\mathrm{w}_{\mathbf{i}}=0.207, \mathrm{t}_{\mathrm{f}}=14 \dot{5}$} & 100 & 1401 & 0.84 \\
\hline & 110 & 1675 & 0.83 \\
\hline & 120 & 1655 & \\
\hline & 130 & 2106 & 0.82 \\
\hline
\end{tabular}




\begin{tabular}{|c|c|c|c|c|}
\hline . & $\begin{array}{l}\text { Time, } t, \\
\text { Minutes }\end{array}$ & $\begin{array}{l}\text { Nucleation } \\
\text { Rate, } B \\
\text { No } \\
\text { cc-min }\end{array}$ & $\begin{array}{l}\text { Fine } \\
\text { Gror } \\
G_{f},\end{array}$ & $\begin{array}{l}\text { e Crystal } \\
\text { wth Rate, } \\
\frac{\text { mic }}{\text { min }}\end{array}$ \\
\hline Run 非25. & 55 & 1492 & & 0.51 \\
\hline additive: $\mathrm{NaCl}, \mathrm{ppm}=1000$ & .65 & 1155 & & 0.65 \\
\hline$R P M=470$ & 75 & 1406 & & 0.66 \\
\hline $\mathrm{T}_{\text {sat }}=34.4, \mathrm{~T}_{\text {crys }}=31.1$ & 90 & 1753 & & 0.69 \\
\hline$w_{.}=0.207, t_{f}=145$ & 100 & 1868 & & 0.72 \\
\hline & 110 & 1713 & & 0.76 \\
\hline Run 非26 & 55 & 1201 & & 0.53 \\
\hline additive: $\mathrm{NaCl}, \mathrm{ppm}=1500$ & 65 & 1912 & & 0.66 \\
\hline$R P M=470$ & 75 & 2425 & & 0.77 \\
\hline $\mathrm{T}_{\text {sat }}=34.4, \mathrm{~T}_{\text {crys }}=31.1$ & 90 & 2320 & & 0.86 \\
\hline \multirow{2}{*}{$W_{i}=0.207, t_{f}=145$} & 100 & 2446 & & 0.86 \\
\hline & 120 & 2562 & & 0.86 \\
\hline Run 非27 & 55 & 2116 & & 0.73 \\
\hline additive: $\mathrm{NaCl}$, & 65 & 2554 & & 0.78 \\
\hline $\mathrm{ppm}=2000, \mathrm{RPM}=470$ & 75 & 2665 & & 0.81 \\
\hline $\mathrm{T}_{\text {sat }}=34.4, \mathrm{~T}_{\text {crys }}=31.1$ & 90 & 2974 & & 0.88 \\
\hline \multirow{4}{*}{$W_{i}=0.207, t_{f}=145$} & 100 & 3035 & & 0.92 \\
\hline & .110 & 3125 & & 0.96 \\
\hline & 120 & 3481 & & 0.96 \\
\hline & 130 & 4176 & & 0.89 \\
\hline Run 非28 & 65 & 941 & & 0.58 \\
\hline additive: No, $\mathrm{ppm}=0.00$ & 75 & 1044 & & 0.65 \\
\hline $\mathrm{RPM}=470$ & 85 & 1043 & & 0.71 \\
\hline$T_{\text {sat }}=34.4, T_{\text {crys }}=31.1$ & 95 & 1120 & & 0.73 \\
\hline \multirow{3}{*}{$W_{i}=0.205, t_{f}=140$} & 105 & 1357 & & 0.70 \\
\hline & 115 & 1363 & & 0.78 \\
\hline & 125 & $1285 \ldots$ & & 0.84 \\
\hline
\end{tabular}


Nucleation

Rate, Bo

Time, $t$, minutes
No

cc-min
Fine Crystal

Growth Rate,

$G_{f}, \frac{\operatorname{mic}}{\min }$

\section{Run 非29}

additive: $\mathrm{MgCl}_{2} \cdot 6 \mathrm{H}_{2} \mathrm{O}$,

$\mathrm{ppm}=200, \mathrm{RPM}=470$

$\mathrm{T}_{\text {sat }}=34.4, \mathrm{~T}_{\text {crys }}=31.1$

$W_{i}=0.205, t_{f}=140$

65

75

85

95

105

115

125

Run \#30

additive: $\mathrm{MgCl}_{2} \cdot 6 \mathrm{H}_{2} \mathrm{O}$,

$\mathrm{ppm}=400, \mathrm{RPM}=470$

$\mathrm{T}_{\text {sat }}=34.4, \mathrm{~T}_{\text {crys }}=31.1$

$W_{i .}=0.205, t_{f}=140$
55

65

75

85

95

115

125

1367

1178

1404

1471

1553

1804

1773

1170

1375

1554

1712

1922

2027

1974
0.68

0.78

0.76

0.81

0.84

0.87

0.66

0.68

0.73

0.76

0.80

0.86

0.91 
APPENDIX C

\section{SUMMARY OF DATA OF SUSPENSION \\ DENSITY AND SEED CRYSTAL SIZE}

The following table lists the dynamic suspension densities of seed crystals and the initial and final volumetric average size of seed crystals obtained in the various runs performed in this study. The following units were used for the listed variables: $\overline{\mathrm{L}}_{\mathrm{v}, i}, \overline{\mathrm{L}}_{\mathrm{v}, f}-$ microns, $\mathrm{M}_{\mathrm{T}}$ - grams/1iter, $t$ - minutes. 


\begin{tabular}{|c|c|c|c|c|}
\hline Run No. & $t$ & $\overline{\mathrm{L}}_{\mathrm{V}, \mathrm{i}}$ & $\overline{\mathrm{L}}_{\mathrm{v}, \mathrm{f}}$ & $\mathrm{M}_{\mathrm{T}}$ \\
\hline 1 & $\begin{array}{l}47 \\
53 \\
59 \\
64 \\
75 \\
90\end{array}$ & 282.6 & 775.6 & $\begin{array}{l}0.79 \\
0.91 \\
1.04 \\
1.16 \\
1.44 \\
1.90\end{array}$ \\
\hline 10 & $\begin{array}{r}75 \\
96 \\
105 \\
115 \\
125 \\
140\end{array}$ & 183.0 & 718.2 & $\begin{array}{l}2.69 \\
4.21 \\
5.01 \\
6.00 \\
7.13 \\
9.06\end{array}$ \\
\hline 11 & $\begin{array}{r}65 \\
79 \\
90 \\
100 \\
110 \\
120 \\
130\end{array}$ & 183.0 & 691.6 & $\begin{array}{l}1.81 \\
2.48 \\
3.11 \\
3.77 \\
4.52 \\
5.36 \\
6.30\end{array}$ \\
\hline 12 & $\begin{array}{r}78 \\
90 \\
100 \\
110 \\
120 \\
130\end{array}$ & 183.0 & 649.9 & $\begin{array}{l}2.28 \\
2.92 \\
3.52 \\
4.20 \\
4.97 \\
5.84\end{array}$ \\
\hline 13 & $\begin{array}{r}95 \\
110 \\
120 \\
130\end{array}$ & 183.0 & 567.4 & $\begin{array}{l}2.23 \\
2.86 \\
3.34 \\
3.87\end{array}$ \\
\hline 14 & $\begin{array}{r}55 \\
65 \\
75 \\
85 \\
100 \\
125\end{array}$ & 261.0 & 755.5 & $\begin{array}{l}1.04 \\
1.30 \\
1.60 \\
1.93 \\
2.52 \\
3.76\end{array}$ \\
\hline 15 & $\begin{array}{r}70 \\
80 \\
95 \\
100 \\
110 \\
126\end{array}$ & 261.0 & 691.0 & $\begin{array}{l}1.19 \\
1.43 \\
1.84 \\
2.00 \\
2.33 \\
2.95 \\
\end{array}$ \\
\hline
\end{tabular}




\begin{tabular}{|c|c|c|c|c|}
\hline Run No. & $t$ & $\overline{\mathrm{L}}_{\mathrm{v}, \mathrm{i}}$ & $\bar{L}_{v, f}$ & $\mathrm{M}_{\mathrm{T}}$ \\
\hline . & $\begin{array}{r}75 \\
90 \\
105 \\
120 \\
135\end{array}$ & 261.0 & 580.0 & $\begin{array}{l}0.88 \\
1.10 \\
1.35 \\
1.64 \\
1.97\end{array}$ \\
\hline 17 & $\begin{array}{r}80 \\
90 \\
100 \\
110 \\
120\end{array}$ & 261.0 & 553.5 & $\begin{array}{l}0.83 \\
1.00 \\
1.15 \\
1.30 \\
1.48\end{array}$ \\
\hline 18 & $\begin{array}{r}55 \\
65 \\
75 \\
85 \\
95 \\
105 \\
120\end{array}$ & 244.0 & 717.6 & $\begin{array}{l}1.09 \\
1.37 \\
1.68 \\
2.05 \\
2.46 \\
2.93 \\
3.73\end{array}$ \\
\hline 19 & $\begin{array}{r}55 \\
65 \\
75 \\
105 \\
120 \\
130\end{array}$ & 244.0 & 686.8 & $\begin{array}{l}0.99 \\
1.22 \\
1.49 \\
2.54 \\
3.21 \\
3.99\end{array}$ \\
\hline 20 & $\begin{array}{r}55 \\
75 \\
95 \\
120 \\
130\end{array}$ & 244.0 & 646.7 & $\begin{array}{l}0.89 \\
1.31 \\
1.86 \\
2.72 \\
3.13\end{array}$ \\
\hline 21 & $\begin{array}{r}55 \\
75 \\
95 \\
105 \\
130\end{array}$ & 244 & 630.8 & $\begin{array}{l}0.86 \\
1.27 \\
1.78 \\
2.09 \\
3.00\end{array}$ \\
\hline 22 & $\begin{array}{r}55 \\
75 \\
95 \\
120 \\
130\end{array}$ & 264.0 & 644.5 & $\begin{array}{l}0.76 \\
1.09 \\
1.50 \\
2.15 \\
2.46\end{array}$ \\
\hline
\end{tabular}




\begin{tabular}{|c|c|c|c|c|}
\hline Run No. & $t$ & $\overline{\mathrm{L}}_{v, i}$ & $\overline{\mathrm{L}}_{\mathrm{V}, \mathrm{f}}$ & $\mathrm{M}_{\mathrm{T}}$ \\
\hline $\begin{array}{l}23 \\
\\
\end{array}$ & $\begin{array}{r}55 \\
65 \\
75 \\
90 \\
100 \\
110 \\
120\end{array}$ & 255.7 & 683.2 & $\begin{array}{l}0.90 \\
1.10 \\
1.33 \\
1.74 \\
2.05 \\
2.40 \\
2.78\end{array}$ \\
\hline 24 & $\begin{array}{r}65 \\
90 \\
100 \\
110 \\
130\end{array}$ & 255.7 & 648.8 & $\begin{array}{l}1.00 \\
1.55 \\
1.81 \\
2.10 \\
2.78\end{array}$ \\
\hline 25 & $\begin{array}{r}65 \\
75 \\
90 \\
100 \\
110\end{array}$ & 255.7 & 622.1 & $\begin{array}{l}0.92 \\
1.09 \\
1.39 \\
1.56 \\
1.88\end{array}$ \\
\hline 26 & $\begin{array}{r}55 \\
65 \\
75 \\
90 \\
100 \\
120\end{array}$ & 255.7 & 644.6 & $\begin{array}{l}0.81 \\
0.99 \\
1.22 \\
1.52 \\
1.78 \\
2.39\end{array}$ \\
\hline 27 & $\begin{array}{r}55 \\
65 \\
75 \\
90 \\
100 \\
110 \\
120\end{array}$ & 255.7 & 670.0 & $\begin{array}{l}0.87 \\
1.06 \\
1.29 \\
1.67 \\
1.97 \\
2.29 \\
2.65\end{array}$ \\
\hline 28 & $\begin{array}{r}65 \\
75 \\
85 \\
95 \\
105 \\
115\end{array}$ & 254.0 & 687.9 & $\begin{array}{l}1.18 \\
1.43 \\
1.72 \\
2.05 \\
2.43 \\
2.83\end{array}$ \\
\hline 29 & $\begin{array}{r}65 \\
85 \\
95 \\
105 \\
115\end{array}$ & 254.0 & 623.4 & $\begin{array}{l}0.90 \\
1.37 \\
1.60 \\
1.86 \\
2.15\end{array}$ \\
\hline
\end{tabular}




\begin{tabular}{lllll}
\hline Run No. & $t$ & $\overline{\mathrm{L}}_{\mathrm{V}, i}$ & $\overline{\mathrm{L}}_{\mathrm{V}, \mathrm{f}}$ & $\mathrm{M}_{\mathrm{T}}$ \\
\hline 30 & 55 & 254.0 & 650.7 & 0.86 \\
& 65 & & & 1.05 \\
& 75 & & & 1.26 \\
& 85 & & 1.50 \\
95 & & & 1.77 \\
& 115 & & 2.15 \\
\hline
\end{tabular}


APPENDIX D

POPULATION DENSITY DATA

Population density data for the experimental runs are tabulated in this appendix. Population density distribution in size is read horizontally for a time instant which is listed vertically at the left edge of the table. The population density listed is expressed as no. $/\left(c_{0} c_{0}\right)(\mu \mathrm{m})$ and the time is expressed in minutes. 
Dynamic Population Density Data

Run 非 5

$\frac{t}{60}$
72
80
90
110
120
130
135
140
150
160
170
180
190

\begin{tabular}{l}
7.50 \\
\hline 100.0 \\
125.9 \\
134.9 \\
158.5 \\
213.8 \\
251.2 \\
288.4
\end{tabular}

10.00

39.8

50.1

63.1

74.1

100.0

134.9

158.5

additive introduced

$$
338.8
$$

338.8

398.1

467.7

630.9

851.1

186.2

186.2

213.8

213.8

288.4

398.1 $\underline{12.50}$

15.9

22.4

29.5

39.8

54.7

63.1

74.1

100.0

85.1

100.0

114.8

158.5

199.5 $\underline{15.00}$

6.3

11.2

15.9

21.4

25.1

33.9

33.9

39.8

39.8

63.1

63.1

85.1

114.1

Run 非 14

\begin{tabular}{r}
\multicolumn{1}{c}{$t$} \\
55 \\
65 \\
75 \\
85 \\
100 \\
110 \\
125 \\
135
\end{tabular}

$\begin{array}{ll}\frac{7.50}{186.2} & \frac{9.38}{100.0} \\ 223.8 & 125.9 \\ 251.2 & 158.5 \\ 316.2 & 199.5 \\ 354.8 & 223.8 \\ 398.1 & 251.2 \\ 446.7 & 281.8 \\ 562.3 & 316.2\end{array}$

13.13

15.00

29.5

15.8

44.7

25.1

50.1

31.6

63.1

39.8

79.4

50.1

89.1

56.2

89.1

63.1

100.0

63.1

Run \# 16

\begin{tabular}{r}
$t$ \\
\hline 75 \\
85 \\
95 \\
105 \\
120 \\
135
\end{tabular}

\begin{tabular}{rr}
7.50 & 9.38 \\
\hline 56.2 & 19.9 \\
63.1 & 28.2 \\
70.8 & 35.5 \\
89.1 & 39.8 \\
112.2 & 56.2 \\
116.7 & 74.1
\end{tabular}

13.13

15.00

7.1

8.9

3.6

11.2

3.7

11.2

5.0

17.8

6.3

10.0

21.4

13.5 
Dynamic Population Density Data

Run \# 18

\begin{tabular}{rr}
$t$ & 7.50 \\
\hline 55 & 158.5 \\
65 & 186.2 \\
75 & 213.8 \\
85 & 251.2 \\
95 & 288.4 \\
105 & 288.4 \\
120 & 354.8
\end{tabular}

11.25

15.00

39.8

8.5

46.8

53.7

63.1

11.7

18.2

85.1

25.1

89.1

25.1

112.2

31.6

35.5

Run 非 22

\begin{tabular}{r}
$t$ \\
\hline 55 \\
65 \\
75 \\
85 \\
95 \\
120 \\
130
\end{tabular}

\begin{tabular}{l}
7.50 \\
\hline 89.1 \\
112.2 \\
158.5 \\
186.2 \\
199.5 \\
251.2 \\
281.8
\end{tabular}

11.25

15.00

28.2

8.7

39.8

10.0

46.8

18.2

53.7

21.4

63.1

22.4

70.8

31.6

79.4

35.5

Run 非 23

\begin{tabular}{rr}
\multicolumn{1}{c}{} & \multicolumn{1}{c}{7.50} \\
\hline 55 & 85.1 \\
65 & 114.8 \\
75 & 114.8 \\
90 & 134.8 \\
100 & 134.8 \\
110 & 158.5 \\
120 & 186.2 \\
130 & 199.5
\end{tabular}

11.25

15.0

21.4

29.5

33.9

$-$

8.5

46.8

11.7

46.8

15.8

15.8

53.7

63.1

18.2

21.4

70.8

21.4

Run \# 26

\begin{tabular}{rrrr}
$t$ & 7.50 & $\frac{11.25}{15.00}$ \\
\cline { 2 - 3 } 55 & 53.7 & 10.0 & 1.9 \\
65 & 158.5 & 39.8 & 10.0 \\
75 & 251.1 & 74.1 & 21.4 \\
90 & 281.8 & 89.1 & 31.6 \\
100 & 316.2 & 100.0 & 39.8 \\
120 & 354.8 & 112.2 & 44.7 \\
130 & 398.1 & 125.9 & 44.7 \\
\hline
\end{tabular}


Dynamic Population Density Data

Run \# 28

\begin{tabular}{r}
$\mathrm{t}$ \\
\hline 55 \\
65 \\
75 \\
85 \\
95 \\
105 \\
115 \\
125
\end{tabular}

\begin{tabular}{r}
7.50 \\
\hline 53.7 \\
72.4 \\
85.1 \\
100.0 \\
114.8 \\
114.8 \\
158.5 \\
158.5
\end{tabular}

11.25

15.00

7.2

11.7

18.2

25.1

29.5

33.9

46.8

53.7

2.5
5.4
7.2
10.0
11.7
13.5
15.8

Run 非 30

\begin{tabular}{r}
$t$ \\
\hline 65 \\
75 \\
85 \\
105 \\
115 \\
125
\end{tabular}

\begin{tabular}{l}
7.50 \\
\hline 114.8 \\
158.5 \\
186.2 \\
251.2 \\
281.8 \\
316.2
\end{tabular}

11.25

15.00

29.5

39.8

53.7

89.1

89.1

100.0

7.2

11.7

13.5

28.2

31.6

31.6 
a

$A_{i}$

$\mathrm{b}$

$\mathrm{B}^{\mathrm{O}}$

$\bar{B}, B(L)$

$\mathrm{C}$

$\mathrm{C}_{i}$

$\mathrm{C}_{i}^{*}$

$\overline{\mathrm{D}}, \mathrm{D}(\mathrm{L})$ death or disappearance function, no./(c.c.) ( $\mu \mathrm{m})(\mathrm{min})$

G

$G_{f}$

$G_{i}$

$\Delta G$

crit

i

j

$k_{\mathrm{N}}$

$\mathrm{k}_{\mathrm{v}}$

$\mathrm{K}$

$\mathrm{K}_{\mathrm{b}}$

$\mathrm{K}_{1}, \mathrm{~K}_{2}$

1

L

$L_{\text {crit }}$

kinetic order of supersaturation in 'growth model area covered by impurity on a crystal surface kinetic order of impurity concentration in growth model nucleation rate, no./(c.c)(min)

birth distribution function, no./(c.c.) ( $\mu \mathrm{m})(\mathrm{min})$

homogeneous nucleation rate constant

impurity concentration, ppm

active impurity concentration, ppm

seed crystal growth rate, $\mathrm{cm} / \mathrm{min}$

growth rate of fine borax crystals, $\mathrm{cm} / \mathrm{min}$

seed crystal growth rate in impure solutions, $\mathrm{cm} / \mathrm{min}$

free energy formation of critical nucleus

kinetic order of supersaturation in power mode1

kinetic order of suspension density in power model

secondary nucleation rate constant

volumetric shape factor

ratio of rate constants of adsorption and desorption

Boltzman constant

constants in Davey and Mullin's model

kinetic order of impurity concentration in power model

linear crystal size, $\mu \mathrm{m}$

critical nucleus size 
$\overline{\mathrm{L}}_{\mathrm{v}, \mathrm{i}} \quad$ volumetric average size of initial seeds, $\mu \mathrm{m}$.

$m_{j}, m_{j}(t) \quad j$ th moment of seed crystal, $(\mathrm{cm})^{j} /\left(c_{.} c_{.}\right)$

$\mathrm{m}_{\mathrm{j}, \mathrm{k}} \quad \mathrm{jth}$ moment of crystals in $\mathrm{kth} \operatorname{stream},(\mathrm{cm})^{j} /\left(c_{.} \mathrm{c}_{\bullet}\right)$

$\mathrm{n}, \mathrm{n}(\mathrm{L})$ population density, no./(c.c.) $(\mu \mathrm{m})$

$\mathrm{n}_{i} \quad$ population density of crystals in $i^{\text {th }}$ stream, no/(c.c.) (um)

$\mathrm{n}^{\circ} \quad$ zero size population density, no./(c.c.) $(\mu \mathrm{m})$

N Avogadro's Number

$\overline{\mathrm{Q}}_{i} \quad$ volumetric flow rate of $i^{\text {th }}$ stream, (c.c.)/min

$\mathrm{Q}_{\mathrm{k}} \quad$ volumetric flow rate of $\mathrm{k}^{\text {th }}$ stream, (c.c.)/min

R gas constant

s supersaturation

S supersaturation ratio $i$.e. ratio of actual concentration to saturation concentration

$t \quad$ time, minutes

T temperature, ${ }^{\circ} \mathrm{C}$ (absolute temperature in Equations (1) to (4)).

$\mathrm{V}$ volume of slurry in crystallizer, (c.c.)

$\mathrm{V}_{\mathrm{m}} \quad$ molecular volume

$W_{i} \quad$ initial weight of seed crystals, gms

Greek Letters
$\sigma$
surface tension
$\tau$ retention time, minutes
$\rho \quad$ crystal density, $g m /\left(c_{. c}.\right)$ 


\section{LIST OF REFERENCES}

1. Becker, R., Ann. Physik., 32, 128 (1938).

2. Bennema, P., J. of Crystal Growth, 1, 287 (1967).

3. Botsaris, G.D., Paper presented at the 6th Symposium on Industrial Crystallization, Usti. nad Labem, Czechoslovakia, Sept. (1975).

4. Botsaris, G.D., E.G. Denk and J. Chua, AIChE Symposium Series, 121, 68, 21 (1972).

5. Botsaris, G.D., E.G. Denk and R.A. Shelden, Paper presented at 6 th Symposium on Industrial Crystallization, Prague, Sept. (1972).

6. Bransom, S.H., D.E. Brown and G.D. Heeby, Paper presented at the Symposium on Industrial Crystallization, Institute of Chemical Engineers, London, Apri1 (1969),

7. Buckley, H.E., 'Crystal Growth', Wiley and Sons, N.Y. (1951).

8. Burton, W.K., N. Cabrera and F.C. Frank, Phil. Trans. Roy. Soc. London A243, 299 (1951).

9. Cayey, N.W. and J. Estrin, I/EC Fundamentals, 6, 13 (1967).

10. Clontz, N.A. and W. McCabe, Paper presented at 62 nd AIChE AnnuaI Meeting, Washington, D.C. (1969).

11. Davey, R.J. and J.W. Mullin, J. of Crystal Growth, 26, 45 (1974).

12. Denk, E.G. and G.D. Botsaris, J. of Crystal Growth, 13/14, 493 (1972).

13. Desai, R.M., J.W. Rachow and D.C. Timm, AIChE J. 20, 1, 43 (1974).

14. Frank, F.C., Discussions Faraday Soc., 5, 48 (1949).

15. Gibbs, J.W., Collected Works, London (1918).

16. Johnson, R.T., R.W. Rousseau and W.L. McCabe, Paper presented at joint meeting AIChE and IMIQ, Denver, Colorado, Sept. (1970).

17. Kahlweit, M., J. of Crystal Growth, 7, 74 (1970).

18. Kirov, G.K. and L. Filizona, Krista11 Und Technik, 5, 3, 387 (1970). 
19. Larson, M.A., D.C. Timm and P.R. Wolff, AIChE J., 14, 3,448 (1968).

20. Larson, M.A. and J.W. Mullin, J. of Crystal Growth, 20, 183 (1970).

21. Liu, Y。 and G.D. Botsaris, AIChE J., 3, 19, 510 (1973).

22. Mason, R.E.A. and R.F. Strickland-Constable, Nature, 197, 987 (1963).

23. Mason, R.E.A. and R.F. Strickland-Constable, Trans: Faraday Soc., $\underline{62}, 455$ (1966).

24. Melia, R.P., J. of App1. Chem., 15, 345 (1965).

25. Melia, T.P. and W.P. Moffit, I/EC Fundamentals, 3, 313 (1964).

26. Michaels, A.S. and F.W. Tausch, Jr., J. Physic. Chem., 65, 1730 (1961).

27. Miers, H.C. and F.J. Isaac, J. Chem. Soc., 89, 413 (1906).

28. Mullin J.W., 'Crystallization', 2nd Ed., Butterworths, London (1972).

29. Mullin, J.W., A. Amatanivadhana and M. Chakravorty, J. App1. Chem., 20, 153 (1970).

30. Mullin, J.W. and J. Garside, Trans. Inst. Chem. Engrs., 45, (1969).

31. Mussard, F. and S. Goldstande, J. of Crysta1 Growth, 13/14, 445 (1972).

32. Ness, J.N. and E.T. White, Paper presented at 77 th National meeting of AIChE, Pittsburgh, P.A., June (1974).

33. Neville, A.M. and J.B. Kennedy, 'Basic Statistical Methods for Engineers and Scientists', International Textbook Company, Scarton, P.A. (1964).

34. Ohara, M. and R.C. Reid, 'Modelling Crystal Growth Rates from Solutions', Prentice Hall, Englewood Cliffs, N.J. (1973)。

35. Randolph, A.D., Can J. of Chem. Eng., 42, 280 (1964).

36. Rando1ph, A.D., J.R. Beckman and Z. I. Kraljevich, AIChE J., 23, 500 (1977).

37. Randolph, A.D. and K。 Rajagopal; I/EC Fundamentals, 9 , 165 (1970).

38. Rando1ph, A.D. and M. A. Larson, 'Theory of Particulate Processes', Academic Press, N.Y. (1971).

39. Randolph, A.D. and M.D. Cise, AIChE J., 18, 4, (197.2). 
40. Randolph, A.D. and S. Koontz, Paper Presented at AIChE 69th Annual Meeting, Chicago (1976).

41. Randolph, A.D. and S.K. Sikdar, I/EC Fundamentals, 15, 64 (1976).

42. Shor, S.M. and M.A. Larson, Chem. Engg. Prog. Symposium Series, $110,67,32$ (1971).

43. Sikdar, S.K. Ph.D. Thesis, University of Arizona, Tucson, (1975).

44. Strickland-Constable, R.F., 'Kinetics and Mechanism of Crystallization', Academic Press, London (1968).

45. Strickland-Constable, R.F., AIChE Symposium Series, 121, 68, 1 (1972).

46. Ting, H.H. and W.L. McCabe, I/EC, 26, 1201 (1934).

47. Verma, A.R., 'Crystal Growth and Dislocations', Butterworths, London (1953).

48. Youngquist, G.R. and A.D. Randolph, AIChE J., 18, 2, 421 (1972). 
$\therefore \quad 11$ 